\title{
The journey of polycarbonate-based composites towards suppressing electromagnetic radiation
}

\author{
Kumari Sushmita', Giridhar Madras ${ }^{2}$ and Suryasarathi Bose ${ }^{3 *}$ (D)
}

\begin{abstract}
Electronic devices' widespread usage has led to a new form of pollution, known as electromagnetic (EM) pollution, causing serious problems like equipment malfunctioning and affecting its reliability. This review article presents a comprehensive literature survey on the various polycarbonate (PC)-based materials for electromagnetic interference (EMI) shielding applications comprising of PC-based composites, blend composites, foams, and more recently, multilayered architectures. Following the state-of-the-art literature available from the previous decade, it is apparent that the properties (conductivity, permittivity and permeability) of nanofiller/fillers and nanocomposite processing/ fabrication techniques control the EMI shielding properties in PC-based materials. Researchers have explored a variety of fillers, but high aspect ratio carbonaceous nanofillers have gained significant attention. Through morphological modifications of PC composites, one can obtain a percolation threshold as low as $0.021 \mathrm{wt} \%$ of carbon nanotubes (CNTs). However, higher connectivity of conductive filler need not necessarily lead to high EMl shielding performance. Thus, detailed insight into the shielding mechanism is also highlighted. This review article will help researchers design PC-based materials with superior EMI shielding performance coupled with good mechanical stability.
\end{abstract}

Keywords: EMI shielding, PC-based composites, Blends, Multilayer structures, Foams

\section{Background}

Polycarbonate (PC) is a thermoplastic polymer characterized by a distinct set of properties such as optical transparency, toughness, high impact strength, dimensional stability, high thermal and electrical resistance [1]. PC is amorphous with a high glass transition temperature $\left(\mathrm{T}_{\mathrm{g}}\right)$ of about $147^{\circ} \mathrm{C}$, above which it gradually softens. The PC structure consists of organic functional groups linked together by carbonate groups $(-\mathrm{O}-(\mathrm{C}=\mathrm{O})-\mathrm{O}-)$ as shown in Fig. 1 [3]. PC can be commercially synthesized by reacting 2,2'-bis(4-hydroxyphenyl) propane (Bisphenol A) with either phosgene or ester interchange with diphenyl carbonate [2]. But the phosgene process (shown in Fig. 1) is industrially favored over ester

\footnotetext{
* Correspondence: sbose@iisc.ac.in

${ }^{3}$ Department of Materials Engineering, Indian Institute of Science, Bangalore 560012 , India

Full list of author information is available at the end of the article
}

interchange as it is economical and provides more control of polymer molecular weight [2]. Phosgene is added to a stirred slurry of aqueous sodium hydroxide, catalytic amine (e.g., triethylamine or pyridine), and Bisphenol A in a solvent (e.g., dichloromethane). To control the molecular weight, a monofunctional phenol, such as phenol, p-t-butylphenol, or pcumylphenol, is often added to end the chain extension [4]. This reaction involves stirred interfacial polymerization and follows a step-growth mechanism [2]. PC synthesis is well studied and the details can be found in several existing articles $[1,2,4-8]$.

The physical, chemical, and mechanical properties of PC pave the way for various applications in automotive and transportation, electrical and electronics, consumer products, building and construction, medical, appliances, packaging, recreation and safety, etc. [9-19]. Since this review article majorly focuses on PC-based composites 


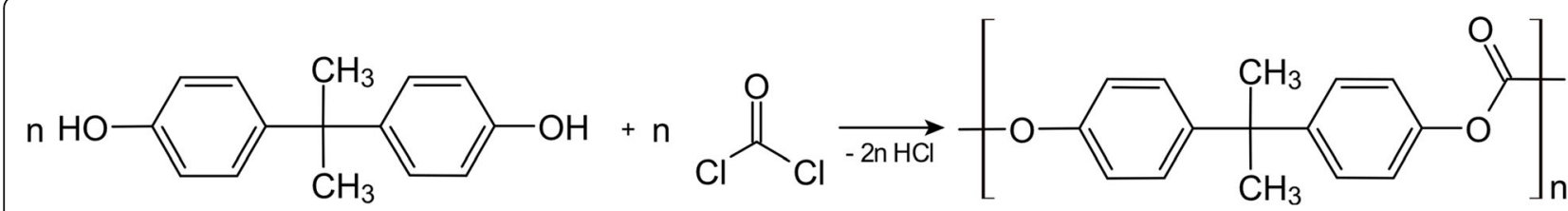

Bisphenol A (BPA)

Phosgene

Polycarbonate (PC)

Fig. 1 The industrially favored process for the production of polycarbonate [2]

to tackle EMI shielding, it becomes crucial to understand why PC is chosen in the first place for the said application. PC is widely used in electronic devices and components, projectors, sensor/detector, car electronics, optical transceiver, digital camera, power distribution housing and covers, equipment housings and components, car audio and navigation, LCD frame, server/ modem/router, IP camera, portable DVD, LCD monitor, mobile telephones, etc. [9].

Some of the key suppliers of PC include SABIC, Teijin, Chi Mei Corp., Idemitsu Kosan, Mitsubishi Engineering Plastics Corp., Lotte Chemical, RTP Company, LG Chem, Covestro, and Trinseo [10, 20, 21]. The current market research and growth prediction of $\mathrm{PC}$ are shown in Fig. 2A, and the country-wise production capacity is shown in Fig. 2B [21]. The global market value of PC was US $\$ 13$ billion in 2016 with applications across various industries, including automotive and transportation, packaging, medical devices, construction, and consumer goods. The study predicted that the market value would grow to about US $\$ 17$ billion in 2020 and the market demand to exceed 5.9 thousand tons in 2020. In contrast, the production capacity in the year 2016 was $5100 \mathrm{Kt} /$ annum and is expected to increase globally due to the increasing demand in the forecasted period.

In terms of applications, $\mathrm{PC}$ is also blended with other polymers such as acrylonitrile-butadiene-styrene (ABS) and polyester for fabricating automotive components $[22,23]$. Areas such as industrial machinery and safety equipment are likely to gain demand in the future. $\mathrm{PC}$ is processed using injection molding, extrusion, foam molding, 3D printing, and vacuum forming [24-31]. This variety in processing techniques has empowered end-users to explore further options for PC usage.

Besides focusing on the critical properties of PC that make it a potential candidate for EMI shielding application, this review article also highlights the processing techniques and fillers that proved to be beneficial in enhancing the shielding performance. Various case studies underscoring fillers and processing approaches influencing the EMI shielding performance are discussed in detail. Multiple strategies such as designing PC composites, PC-based blends and blend composites, PC-based multilayer structures, and PC-based foams are highlighted in Fig. 3. Also, the mechanical property of the EMI shield is vital for commercial applications. PC is a brittle polymer, and EMI shielding requires incorporating various fillers. The addition of fillers to PC matrix may cause mechanical property decline (in some cases), depending upon the quantity and type of filler. Thus, our focus is to study EMI shielding performance along with the mechanical behavior of PC composites. Given the volume of work in this field, we have restricted our study to the previous decade. This field has evolved significantly in the past decade; a comprehensive review article summarizing the EMI shielding performance is much needed. To the best of our knowledge, there exists only one review article on PC-based EMI shielding materials, and that too highlights mainly the carbonaceous fillers in PC [19]. In contrast, this review focused on EMI shielding systematically highlights PC-based hybrid systems having different architectural designs.

\section{Can a polymeric material be utilized for EMI shielding?}

The material chosen for EMI shielding enhancement should minimize the transmission of EM waves by either obstructing/re-directing the pathway or dissipating the energy in the form of heat. For a material to act as an effective EMI shield, it must have the ability to interact with the incoming EM waves either by reflection, multiple reflections, and/or absorption, as shown in Fig. 4 [32]. Reflection is related to the impedance mismatch between air and shielding material. The presence of nomadic surface charges or mobile charge carriers (electrons or holes) is essential for the reflection, while absorption arises due to ohmic losses and polarization losses. Ohmic losses lead to energy dissipation arising from nomadic charges through conduction, hopping, and tunneling mechanisms. Polarization losses originate from defects, functional groups, and interfaces within the shield material. Multiple reflections are due to reflections on various surfaces or interfaces derived from material inhomogeneity [33]. Broadly categorizing, the material must be either conducting or dielectrically lossy (high loss tangent or $\tan \delta_{\varepsilon}$ ) or magnetically lossy (high 


\section{(A) PC Global Market Analysis}

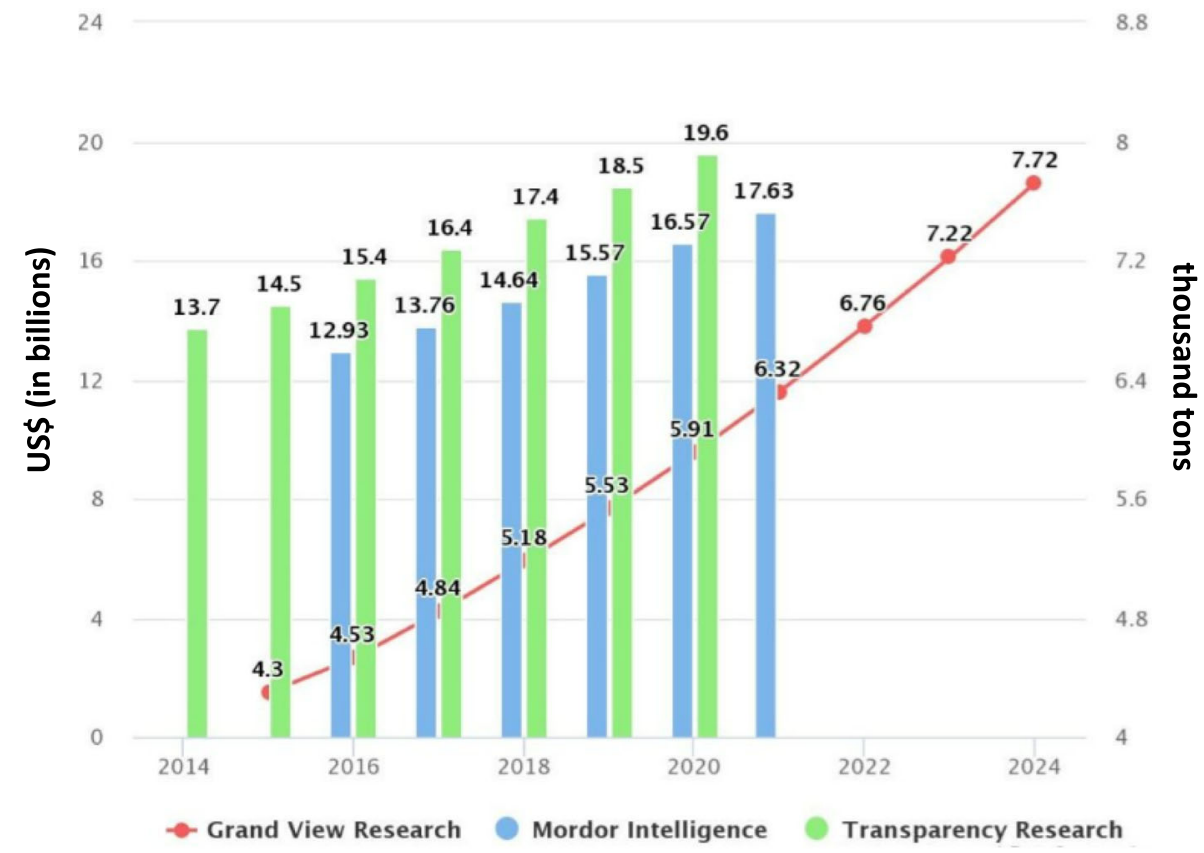

(B) Global Production Capacity of PC (in 2016)

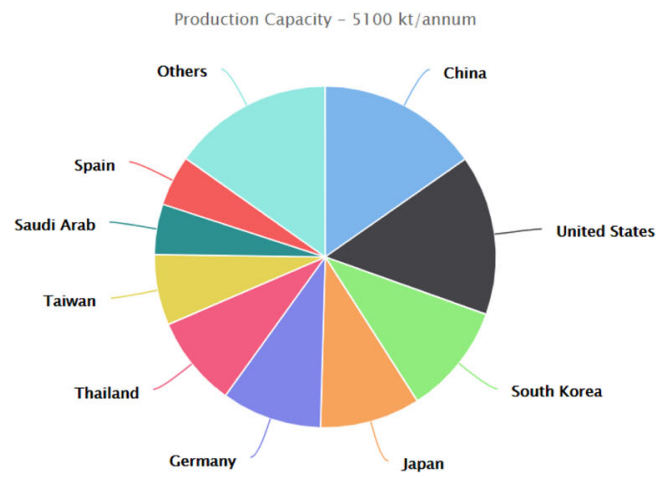

Fig. 2 (A) Market analysis of PC as obtained from different sources: market value (left axis) and demand (right axis) vs. years (2014-2024); (B) Global production capacity of PC. Courtesy of Plastic Insights from reference [21]

loss tangent or $\tan \delta_{\mu}$ ) in the desired frequency range [34]. Some literature reports that electrical conductivity of $1.0 \mathrm{~S} / \mathrm{m}$ is required for total shielding effectiveness $\left(\mathrm{SE}_{\mathrm{T}}\right)$ of $-20 \mathrm{~dB}$ [35], while others say surface resistivity lower than $10 \Omega \mathrm{sq}^{-1}$ for $\mathrm{SE}_{\mathrm{T}}$ of $-30 \mathrm{~dB}$ [36]. The critical aspect is that these electrical conductivity/resistivity values fall in the semiconducting range.

Most polymers are transparent to EM waves because of their insulating nature and lack of electric and magnetic dipoles. PC comes under this category and has an electrical conductivity of $10^{-12}-10^{-14} \mathrm{~S} / \mathrm{m}$ and shows a $\mathrm{SE}_{\mathrm{T}}$ value of $0 \mathrm{~dB}$ [35]. Intrinsically conducting polymers such as polyaniline, polypyrrole, etc. can be used as EMI shield material [37-44]. However, the low conductivity of such polymers makes them less suitable for EMI shielding applications, and thus they are generally used in combination with some conducting/ dielectric/magnetic fillers to meet the commercial shielding requirement, which is shown in Fig. 5B [45]. Intrinsically conducting polymers generally do not have excellent mechanical properties to be molded into complex shapes; thus, they are used in combination with other polymers or as a dispersion for coating applications. So, in conclusion, polymers by themselves are not suitable for EMI shielding applications. However, it remains an ideal choice for the scientific and industrial community mainly because of its various 


\section{Different Configurations of PC-based EMI Shields}

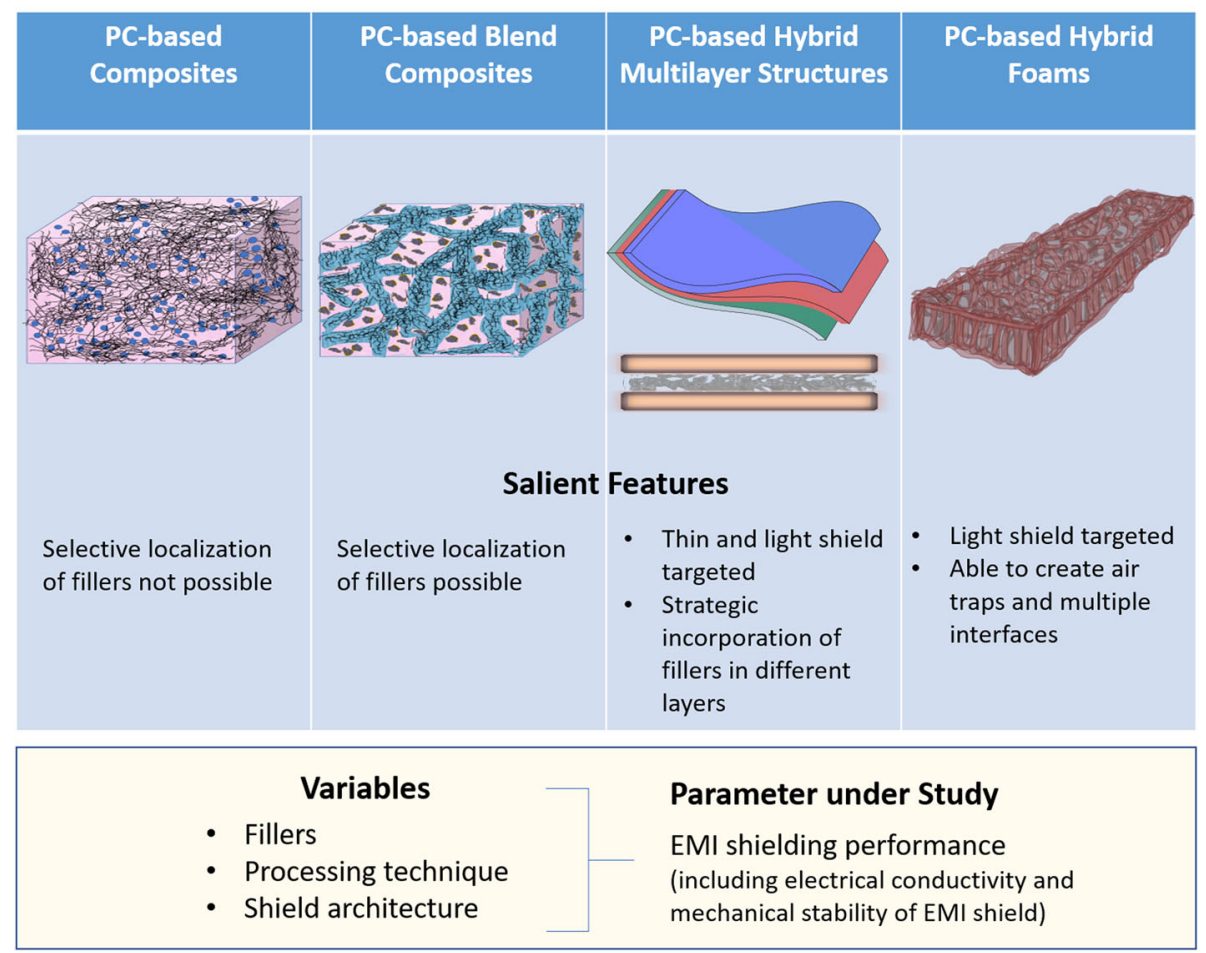

Fig. 3 Schematic representation of the different configurations of PC-based EMI shields discussed in this review article, along with their advantages

applications which can be attributed to its ease of processability, flexible part geometry, excellent surface finish, corrosion resistivity, low weight, tunable absorption and bandwidth properties, and reasonable cost [46]. Metal enclosures and shields are known to prevent EM transmission, primarily by reflection mechanism [47]. Moreover, metal sheets possess seams in them, which may lead to leakage of EM radiations.

Markham et al. [45] studied the shielding requirements for electronic devices/systems in the late

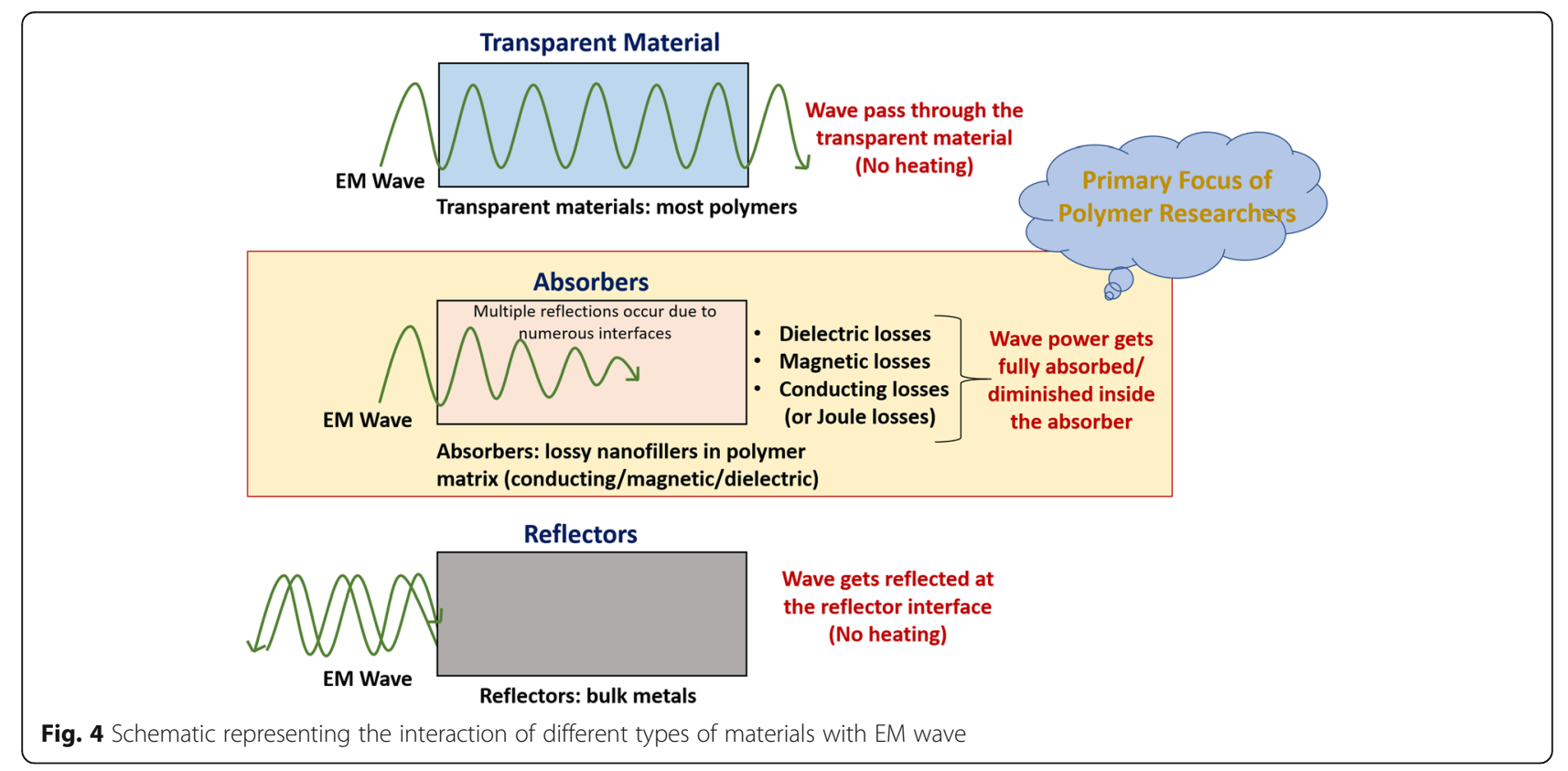




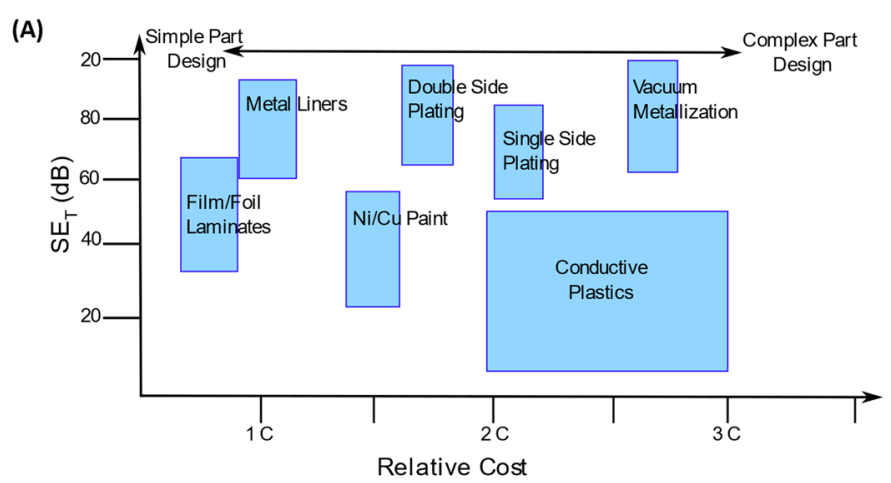

(B)

\begin{tabular}{|l|l|}
\multicolumn{1}{|c|}{ Application } & \multicolumn{1}{|c|}{ Required SE $_{\mathrm{T}}$} \\
\hline Notebook computer & $\mathbf{1 5 - 2 0 ~ d B}$ \\
\hline Desktop computer & $\mathbf{1 5 - 2 0 ~ d B}$ \\
\hline Cell phone & $70-90 \mathrm{~dB}$ \\
\hline Cable tap & $\mathbf{7 0 - 9 0 ~ d B}$ \\
\hline Workstation/ Server & $\mathbf{3 0 - 4 0 ~ d B}$ \\
\hline
\end{tabular}

(C)

\begin{tabular}{|l|l|}
\hline \multicolumn{1}{|c|}{ Common applications } & \multicolumn{1}{|c|}{$\begin{array}{c}\text { Operating } \\
\text { frequency range }\end{array}$} \\
\hline Submarine communication & $3 \mathrm{~Hz}-30 \mathrm{kHz}$ \\
\hline $\begin{array}{l}\text { Communication within mines } \\
\text { Wireless heart rate monitors }\end{array}$ & $300 \mathrm{~Hz}-3 \mathrm{kHz}$ \\
\hline FM & $3-30 \mathrm{kHz}$ \\
\hline Television broadcast & $30-300 \mathrm{MHz}$ \\
\hline Cell phones & $30 \mathrm{MHz}-3 \mathrm{GHz}$ \\
\hline Wireless LAN & $300 \mathrm{MHz}-4 \mathrm{GHz}$ \\
\hline Modern microwave Oven & $300 \mathrm{MHz}-30 \mathrm{GHz}$ \\
\hline $\begin{array}{l}\text { Cable and satellite television broadcasting, satellite } \\
\text { communications, most modern RADARS }\end{array}$ & $800 \mathrm{MHz}-2.5 \mathrm{GHz}$ \\
\hline $\begin{array}{l}\text { Microwave remote sensing, directed energy weapon, } \\
\text { millimeter wave scanner }\end{array}$ & $30-300 \mathrm{GHz}$ \\
\hline Terahertz-based research & $300-3000 \mathrm{GHz}$ \\
\hline
\end{tabular}

Fig. 5 (A) Relative cost vs. performance of various shielding options; (B) Typical shielding requirement for various applications; (C) Some common applications with their operating frequency range. Adapted with permission from Markham et al. [45], copyright 1999 Elsevier

1990 s and reported the assessment of three different parameters on a single plot i.e., shielding, cost, and finished product complexity (shown in Fig. 5A). It is interesting to note that conductive plastics are mainly superior in the ease of fabrication of complex geometries [45]. Thus, to harness the advantages of polymer-based materials for microwave absorption, polymers are used as matrix material, and various fillers such as CNTs, rGO, graphene, carbon black, graphite, Ag nanostructures, MXenes, $\mathrm{ZnO}, \mathrm{MoS}_{2}$, $\mathrm{Fe}_{3} \mathrm{O}_{4}, \mathrm{Ni}, \mathrm{Al}, \mathrm{Cu}$, nanoparticles, etc. are incorporated into it [46, 48-55]. Another captivating feature of a polymer-based EMI shield is that the type, concentration, geometry, and dispersion of the filler can be tuned to meet the shielding requirement for myriads of applications [56-59]. Among the various fillers, carbon-based fillers are quite popular due to their low density, excellent oxidization resistance, ability to form conductive networks and unique architectures at the nanoscale level [46, 60, 61]. Magnetic fillers such as ferrites yield enhanced absorption but are generally more efficient at the low-frequency range due to Snoek's limit [62]. Also, it is worth mentioning that absorption-based shielding is preferable compared to reflection-based shielding as absorbers eliminate EM signals, while reflectors re-direct it in unwanted directions/locations [63]. However, designing an absorption-based or reflection-based EMI shield depends upon the target application and its requirements.

Another critical aspect of the EMI shield is the targeted frequency range. The various industrial and medical equipment, electrical and electronic devices, communication and navigation systems, radar, and satellite communication operate at a defined frequency/range of frequencies as shown in Fig. 5C [46, 64]. So, there is also a need to design EMI shields selective to a specific frequency band.

\section{Terminologies used for quantification of EMI shielding}

Electromagnetic shielding refers to blocking the electromagnetic field with barriers made of conductive or dielectrically/ magnetically lossy materials. It is generally expressed in terms of $\mathrm{SE}_{\mathrm{T}}$ and reflection loss/ reflection coefficient (RL/RC) and is measured in units of decibels (dB). 


\section{Total shielding effectiveness}

$\mathrm{SE}_{\mathrm{T}}$ of a material is defined in terms of the ratio of transmitted power $\left(P_{T}\right)$ to incident power $\left(P_{I}\right)$ as shown in Eq. $1[65,66]$.

$$
S E_{T}=-10 \log \frac{P_{I}}{P_{T}}=S E_{A}+S E_{R}+S E_{M R}
$$

where $S E_{A}, S E_{R}$ and $S E_{M R}$ refers to the shielding via absorption, reflection, and multiple reflections, respectively. $S E_{M R}$ is negligibly small when $\mathrm{SE}_{\mathrm{T}}>15 \mathrm{~dB}$ or when the shield thickness is greater than the skin depth. If $S E_{A}$ is high, the amplitude of the absorbed waves becomes negligible when it reaches the second boundary. However, the role of $S E_{M R}$ is noticeable in thin metals and when used at low EM band frequencies, i.e. $\sim \mathrm{kHz}$ range [46].

Since the time-averaged power of an EM wave is proportional to the square of rms electric field strength $(E)$, $\mathrm{SE}_{\mathrm{T}}$ can also be expressed in terms of electric field strength, as shown in eq. 2.

$$
S E_{T}=-20 \log \frac{E_{I}}{E_{T}}
$$

where $E_{I}$ is the incident rms field strength and $E_{T}$ is the transmitted rms field strength.

Similarly, $S E_{T}$ can be expressed in terms of magnetic field strength $(H)$ as below [67].

$$
S E_{T}=-20 \log \frac{H_{I}}{H_{T}}
$$

Now, $S E_{A}, S E_{R}$ and $S E_{M R}$ can be calculated using Eqs. 4,5 and 6 , respectively.

$$
\begin{aligned}
& S E_{A}=-8.68 d \sqrt{\frac{\omega \sigma \mu_{r}}{2}} \\
& S E_{R}=-10 \log \frac{\sigma}{16 \omega \varepsilon_{0} \mu_{r}} \\
& S E_{M R}=20 \log \left|\left(1-10^{\frac{-S E_{A}}{10}}\right)\right|
\end{aligned}
$$

Here $\sigma$ represents the total conductivity, $\omega$ corresponds to angular frequency $(\omega=2 \pi f), \mu_{r}$ refers to the relative permeability of the shield material, $d$ is the thickness of the shield, $\varepsilon_{0}$ represents the dielectric constant in free space. Here, $S E_{A}$ is a function of $\left(\sigma \mu_{r}\right)$ and $S E_{R}$ is a function of $\left(\sigma / \mu_{r}\right)$. Also, these theoretical equations imply that if the rest of the parameters are constant, $S E_{A}$ increases with increasing frequency while $S E_{R}$ decreases with increasing frequency [46].

Apart from the theoretical expression shown in eq. 4, 5 and 6, the shielding effectiveness is experimentally calculated using the scattering parameters $\left(\mathrm{S}_{11}, \mathrm{~S}_{12}, \mathrm{~S}_{21}\right.$ and $\mathrm{S}_{22}$ ) obtained from a two-port vector network analyzer (VNA), as shown in eqs. 7,8 and $9[46,66,68]$.

$$
\begin{aligned}
S E_{T} & =10 \log _{10} \frac{1}{\left|S_{12}\right|^{2}}=10 \log _{10} \frac{1}{\left|S_{21}\right|^{2}} \\
& =10 \log _{10} \frac{1}{T} \\
S E_{R} & =10 \log _{10} \frac{1}{\left(1-\left|S_{11}\right|^{2}\right)}=10 \log _{10} \frac{1}{(1-R)} \\
S E_{A} & =10 \log _{10} \frac{\left(1-\left|S_{11}\right|^{2}\right)}{\left|S_{21}\right|^{2}}=10 \log _{10} \frac{(1-R)}{T} \\
& =S E_{T}-S E_{R}
\end{aligned}
$$

where $S_{11}, S_{22}$ is associated with reflection and $S_{12}, S_{21}$ is associated with absorption. These $S$ parameters can be related to the coefficient of shielding mechanism as; $\mathrm{R}=$ $\left|S_{11}\right|^{2}=\left|S_{22}\right|^{2}, \mathrm{~T}=\left|S_{12}\right|^{2}=\left|S_{21}\right|^{2}$ and $\mathrm{A}=(1-\mathrm{R}-\mathrm{T})$.

Some articles report $\mathrm{SE}_{\mathrm{T}}$ value calculated using a scalar network analyzer (SNA), which measures the amplitude of electrical signals only, i.e., it is unable to determine complex signals such as complex permittivity $\left(\varepsilon^{*}\right)$ and complex permeability $\left(\mu^{*}\right)$. But VNA is the preferred approach of $\mathrm{SE}_{\mathrm{T}}$ measurement as it holds the ability to measure both the phase and magnitude of the various signals [46].

Also, few works in the literature report the evaluation of $\mathrm{SE}_{\mathrm{T}}$ using a theoretical model shown in eqs. 10 and 11 , which is primarily based on electrical conductivity. Colaneri et al. have explained the details of the far-field and near-field approximation of $\mathrm{SE}_{\mathrm{T}}$ [65]. Eq. 10 is derived for far-field (or plane wave) regime and with several assumptions such as "good conductor approximation" where $\sigma / \omega \varepsilon_{0}>>0$ and for frequency much lower than $\omega_{\mathrm{c}}$ (the case of electrically thin shield, $\mathrm{d}<<\delta$. Here $\delta$ is the skin depth and is expressed as $\delta=\sqrt{\frac{2}{\mu_{0} \omega \sigma}}$ ).

$$
S E_{T}=20 \log \left(1+\frac{Z_{0} \sigma d}{2}\right)
$$

where $Z_{0}$ is the impedance of free space $\left(377 \mathrm{~S}^{-1}\right)$.

Equation 11 is similar to the previous equation, except that it is for frequencies above $\omega_{\mathrm{c}}$ (sheet thickness greater than skin depth $d>>\delta$ ).

$$
S E_{T}=10 \log \left(\frac{\sigma}{16 \omega \varepsilon_{0}}\right)+20 \frac{d}{\delta} \log e
$$

The first term in eq. 11 contributes to the shielding due to the single reflections to the incident wave by the sample's front and back surfaces. The second term denotes the attenuation by absorption as the wave passes through the sheet. At high frequencies (greater than $\left.2 \omega_{\mathrm{c}}\right)$, second terms become dominant, and shielding increases monotonically with frequency. The contribution of the multiple reflections is ignored in this model. It is 
observed that this model gives reliable $\mathrm{SE}_{\mathrm{T}}$ values for low-frequency measurement but not so reliable for higher frequency measurement where multiple reflections aren't negligible [69].

Recently $\mathrm{SSE}_{\mathrm{t}}$ and specific $\mathrm{SE}_{\mathrm{T}}$ gained popularity as a parameter to assess the shielding performance, especially in thin films and foams known for their low density [33, 70]. $\mathrm{SSE}_{\mathrm{t}}$ is defined as $\mathrm{SE}_{\mathrm{T}} /$ (density $\times$ thickness), and it has a unit of $\mathrm{dBcm}^{2} \mathrm{~g}^{-1}$. At other places, specific $\mathrm{SE}_{\mathrm{T}}$ is used, which has a unit of $\mathrm{dBcm}^{3} \mathrm{~g}^{-1}$. Some authors further modify $\mathrm{SSE}_{\mathrm{t}}$ to incorporate the shield's mechanical strength and introduce terms like (SSE $\mathrm{S}_{\mathrm{t}}$.strength) [70].

Table 1 shows the relationship between $\mathrm{SE}_{\mathrm{T}}$ value and the percentage of blocked/shielded power $\left(P_{S}\right)$. It is to be noted that transmitted power is obtained by rearranging eq. 1. As can be interpreted from Table $1, \mathrm{SE}_{\mathrm{T}}$ value of $-10 \mathrm{~dB}$ implies that $90 \%$ of the incident EM wave being blocked (or shielded) by the material, $\mathrm{SE}_{\mathrm{T}}$ value of -20 $\mathrm{dB}$ implies that $99 \%$ of the incident EM wave being shielded by the material, and so on.

\section{Reflection loss or reflection coefficient}

For magnetic metallic materials with dielectric loss and magnetic loss properties $(\varepsilon$ and $\mu$ ), shielding is preferably defined in terms of reflection loss or reflection coefficient (RL or RC) calculated using eqs. 12 and 13 [71]. So, RL minimum means that the losses are mainly via the absorption mechanism.

$$
\mathrm{RL} \text { or } \mathrm{RC}=20 \log \frac{\left|Z_{\text {in }}-Z_{0}\right|}{\left|Z_{\text {in }}+Z_{0}\right|}
$$

$Z_{\text {in }}$ is the input characteristic impedance and is expressed as:

$$
Z_{\text {in }}=Z_{0} \sqrt{\frac{\mu_{r}}{\varepsilon_{r}}} \tanh \left\{j\left(\frac{2 \pi f d}{c}\right) \sqrt{\mu_{r} \varepsilon_{r}}\right\}
$$

where $\varepsilon_{r}$ refers to the relative permittivity of the shield material, $\mathrm{f}$ is the frequency of incident $\mathrm{EM}$ wave, and $\mathrm{c}$ is the velocity of light in vacuum.

\section{PC for EMI shielding applications}

\section{PC-based composites}

Sundararaj et al. [36] studied the effect of CNT alignment on the electrical and EMI shielding properties of $\mathrm{PC} / \mathrm{CNT}$ composite. Injection molding and compression molding techniques were used for sample preparation. It was found that the flow-induced alignment of CNTs during injection molding led to higher resistivity than compression-molded samples (random distribution). Alignment diminishes the likelihood of CNTs interconnection, making tunneling a favorable electron transfer mechanism (assuming the conducting fillers' insulative gaps to be less than $10 \mathrm{~nm}$ ). EMI shielding samples were prepared by diluting $15 \mathrm{wt} \% \mathrm{PC} / \mathrm{CNT}$ masterbatch by melt mixing approach to obtain $\mathrm{PC} / \mathrm{CNT}$ ( $5 \mathrm{wt} \%$ ) composite, which was further compression molded. $\mathrm{SE}_{\mathrm{T}}$ value of $\sim-24 \mathrm{~dB}$ was observed for a shield with a thickness of $1.85 \mathrm{~mm}$ in the X-band. Absorption was found to be the dominant mechanism, and the increase in $\mathrm{SE}_{\mathrm{T}}$ with CNT loading or thickness was attributed to the rise in the source of free electrons and enhancement in the 3-D conductive network. Here it becomes necessary to mention that conductive filler connectivity is essential for conductivity but not very important for shielding. There exist other mechanisms too that come into play even in the absence of connectivity.

Mathur et al. [67] prepared CNT reinforced PC using a micro twin-screw extruder with backchannel flow, followed by injection molding technique to fabricate composites. With $2 \mathrm{wt} \% \mathrm{CNT}$ in the PC matrix, tensile strength and flexural strength showed a value of 79.6 $\mathrm{MPa}$ and $110 \mathrm{MPa}$, respectively, which corresponds to a $19.6 \%$ and $14.6 \%$ increase over the neat PC. It was found that $10 \mathrm{wt} \% \mathrm{CNT}$ in the PC matrix showed the dc electrical conductivity and $\mathrm{SE}_{\mathrm{T}}$ value of $1.3 \times 10^{-2} \mathrm{~S} / \mathrm{cm}$ and $-27.2 \mathrm{~dB}$ (in the Ku band), respectively. The percolation threshold was observed below $2 \mathrm{wt} \% \mathrm{CNT}$, and absorption was the dominant shielding mechanism.

Mathur et al. [72] prepared PC/CNT composite using solvent casting, followed by a compression molding technique. With the increasing CNT amount, the polymer's failure mechanism showed a ductile to brittle transition under tensile loading. The percolation threshold of 2-3 wt\% CNT was observed. Further, it was observed that the low-pressure compression molding technique yielded a $\mathrm{SE}_{\mathrm{T}}$ value of $-35 \mathrm{~dB}$, and high pressure resulted in the $\mathrm{SE}_{\mathrm{T}}$ value of $-21 \mathrm{~dB}$ with CNT loading of $10 \mathrm{wt} \%$ and thickness $\sim 2 \mathrm{~mm}$. This enhancement in shielding can be attributed to the increased porosity and low density of composite observed in reduced/low-pressure molding. $\mathrm{SE}_{\mathrm{T}}$ of a five-layered system $(\sim 2 \mathrm{~mm}$

\begin{tabular}{|c|c|c|c|c|c|c|c|}
\hline $\mathrm{SE}_{\mathrm{T}}$ value (in dB) & -10 & -20 & -30 & -40 & -50 & -60 & -70 \\
\hline $\begin{array}{l}\text { Transmitted power } \\
P_{T}=\frac{P_{t}}{10\left(\frac{S E_{T}}{-10}\right)}\end{array}$ & $10^{-1} P_{l}$ & $10^{-2} P_{l}$ & $10^{-3} P_{l}$ & $10^{-4} P_{l}$ & $10^{-5} P_{l}$ & $10^{-6} P_{1}$ & $10^{-7} P_{1}$ \\
\hline $\begin{array}{l}\% \text { Shielded power } \\
\% P_{S}=\frac{\left(P_{l}-P_{T}\right)}{P_{l}} \times 100\end{array}$ & $90 \%$ & $99 \%$ & $99.9 \%$ & $99.99 \%$ & $99.999 \%$ & 99.9999\% & $99.99999 \%$ \\
\hline
\end{tabular}

Table 1 Relation between $\mathrm{SE}_{T}$ and the percentage of incident EM wave blocked by the shield material 


\section{(A)}

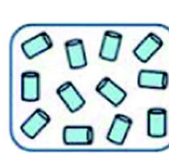

PC beads

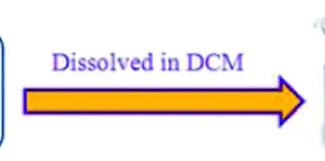

Dissolved solution
of PC in DCM

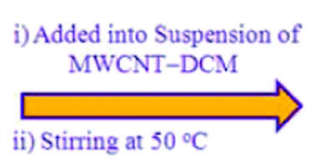

Stirring at $50^{\circ} \mathrm{C}$

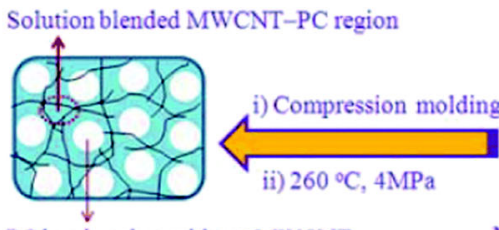

PC bead region without MWCNT

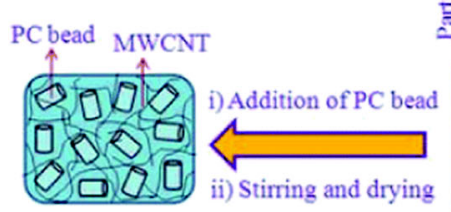

MWCNT/PC composites

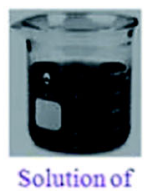

MWCNT-PC
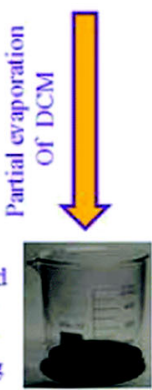

Highly viscous MWCNT-PC

(B)
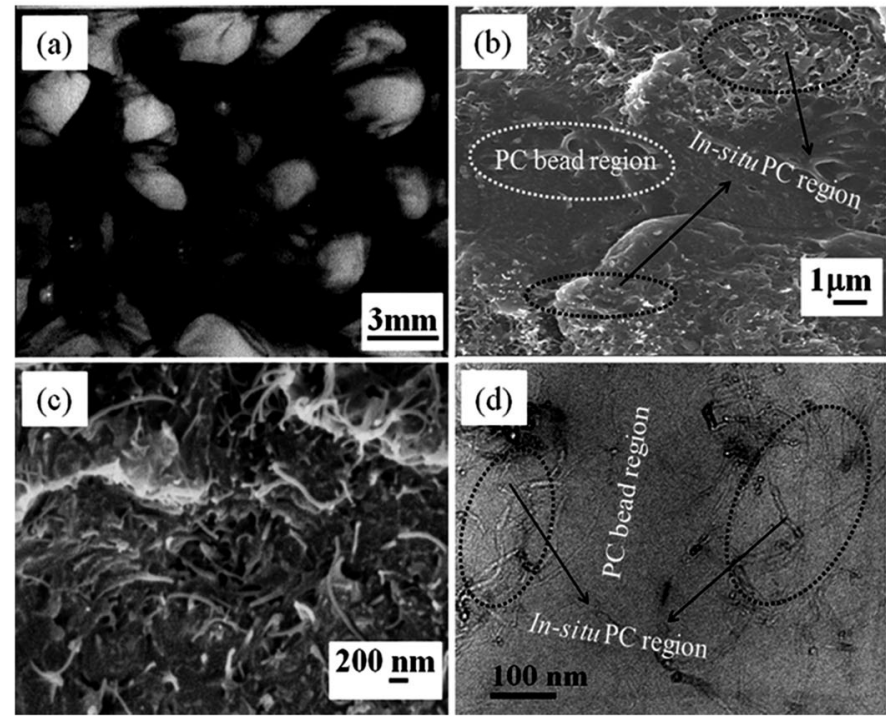

Fig. 6 (A) Schematic for solution blending of PC and CNT (here labeled as MWCNT) in the presence of PC beads; (B) (a) Optical micrograph, (b and c) scanning electron micrographs at two different magnifications, and (d) high resolution transmission electron micrograph of PC/CNT composites with $70 \mathrm{wt} \% \mathrm{PC}$ bead and $0.10 \mathrm{wt} \%$ CNT loading. Reprinted with permission from Khatua et al. [73], copyright 2014 Royal Society of Chemistry

thick) of PC/CNT composite films at $20 \mathrm{wt} \%$ loadings reached a value of $-43 \mathrm{~dB}$ in the X-band (8.2-12.4 $\mathrm{GHz}$ ). Absorption was the primary shielding mechanism, but the shielding performance increased at the cost of decreased strength.

Khatua et al. [73] developed a feasible method that involved solution blending of $\mathrm{PC}$ and $\mathrm{CNT}$ in commercial PC beads, as shown in Fig. 6A. CNT was selectively localized in the solvent-dried continuous PC component. The PC beads in the matrix component act as the excluded volume where CNTs failed to penetrate. Therefore, the effective concentration of CNT in the solution blended (solvent dried) PC region increased (shown in
Fig. 6B). This leads to an increase in the composites' electrical conductivity, and the percolation threshold was found to be as low as $0.021 \mathrm{wt} \%$. This can be attributed to the conductive interconnected network of CNTs and the strong $\pi-\pi$ interaction between the phenyl ring of PC and electron-rich CNTs. The authors also observed that dc conductivity increases with the molding pressure due to the decrease in the gap between adjacent nanofillers as polymers are comparatively more compressible than nanofillers. PC/CNT composites were found to be semiconducting as they showed an increase in dc conductivity with increasing temperature. EMI shielding performance study showed the $\mathrm{SE}_{\mathrm{T}}$ value of - 
$23.1 \mathrm{~dB}$ at low $\mathrm{CNT}$ loading (2 $\mathrm{wt} \%$ ) in the presence of $70 \mathrm{wt} \%$ PC bead for $5.6 \mathrm{~mm}$ thick sample in the frequency range $8.2-12.4 \mathrm{GHz}$.

In the research work by Odegard et al. [74], they studied the effects and interactions of three different carbonbased fillers [carbon black (CB), CNT, and graphene nanoplatelets (GNP)] on $\mathrm{SE}_{\mathrm{T}}$. Through statistical study via factorial design, they developed equations to relate $\mathrm{SE}_{\mathrm{T}}$ to the weight fraction of fillers, as shown in Table 2 . The samples of $3.5 \mathrm{~mm}$ thickness were prepared by incorporating a maximum of $10 \mathrm{wt} \% \mathrm{CB}, 8 \mathrm{wt} \% \mathrm{CNT}$, and $15 \mathrm{wt} \%$ GNP in PC. Above these levels, the composite melt viscosity was too high to allow the material to be extruded and injection molded. Most $\mathrm{PC} / \mathrm{CB}, \mathrm{PC} / \mathrm{CNT}$, and PC/GNP composites showed absorption-based shielding, but the reflected power was more than the absorbed power at a high filler concentration. The highest aspect ratio filler (CNT) showed maximum shielding efficiency, which can be attributed to the sample's lower electrical resistivity. Highly branched CB and high aspect ratio $\mathrm{CNT}$ showed maximum shielding $(>20 \mathrm{~dB})$ and can be used for commercial applications (in the frequency range of $300 \mathrm{MHz}$ to $1.5 \mathrm{GHz}$ ). $\mathrm{PC} / \mathrm{CB} / \mathrm{GNP}$ composite showed a statistically significant interaction term that signifies that CB-GNP's combined effect showed a higher $\mathrm{SE}_{\mathrm{T}}$ than what would be expected from the additive effect of every single filler. The authors also mention that in another work on $\mathrm{PC} / \mathrm{CB}$ composites with the same set of conditions but different $\mathrm{PC}$, they reported a shielding value of ca. $-22 \mathrm{~dB}$.

In another work by Khatua et al. [75], they studied PC/GNP/CNT hybrid composite prepared by melt mixing PC with GNP and CNT (weight ratio of GNP: $\mathrm{CNT}=3: 2)$ at $330^{\circ} \mathrm{C}$, which is higher than the usual processing temperature $\left(260-280^{\circ} \mathrm{C}\right)$. The extruded samples were compression molded at $280^{\circ} \mathrm{C}$ to prepare a specimen with a thickness of $5.6 \mathrm{~mm}$, and shielding performance was measured in the frequency range of 8.2-12.4
GHz. Above the usual processing temperature, PC's melt viscosity is low, leading to nanofillers' homogeneous dispersion $(\mathrm{GNP} / \mathrm{CNT})$. $\mathrm{SE}_{\mathrm{T}}$ value as high as ca. $-21.6 \mathrm{~dB}$ was achieved at $4 \mathrm{wt} \%$ filler loading of (GNP/CNT) instead of $-8.3 \mathrm{~dB}$ observed for composite prepared at $280^{\circ} \mathrm{C}$. Additionally, $\mathrm{PC} / \mathrm{GNP} / \mathrm{CNT}$ hybrid composite (prepared at $330^{\circ} \mathrm{C}$ ) exhibited a percolation threshold as low as $0.072 \mathrm{wt} \%$. In contrast, $\mathrm{PC} / \mathrm{CNT}$ or PC/GNP composites show insulating behavior up to $1.5 \mathrm{wt} \%$ loadings of CNT or GNP. It can be concluded that the low melt viscosity of $\mathrm{PC}$ obtained at high processing temperature results in a strong interconnected 3D conductive network of nanofillers, leading to enhanced electrical conductivity and shielding performance. They also observed that the dc electrical conductivity of composites increased with pressure and temperature, confirming the PC composite's semiconducting behavior. The authors claim the presence of $\pi-\pi$ interaction between the electron-rich phenyl ring of PC with GNP and CNT. Also, the PC composites' storage modulus showed an increasing trend with an increase in fillers' concentration due to the formation of an interconnected physical bond between the PC and fillers, which helps restrict the chain mobility of the PC.

Jasiuk et al. [76] varied the content of three different carbon filler types (CB, CNT, GNP) in the PC matrix and studied the EMI shielding properties in the frequency range of $8.5-12 \mathrm{GHz}$. The $\mathrm{SE}_{\mathrm{T}}$ value at $8.5 \mathrm{GHz}$ for PC/CNT (4 $w t \%), P C / C B ~(6 w t \%)$, and PC/GNP (12 wt\%) were found to be approx. $-14 \mathrm{~dB},-13 \mathrm{~dB}$ and -7 $\mathrm{dB}$, respectively, which was in the same trend as that observed by Odegard et al. [74]. It was found that $\mathrm{SE}_{\mathrm{T}}$ and electrical conductivity increase with an increase in CNT content but both these parameter shows negligible frequency dependence. Absorption was found to increase with CNT concentration and shielding material thickness. However, Odegard et al. [74] reported reflected power to be more than the absorbed power at high

Table 2 Comparative study of shielding performance of single filler and a combination of fillers in the PC matrix

\begin{tabular}{|c|c|c|c|}
\hline $\begin{array}{l}\text { Sample } \\
\text { details }\end{array}$ & $\mathrm{SE}_{\mathrm{T}}$ at $800 \mathrm{MHz}$ (in dB) & $\begin{array}{l}\text { Percolation } \\
\text { threshold }\end{array}$ & Comments \\
\hline $\mathrm{PC} / \mathrm{CB}$ & $\begin{array}{l}-18.9 \text { (at } 10 w t \% C B \text { ) } \\
-13.3 \text { (at } 8 w t \% C B \text { ) }\end{array}$ & $\begin{array}{l}\sim 2.3 \text { vol\% or } \\
3.5 \mathrm{wt} \%\end{array}$ & High $\mathrm{SE}_{\mathrm{T}}$ due to presence of highly branched $\mathrm{CB}$ \\
\hline PC/CNT & -18.4 (at 8 wt $\%$ CNT) & $\begin{array}{l}\sim 0.8 \text { vol\% or } \\
1.2 \mathrm{wt} \%\end{array}$ & High $\mathrm{SE}_{\mathrm{T}}$ due to the high aspect ratio of $\mathrm{CNT}$ \\
\hline PC/GNP & -6.3 (at 15 wt $\%$ GNP) & $\begin{array}{l}\sim 4 \text { vol\% or } 7 \\
\text { wt } \%\end{array}$ & Low $\mathrm{SE}_{\mathrm{T}}$ due to the low aspect ratio of platelet structure \\
\hline $\begin{array}{l}\mathrm{PC} / \mathrm{CB} / \\
\mathrm{CNT}\end{array}$ & $\begin{array}{l}-21.4 \text { (at } 5 \text { wt } \% \text { CB and } \\
5 \text { wt } \% \text { CNT) }\end{array}$ & & $\begin{array}{l}\mathrm{SE}_{\mathrm{T}}(\mathrm{dB})=-0.947+0.2289 w_{C B}^{2}+3.0557 w_{C N T}^{2} ; R^{2}=0.99 \text { and } w_{C B}, W_{C N T} \text { are weight } \\
\text { percentages of } \mathrm{CB} \text { and } \mathrm{CNT} \text {, respectively. }\end{array}$ \\
\hline $\begin{array}{l}\mathrm{PC} / \mathrm{CB} / \\
\mathrm{GNP}\end{array}$ & $\begin{array}{l}\sim-9.2 \text { (at } 5 \text { wt } \% \text { CB and } \\
5 \text { wt } \% \text { GNP) }\end{array}$ & & $\begin{array}{l}S_{E_{T}}(\mathrm{~dB})=-0.4492 w_{C B}+0.3153 w_{C B}^{2}+0.02849 w_{G N P}^{2}+0.11051 w_{C B} W_{G N P} ; R^{2}=1 \text { and } w_{C B} \text {, } \\
W_{G N P} \text { are weight percentages of } C B \text { and } G N P \text {, respectively. }\end{array}$ \\
\hline $\begin{array}{l}\text { PC/CNT/ } \\
\text { GNP }\end{array}$ & $\begin{array}{l}\sim-15.5 \text { (at } 5 \mathrm{wt} \% \text { CNT } \\
\text { and } 5 \text { wt } \% \text { GNP) }\end{array}$ & & $\begin{array}{l}\mathrm{SE}_{\mathrm{T}}(\mathrm{dB})=0.56627 w_{C N T}^{2}+0.04642 w_{G N P}^{2} ; R^{2}=1 \text { and } w_{C N T}, w_{G N P} \text { are weight percentages of } \\
C N T \text { and GNP, respectively. }\end{array}$ \\
\hline
\end{tabular}


loading. From work done by Jaisuk et al. [76] and Odegard et al. [74], it is evident that dispersion, distribution, aggregations, and orientation of fillers might also significantly influence the shielding mechanism. However, the PC/GNP composite showed a peculiar behavior in some frequency range, and the $\mathrm{SE}_{\mathrm{T}}$ was found to be lower even though the weight fraction of filler was higher. It is to be noted that though increasing the filler concentration increases the electrical conductivity and relative permittivity, it may or may not lead to an increase in $\mathrm{SE}_{\mathrm{T}}$. The authors theoretically explained this behavior, and it was concluded that the maximum $\mathrm{SE}_{\mathrm{T}}$ was obtained when $\left(\sigma / \omega \varepsilon_{r}\right)$ was maximized. Moreover, a thicker specimen results in more power dissipation within the composite, resulting in a higher $\mathrm{SE}_{\mathrm{A}}$. Also, the effect of increasing thickness is more dominant in the case of higher filler concentration.

Bose et al. [77] prepared PC nanocomposites containing CNTs and "brick-like" ferromagnetic and crystalline $\mathrm{Fe}_{3} \mathrm{O}_{4}$ nanoparticles encapsulated with amorphous carbon $\left(\mathrm{Fe}_{3} \mathrm{O}_{4} @ \mathrm{C}\right)$, using a combination of solution mixing and melt mixing approach. $\mathrm{Fe}_{3} \mathrm{O}_{4} @ \mathrm{C}$ core/shell nanoparticles (20-80 nm size; approximately $25 \mathrm{wt} \% \mathrm{C}$ ) with saturation magnetization $\sim 27.1 \mathrm{emu} / \mathrm{g}$ were synthesized, as opposed to commercial $\mathrm{Fe}_{3} \mathrm{O}_{4}$ nanoparticles (100$150 \mathrm{~nm}$ size) with a saturation magnetization of $73 \mathrm{emu} /$ $\mathrm{g}$ used for control experiments. The percolation threshold of CNTs was observed to be $1 \mathrm{wt} \%$. At $18 \mathrm{GHz}$ frequency, $\mathrm{PC} / 3$ wt\% CNT, PC/3 wt\% CNT/10 wt\% $\mathrm{Fe}_{3} \mathrm{O}_{4}$ and $\mathrm{PC} / 3 \mathrm{wt} \% \mathrm{CNT} / 10 \mathrm{wt} \% \mathrm{Fe}_{3} \mathrm{O}_{4} @ \mathrm{C}$ showed $\mathrm{SE}_{\mathrm{T}}$ value of approximately $-17 \mathrm{~dB},-19.5 \mathrm{~dB}$ and $-22.8 \mathrm{~dB}$ respectively. The minimum RL value of $\mathrm{PC} / 3 \mathrm{wt} \% \mathrm{CNT}$, $\mathrm{PC} / 3 \mathrm{wt} \% \mathrm{CNT} / 10 \mathrm{wt} \% \mathrm{Fe}_{3} \mathrm{O}_{4}$ and $\mathrm{PC} / 3 \mathrm{wt} \% \mathrm{CNT} / 10$ wt\% $\mathrm{Fe}_{3} \mathrm{O}_{4} @ \mathrm{C}$ was found to be $-32.1 \mathrm{~dB}(@ 11.2 \mathrm{GHz}, 2$ $\mathrm{mm}$ thick), $-21.8 \mathrm{~dB}$ (@6.1 GHz, $3 \mathrm{~mm}$ thick) and -41.3 $\mathrm{dB}(@ 17.7 \mathrm{GHz}, 1 \mathrm{~mm})$ respectively. It was noted that an appropriate shield thickness for specific applications depends on the working frequency as the RL minima shifts toward higher frequencies with decreasing shield thickness. The electrical conductivity, the dielectric, and the magnetic losses were the major contributing factors towards microwave attenuation through absorption. The real part of permittivity $\left(\varepsilon^{\prime}\right)$ and the imaginary part of permittivity $(\varepsilon ")$ was maximum for $\mathrm{PC} / 3 \mathrm{wt} \% \mathrm{CNT} / 10$ wt\% $\mathrm{Fe}_{3} \mathrm{O}_{4} @ \mathrm{C}$ in most of the frequency range (2-18 $\mathrm{GHz})$. But the real part of permeability $\left(\mu^{\prime}\right)$ and the imaginary part of permeability $(\mu$ ") showed only marginal improvement (with variations) in the entire frequency range.

Javadi et al. [78] prepared PC/CNT composites containing $0.5-3 \mathrm{wt} \%$ of CNTs via two different processing techniques, namely melt mixing $\left(250^{\circ} \mathrm{C}, 100 \mathrm{rpm}, 10\right.$ $\mathrm{min}$ ) and solution mixing; which was then followed by compression molding $\left(265^{\circ} \mathrm{C}, 50\right.$ bar for $\left.1 \mathrm{~min}\right)$ to get specimens for EMI shielding measurements. EMI shielding measurement was performed by a scalar network analyzer, unlike the vector network analyzer used in most cases. Solution mixing gave a better dispersion and distribution of CNTs in the PC matrix, which can be attributed to enhanced erosion of CNTs in the solutionmixed samples, caused by sonication and low viscosity of the solution-mixed system, which facilitates the application of shear forces to CNT clusters. Contrary to this, the melt mixed system's high viscosity doesn't allow the applied forces to be transferred to the CNT agglomerates very well, so the number of entangled CNTs is generally higher than the solution mixed system. Increasing the time and the applied force in either method, CNTs will be damaged and shortened, so an optimum condition was chosen. Melt-mixed samples showed a more profound effect on the shortening of CNTs lengths with applied shear. The electrical percolation threshold for solution mixed and melt mixed samples was 0.74 and $0.84 \mathrm{wt} \%$, respectively. The difference between the two percolation thresholds for the processes is low, probably because compression molding could have affected the dispersion of CNTs. The $\mathrm{SE}_{\mathrm{T}}$ is found to increase with the CNT content due to the increase in free electrons in the material that can interact with incoming EM waves. The $\mathrm{SE}_{\mathrm{T}}$ for melt mixed samples and solution mixed samples were observed to be $-14 \mathrm{~dB}$ and $-16.4 \mathrm{~dB}$ at a CNT loading of 3 wt\% (@11 GHz, 1 mm thick), with absorption being the primary mechanism of shielding in both cases. Absorption is found to be more dependent on the thickness of specimens, regardless of the processing technique; and the state of dispersion is not that important in samples with high CNT content, but the effect is more profound at lower CNT concentration. PC/ $2 \mathrm{wt} \%$ CNT prepared by melt mixed approach showed the $\mathrm{SE}_{\mathrm{T}}$ value of $-19.6 \mathrm{~dB}$ (@11 GHz) at a shield thickness of $3.5 \mathrm{~mm}$, which was quite near the commercial requirement of $-20 \mathrm{~dB}$.

Kim et al. [79] incorporated acid-treated CNT (a-CNT) and acid-treated carbon fiber $(\mathrm{a}-\mathrm{CF})$ in the $\mathrm{PC}$ matrix using a MiniMAX molder, followed by compression molding. The electrical conductivity and the $\mathrm{SE}_{\mathrm{T}}$ followed the same trend i.e., highest for PC/a-CF $(10 \mathrm{phr}) / \mathrm{a}-\mathrm{CNT}$ (0.5 phr), followed by PC/a-CF (10 phr) /CNT (0.5 phr) and then PC/a-CF (10.5 phr) as shown in Fig. 7B and C. This was primarily because a-CNT showed good dispersion on the surface of a-CF. The amount of a-CNT grafted on the surface of a-CF appeared to be greater than that of $\mathrm{CNT}$ on the surface of a-CF (shown in Fig. 7A) due to the expected $\mathrm{H}$-bonding between the carboxyl group on $\mathrm{CF}$ and carboxyl group on CNT. The percolation threshold of CNTs was found to be $0.5 \mathrm{wt} \%$. The $\mathrm{SE}_{\mathrm{T}}$ value of $\mathrm{PC} / \mathrm{a}-$ CF/a-CNT composite was $-26 \mathrm{~dB}$ (@ $10.0 \mathrm{GHz}, 2 \mathrm{~mm}$ thick), which was $91.2 \%$ higher than $\mathrm{PC} / \mathrm{a}-\mathrm{CF}$ composite 

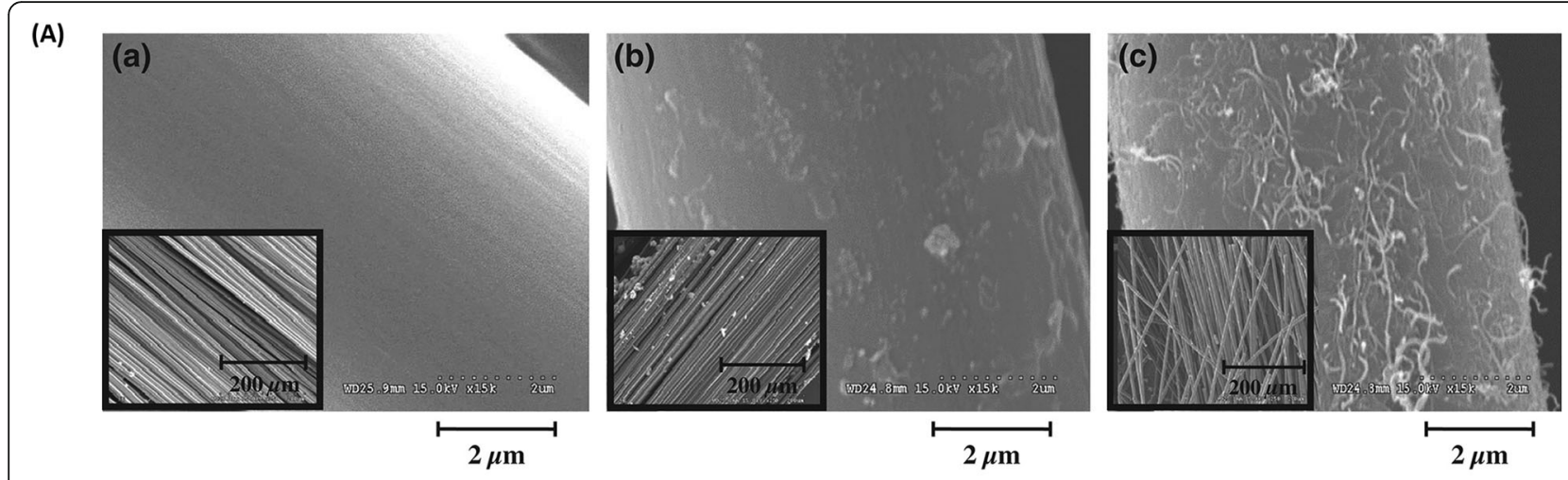

(B)
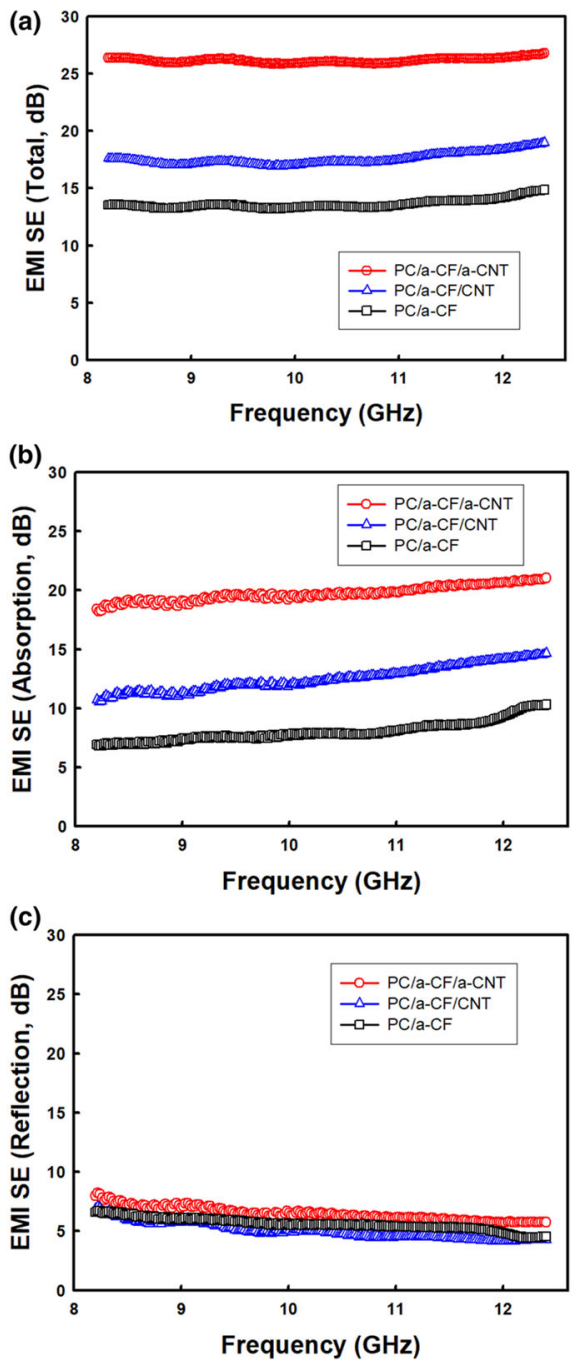

(C)

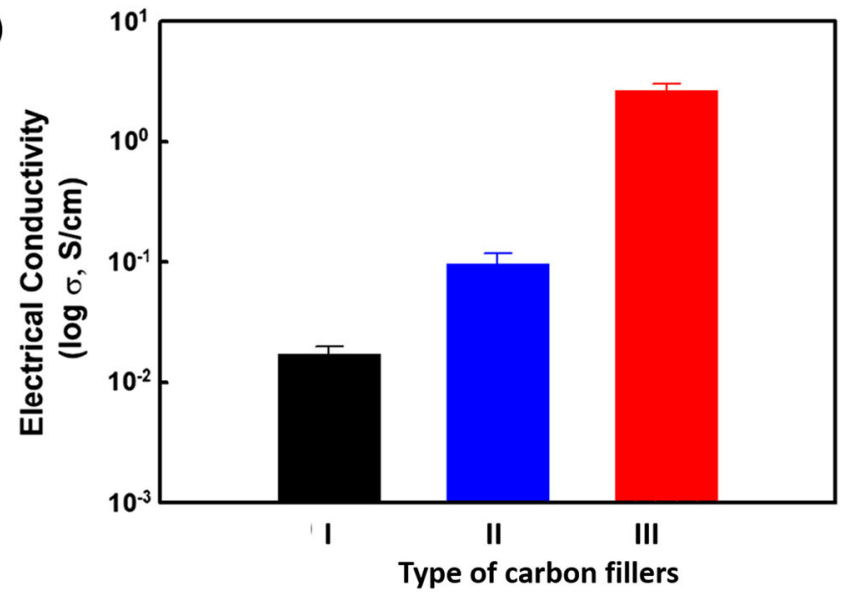

Fig. 7 (A) Scanning electron micrograph of (a) a-CF only, (b) a-CF/CNT, and (c) a-CF/a-CNT; (B) Shielding effectiveness of PC/a-CF, PC/a-CF/CNT, and PC/a-CF/a-CNT composites: (a) $\mathrm{SE}_{\mathrm{T}}$, (b) $\mathrm{SE}_{\mathrm{A}}$, and (c) $\mathrm{SE}_{\mathrm{R}}$; (C) Electrical conductivity of (I) PC/a-CF composite, (II) PC/a-CF/CNT composite, and (III) PC/a-CF/a-CNT composite. Reprinted with permission from Kim et al. [79], copyright 2018 Wiley

at the same amount of total filler content. This can be attributed to the good electrical pathways, high relative permittivity, and dielectric loss factor in the PC/a-CF/ a-CNT composite. Shielding due to absorption (primarily dielectric loss) was dominant, and $\mathrm{SE}_{\mathrm{A}}$ increased with frequency because the composite's skin depth decreases with an increase in frequency. The relative permittivity, $\tan \delta_{\varepsilon}$, tensile strength, tensile 
modulus, complex viscosity, storage, and loss modulus all followed the same trend i.e., the highest value for $\mathrm{PC} / \mathrm{a}-\mathrm{CF} / \mathrm{a}-\mathrm{CNT}$ and lowest for PC/a-CF.

Goyal et al. [35] prepared PC/GNP nanocomposites by solution mixing in combination with the hot compaction method and studied GNP's effect on electrical and EMI shielding properties in X-band. A low percolation threshold of $0.5 \mathrm{vol} \%$ fraction GNP was achieved. The authors mention that the existing literature claims that the electrical conductivity of $1.0 \mathrm{~S} / \mathrm{m}$ is necessary to achieve the $\mathrm{SE}_{\mathrm{T}}$ of $-20 \mathrm{~dB}$ required for commercial applications. However, they obtained a $\mathrm{SE}_{\mathrm{T}}$ value of approximately - $35 \mathrm{~dB}$ (@1 mm thick) for PC/GNP (6 wt\%) with an electrical conductivity of about $0.413 \mathrm{~S} / \mathrm{m}$. From this result, one can infer that electrical conductivity is not the only factor determining the $\mathrm{SE}_{\mathrm{T}}$. Absorption was found to be the dominant shielding mechanism, as shown in Fig. 8A. Further increase in sample thickness to $2 \mathrm{~mm}$, resulted in a $\mathrm{SE}_{\mathrm{T}}$ value of $-47 \mathrm{~dB}(@ 8.2 \mathrm{GHz})$, as shown in Fig. 8B.

Bose et al. [80] fabricated PC-based nanocomposites with doped rGO and CNTs as nanofillers using melt mixing, followed by a compression molding technique. They explored two different dopants i.e., ferrimagnetic $\left(\mathrm{Fe}_{3} \mathrm{O}_{4}\right)$ and paramagnetic $\left(\mathrm{Gd}_{2} \mathrm{O}_{3}\right)$, and studied the shielding performance and underlying mechanism in $\mathrm{X}$ - and $\mathrm{Ku}$-band. The percolation threshold of CNTs was found to be lower than $0.5 \mathrm{wt} \%$. Atomic wt\% of $\mathrm{Gd}$ was less than Fe, and GO reduction was slightly more in $\mathrm{rGO}-\mathrm{Fe}_{3} \mathrm{O}_{4}$ than rGO$\mathrm{Gd}_{2} \mathrm{O}_{3}$. It was observed that $\mathrm{PC} / 3 \mathrm{wt} \% \mathrm{CNT}, \mathrm{PC} / 3 \mathrm{wt} \%$ $\mathrm{CNT} / 5 \mathrm{wt} \% \mathrm{rGO}-\mathrm{Fe}_{3} \mathrm{O}_{4}$ and $\mathrm{PC} / 3 \mathrm{wt} \% \mathrm{CNT} / 5 \mathrm{wt} \%$ rGO- $\mathrm{Gd}_{2} \mathrm{O}_{3}$ resulted in the $\mathrm{SE}_{\mathrm{T}}$ value of $-23,-28$ and $33 \mathrm{~dB}$ respectively for $5 \mathrm{~mm}$ thickness and at $18 \mathrm{GHz}$ frequency as shown in Fig. 9B. Absorption was determined to be the dominant shielding mechanism in all the composites (as shown in Fig. 9C), with magnetic losses being the primary mechanism in the $\mathrm{rGO}-\mathrm{Fe}_{3} \mathrm{O}_{4}$-based nanocomposite and dielectric losses being primary in rGO- $\mathrm{Gd}_{2} \mathrm{O}_{3}$ - based nanocomposite.

$\mathrm{Li}$ et al. [81] designed a reflection-absorption compartment unit with a lossy core made up of $\mathrm{rGO}-\mathrm{Fe}_{3} \mathrm{O}_{4}$ (RGF) dispersed in PC and a conductive shell made up of CNTs wrapped onto the microspheres, as shown in Fig. 10A. CNT-wrapped microspheres of uniform size with an average diameter of $237.9 \mu \mathrm{m}$ were then consolidated at $260^{\circ} \mathrm{C}$ and $100 \mathrm{MPa}$ to obtain a honeycomblike architecture of CNT/RGF/PC with distinct conductive pathways formed by cementing the CNT walls between neighboring shielding compartments as shown in Fig. 10B. The average size of $\mathrm{Fe}_{3} \mathrm{O}_{4}$ was around $10 \mathrm{~nm}$, and the mass fraction of $\mathrm{Fe}_{3} \mathrm{O}_{4}$ anchored on $\mathrm{rGO}$ was about $80 \mathrm{wt} \%$ (saturation magnetization of RGF 50.7 emu/g). $\mathrm{SE}_{\mathrm{T}}$ value of $-43.5 \mathrm{~dB}$ with a $\mathrm{SE}_{\mathrm{A}} / \mathrm{SE}_{\mathrm{T}}$ ratio of $\sim 90 \%$ was acquired for the composite constructed using $4 \mathrm{wt} \% \mathrm{CNT} / 5 \mathrm{wt} \%$ RGF compartments in X-band for 2 $\mathrm{mm}$ thick sample. This $\mathrm{SE}_{\mathrm{T}}$ value is about $22.5 \%$ higher than that of randomly dispersed filler $(-35.5 \mathrm{~dB})$. It is worth noting that the $\mathrm{SE}_{\mathrm{T}}$ value of $\mathrm{CNT} / \mathrm{PC}$ compartment based-composites is inferior to that of CNT/RGF/ PC compartment-based composites when adding the same CNT content; e.g., for $4 \mathrm{wt} \% \mathrm{CNT}$, the $\mathrm{SE}_{\mathrm{T}}$ value is $10.3 \mathrm{~dB}$ higher in CNT/RGF/PC compartment-based composite. The electrical conductivity shows no significant difference in CNT/ PC and CNT/RGF/PC compartment-based composites because they have the same conductive network; however electrical conductivity for random dispersion of fillers was significantly lower than the compartment model. The shielding mechanism is shown in Fig. 10C. The outer CNT walls served as reflectors to generate multiple reflections.

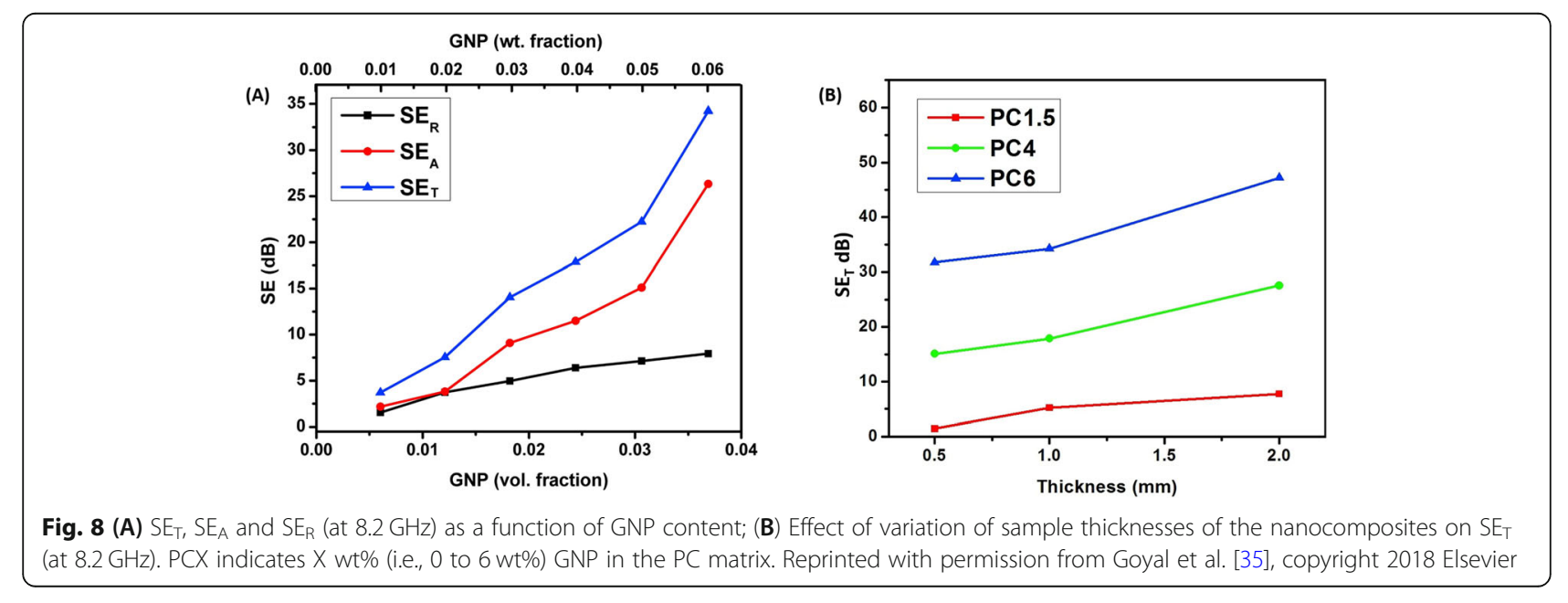


(A)
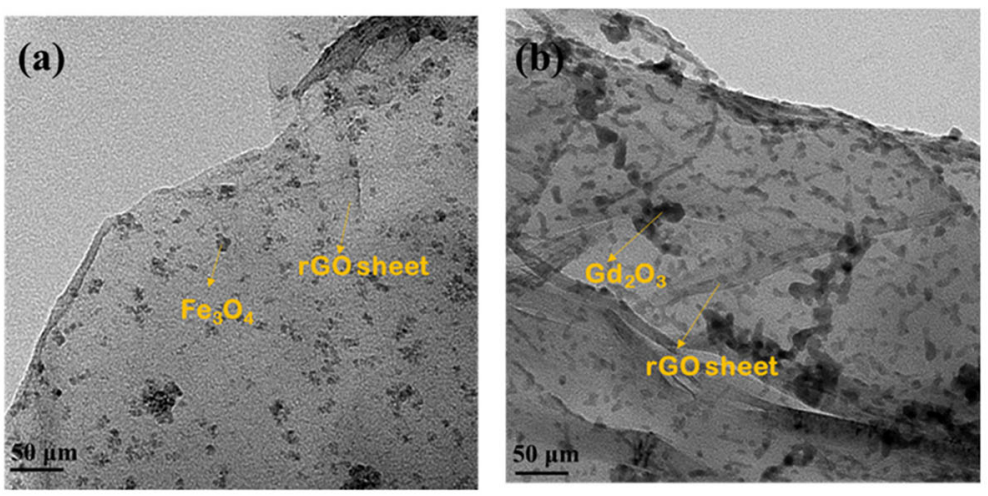

(B)

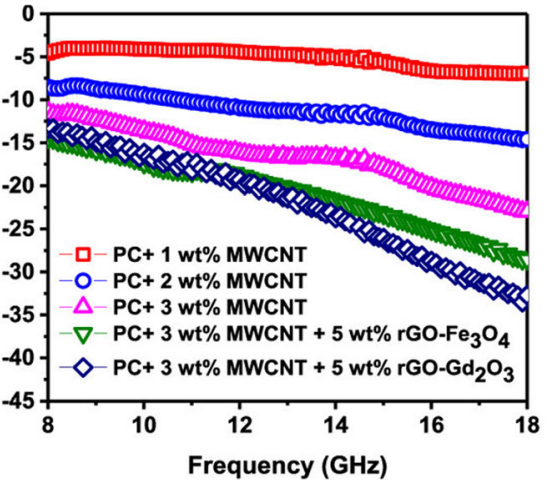

(C)

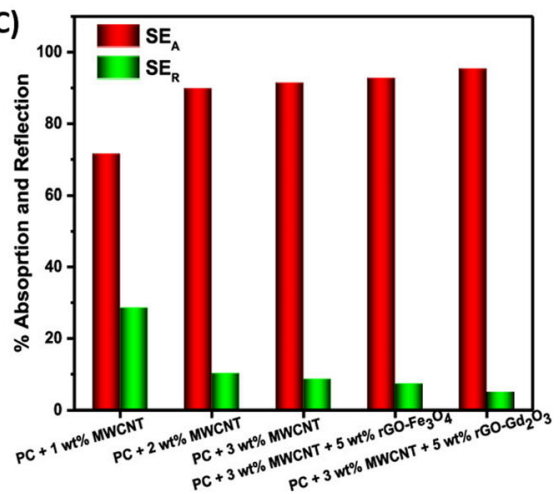

Fig. 9 (A) Transmission electron micrographs of (a) $\mathrm{rGO}-\mathrm{Fe}_{3} \mathrm{O}_{4}$ and (b) $\mathrm{rGO}-\mathrm{Gd}_{2} \mathrm{O}_{3}$; (B) $\mathrm{SE}$ T vs. frequency; (C) \% Absorption and reflection at 18 $\mathrm{GHz}$. Adapted with permission from Bose et al. [80], copyright 2019 American Chemical Society

However, the permittivity and permeability study of RGF hybrids showed that both dielectric and magnetic loss made the inner core absorbers.

\section{PC-based blend composites}

PC-based blends serve as an excellent approach to tune in the structural properties to suit specific applications. For example, PC/ABS copolymer is commercially used for mobile phone housing and is specialized for highimpact and low-temperature applications. With the addition of fillers, it can be used for application in car audio chassis. ABS is also blended with PC to improve flow and chemical resistance [7]. PC composite toughness is often increased by blending it with another thermoplastic as polyester (polyethylene terephthalate, polybutylene terephthalate (PBT), etc.). Blending is favorable as polyesters and PC are partially miscible. Cyclic butylene terephthalate (CBT) is also known to enhance toughness, impact resistance and melt recyclability. Polycarbonate/poly (lactic acid) (or PC/ PLA) blends have gained attention owing to their application in the electronic industry [82]. PLA being a biodegradable polymer, find several applications in biomedical areas.
Choi et al. [83] researched PC/ABS-based composite mixed with glass fibers (GF) and metal fibers (MF). GFs are less expensive fillers and are used to improve the polymer composites' mechanical strength and stiffness. At the same time, MFs are known to balance the composites' thermal conductivity, mechanical and electrical properties. GFs have key elements as 'Si' and 'Al', while MFs are comprised of stainless steel (mainly $\mathrm{Cr}$ and $\mathrm{Fe}$ ). Fillers were incorporated in the blend matrix using an injection molding technique. It was observed that MFs show poor interfacial adhesion compared to GFs in PC/ ABS blends due to poor wetting onto the metal fibers. GFs were coated by a coupling agent, amino-silane, which helped enhance the adhesion of GFs in PC/ABS, thus promoting mechanical stability. $\mathrm{SE}_{\mathrm{T}}$ value of -40 $\mathrm{dB}$ is considered optimum for car audio applications. With a shield thickness of $2 \mathrm{~mm}, \mathrm{PC} / \mathrm{ABS}$ blend with 7 $w t \%$ GFs and $3 \mathrm{wt} \%$ MFs achieved shielding of $-40 \mathrm{~dB}$ at $1 \mathrm{~Hz}$ frequency. Moreover, the car audio chassis' weight was approximately $49 \%$ of the weight of the chassis made from conventional stainless steel.

Ramakrishnan et al. [84] prepared nanostructured polyaniline-polyhydroxy iron-clay (PPIC) composite, comprised of exfoliated/intercalated nanoclay layers with 


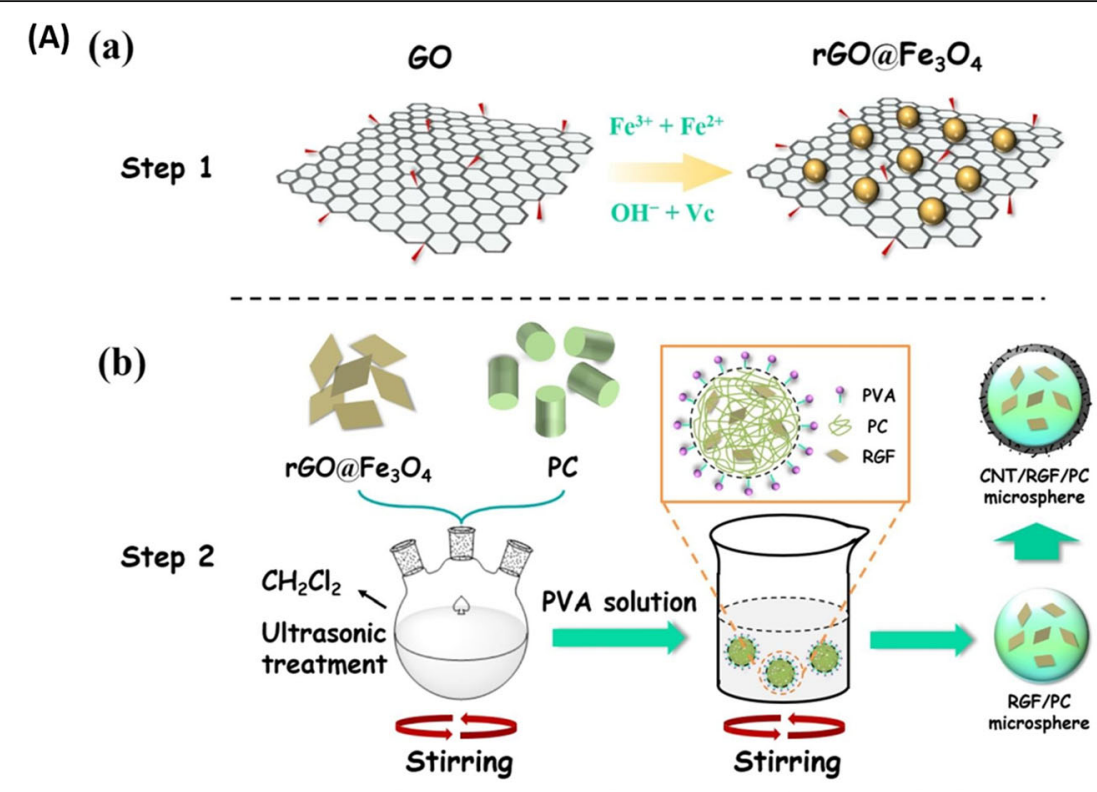

(c)

Step 3

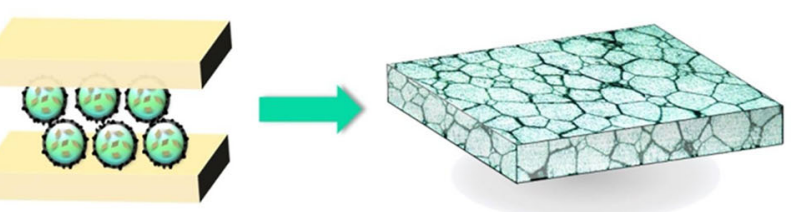

(B)
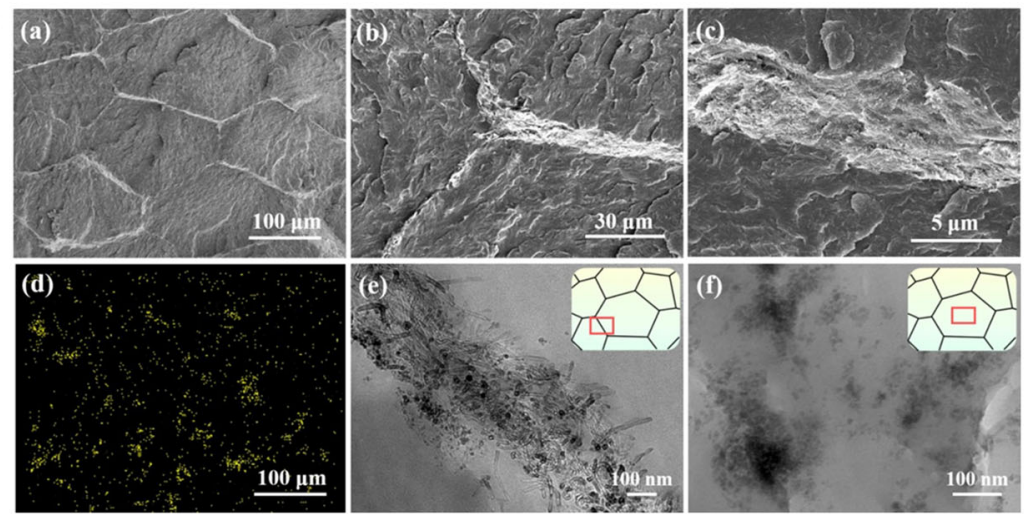

(C)

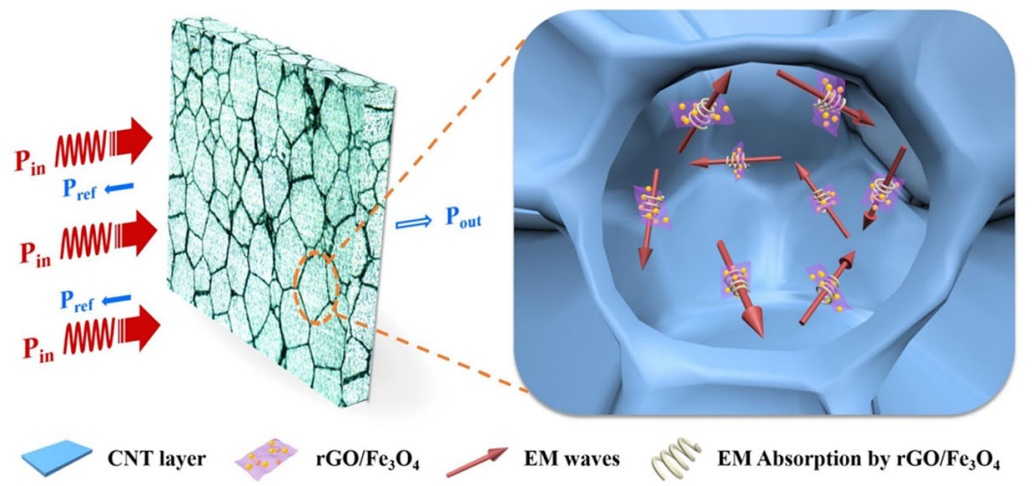

Fig. 10 (See legend on next page.) 
(See figure on previous page.)

Fig. 10 (A) Schematic for (a) synthesis of RGF, (b) preparation of reflection-absorption-integrated shielding compartments, and (c) CNT/RGF/PC composites; (B) (a) Scanning electron micrograph of CNT/RGF/PC composite, (b) and (c) are the higher magnification micrographs of (a), (d) energy dispersive X-ray elemental mapping of Fe and $(\mathbf{e}, \mathbf{f})$ transmission electron micrograph of CNT/RGF/PC composite. The inset cartoons show the composite's observing area; (C) Shielding mechanism of the reflection-absorption-integrated shielding compartment. Adapted with permission from Li et al. [81], copyright 2020 Elsevier

high aspect ratio, dispersed in nanomagnets encapsulated polyaniline (PANI). Thereafter, solution blending technique was used to mix PPIC in the PC matrix at different proportions to obtain an electrically conducting blend designated as PPPC. It is known that conducting polymers such as PANI and polypyrrole (PPy) exhibit a low percolation threshold due to the hydrogen bonding interaction between the two polymers (shown in Fig. 11A). It is observed that with the increasing content of PPIC, an interconnected conductive network is formed (shown in Fig. 11B), thus enhancing the shielding performance. At $8 \mathrm{GHz}$ frequency, the conductive PPPC films showed the $\mathrm{SE}_{\mathrm{T}}$ values of $-24 \mathrm{~dB}(5 \mathrm{wt} \%)$, $42 \mathrm{~dB}(10 \mathrm{wt} \%),-50 \mathrm{~dB}$ (15 wt\%), and $-52 \mathrm{~dB}$ (30 wt\%) for the film thickness of $2 \mathrm{~mm}$. The mechanism of shielding is attributed to the absorption losses due to the magnetic and electric dipoles. Further, the author claims that reflection and multiple reflections add to shielding owing to magnetic polyhydroxy iron species and the presence of porous multilayered clay.

Abad et al. [69] did melt mixing with commercial masterbatch to obtain $\mathrm{PC} / \mathrm{CNT}$ composite (2 and $5 \mathrm{wt} \%$ CNT). The authors claim that PC's viscosity affects the electrical percolation threshold, and they found the electrical percolation threshold to be around $1 \mathrm{wt} \% \mathrm{CNT}$. However, the adequate electrical conductivity value for shielding applications is obtained at a higher concentration of CNTs. But too high concentration makes the processing as well as mechanical property decline. It is known that PC undergoes a tough-to-brittle transition in between 2 and $4 \mathrm{wt} \%$ of CNT. In their work, they have added a low viscosity CBT (5wt\%) and used different molding techniques (injection molding-thermal annealing and compression molding) to figure out the impact of processing on the mechanical and electrical behavior of composites. Dynamic moduli and viscosity increase with the increase in CNT content in the PC matrix. However, $\mathrm{CBT}$ acts as an external lubricant (aiding processability) without changing nanocomposites' melt viscosity. They used the classical electromagnetic theory mentioned in eq. 11 to obtain the $\mathrm{SE}_{\mathrm{T}}$ value from the electrical conductivity values. $\mathrm{SE}_{\mathrm{T}}$ value of around $-40 \mathrm{~dB}$ was obtained for nanocomposites with $5 \mathrm{wt} \%$ of $\mathrm{CNT}$ in the frequency range of $500-3000 \mathrm{MHz}$ for a specimen thickness of 4 $\mathrm{mm}$. $\mathrm{SE}_{\mathrm{T}}$ value for $\mathrm{PC} / 5 \mathrm{wt} \% \mathrm{CBT} / 5 \mathrm{wt} \% \mathrm{CNT}$ (compression molded) was slightly lower than $\mathrm{PC} / 5 \mathrm{wt} \% \mathrm{CNT}$ but PC/ $5 \mathrm{wt} \% \mathrm{CBT} / 5 \mathrm{wt} \% \mathrm{CNT}$ (injection-molded and annealed) was calculated to be the lowest. This is because CNTs are highly oriented in injection molding, leading to interruption of the tube-tube contacts (good dispersion), resulting in a decline in conductivity. Moreover, at high shear rates, as in injection molding, nanotube shortening can occur. The annealing treatment brings only slight changes in PC/CNT composites' conductivity value because CNT mobility during the thermal treatment is inadequate to improve the network structure. Compression

(A)

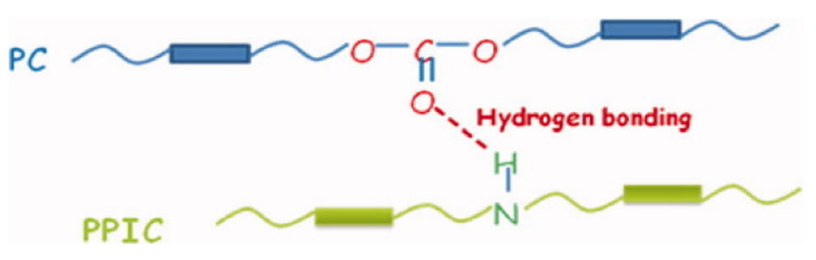

(B)

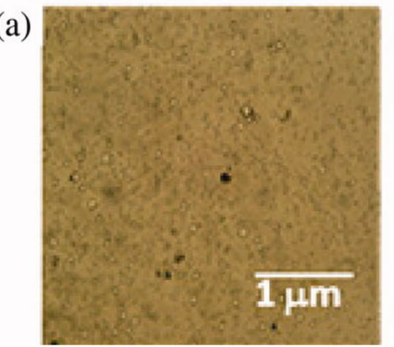

(b)
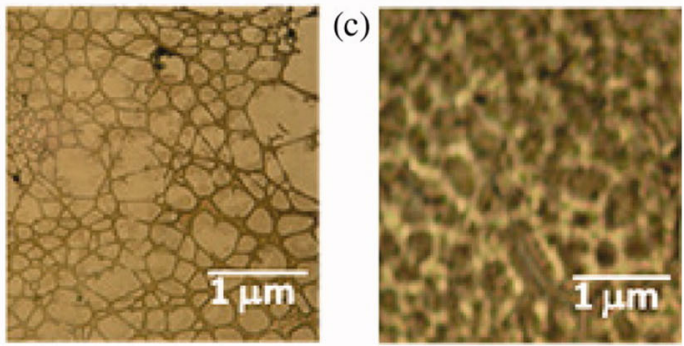

Fig. 11 (A) Hydrogen bonding between PC and PPIC; (B) Polarized light micrographs of (a) 5\% PPIC, (b) 10\% PPIC, and (c) 15\% PPIC blends showing the percolated network formation. Adapted with permission from Ramakrishnan et al. [84], copyright 2012 Wiley 
molding introduces low shear, and the melt doesn't suffer orientation in a preferential direction, leading to more tube-tube contacts (agglomerates of CNTs). The addition of CBT enhances the electrical behavior of composites similarly for both processing techniques.

Bose et al. [57] synthesized $\mathrm{NH}_{2}$ terminated CNTs using two different synthesis protocols and further melt blended $1 \mathrm{wt} \%$ of these modified CNTs individually with polycarbonate/ poly (styrene-co-acrylonitrile) (PC/ SAN$50 / 50, \mathrm{w} / \mathrm{w})$. The extruded strands were further compression molded. In the first method of CNT covalent modification, ethylenediamine (EDA) was grafted onto CNTs by diazonium reaction of the para-substituted benzene ring of CNT (labeled as MWNT-II). In the second method, carboxyl functionalized CNTs were reacted with thionyl chloride to give EDA grafted CNTs (labeled as MWNT-III). For the control experiment, the authors used commercially available $\mathrm{NH}_{2}$ terminated CNTs that were smaller in length than CNTs used for chemical modification (labeled as MWNT-I). $\mathrm{NH}_{2}$ functionalization was to trap CNTs in the PC component through melt interfacial reaction between amine functional groups on the surface of CNTs with ester groups of PC, thus promoting double percolation in the blend. It is to be noted that in the non-covalent functionalization of CNTs, the $\pi$-electron cloud of CNT promotes the adsorption of various moieties and maintains the integrity of CNTs. In contrast, the covalent functionalization results in more defects in CNTs, thus deteriorating the electrical conductivity. The percentage concentration of $\mathrm{N}$ in MWNT-I, MWNT-II, and MWNT-III was found to be $0.66,3.01$ and 22, respectively. Figure 12A shows the schematic illustration of the effect of the concentration of $\mathrm{NH}_{2}$ terminal groups on the chain scission of PC. Chain scission of PC was observed in the case of MWNT-III, which is caused by the specific interactions between EDA and PC, resulting in smaller PC grafts on the surface of CNTs due to higher content of $\mathrm{NH}_{2}$ terminal groups, which further lead to an insulating coating. The chain scission of PC decreased its viscosity, resulting in good dispersion of CNTs in the PC component, reducing the nanotube-nanotube contact, thus reducing the electrical conductivity (shown in Fig. 12B). PC/SAN with MWNT-II shows seven orders of increase in bulk electrical conductivity than neat blends. This can be due to the high aspect ratio and selective localization of MWNT-II. PC/SAN with MWNT-I, MWNT-II, and MWNT-III exhibit $\mathrm{SE}_{\mathrm{T}}$ of $-8.4 \mathrm{~dB},-14 \mathrm{~dB}$ and $-3 \mathrm{~dB}$ in the frequency range of $8-18 \mathrm{GHz}$ (shown in Fig. 12C).

In another work by Bose and coauthors [85], they studied the effect of incorporating CNTs, physical mixture of CNTs and dopamine anchored- $\mathrm{Fe}_{3} \mathrm{O}_{4}$, and CNTgrafted $\mathrm{Fe}_{3} \mathrm{O}_{4}$ on the EMI shielding properties of $\mathrm{PC}$ and PC/SAN (60/40 and 50/50) blends. The authors adopted a two-step mixing protocol, wherein the nanoparticles were solution blended with PC, dried, and then melt mixed with SAN with an aim to selectively localize nanoparticles in a given component of blend and promote double percolation. Both CNTs and modified CNTs resulted in high electrical conductivity when selectively localized in the $\mathrm{PC}$ component of the PC/SAN blend compared to only PC composites. PC/SAN composites (with $3 \mathrm{wt} \% \mathrm{CNT}$-grafted $\mathrm{Fe}_{3} \mathrm{O}_{4}$ ) showed a $\mathrm{SE}_{\mathrm{T}}$ value of $-32.5 \mathrm{~dB}$ and $-30 \mathrm{~dB}$ for the blend composition $60 / 40$ and 50/50, respectively. The detailed shielding value and percentage absorption analysis are shown in

(A)
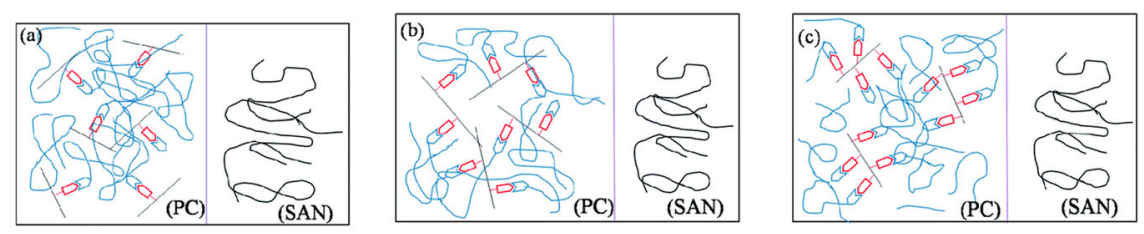

(B)

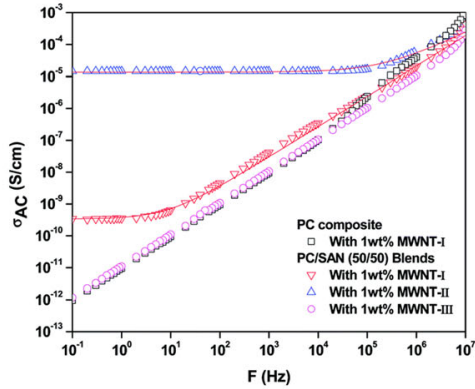

(c)

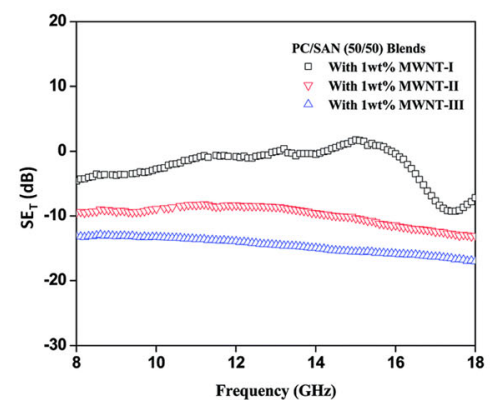

Fig. 12 (A) Schematic illustration of the effect of concentration of $\mathrm{NH}_{2}$ terminal groups on the chain scission of PC (a) MWNT-I, (b) MWNT-II and (c) MWNT-III; (B) AC conductivity as a function of frequency for PC/SAN (50/50) blends with different MWNTs; (C) SET for PC/SAN (50/50) blends with different types of MWNTs. Reprinted with permission from Bose et al. [57], copyright 2014 Royal Society of Chemistry 
Table 3. It is observed that the double percolation of $\mathrm{CNT}$ has also impacted the $\mathrm{SE}_{\mathrm{T}}$ values wherein the blend shows $-31 \mathrm{~dB}$ (for $60 / 40$ blend with $3 \mathrm{wt} \% \mathrm{CNT}$ ) compared to PC composites $(-23 \mathrm{~dB}$ for $3 \mathrm{wt} \% \mathrm{CNT}$ in PC). It is also observed that reflection dominated shielding in the blends with only CNTs, whereas absorption dominated in the case of blends with CNT-grafted $\mathrm{Fe}_{3} \mathrm{O}_{4}$. This can be attributed to the higher complex permeability in CNT-grafted $\mathrm{Fe}_{3} \mathrm{O}_{4}$-based samples, as compared to blends with only CNTs and physical mixture of nanofillers.

Kim et al. [86] investigated PC/ABS (80/20)/CNT composite with poly (styrene-co-acrylonitrile)-g-maleic anhydride (or SAN-g-MAH) as a compatibilizer, prepared by melt mixing technique. The SAN-g-MAH was kept constant at $5 \mathrm{phr}$ in the $\mathrm{PC} / \mathrm{ABS}$ blend and $\mathrm{PC} /$ $\mathrm{ABS} / \mathrm{CNT}$ composite. It was found that the droplet size of the ABS decreased with the addition of SAN-g-MAH, which proved to be an effective compatibilizer for the PC/ABS (80/20) blend, as shown in Fig. 13A and B. It is worth noting that Maleic anhydride (MAH) contains a carbonyl group that makes it highly polar and interacts with the polar ester group in PC. On the other hand, ABS has the SAN group, and Van der Waals forces exist between the ABS and SAN-g-MAH. The interfacial tension between $\mathrm{PC}$ and $\mathrm{ABS}$ decreases with the addition of the SAN-g-MAH in the PC/ABS blend. Also, CNTs preferably localized in the $\mathrm{ABS}$ component (dispersed phase) compared to the PC component (continuous phase) due to the low interfacial tension of the ABS/ CNT composite compared to $\mathrm{PC} / \mathrm{CNT}$ composite as shown in Fig. 13A and C. It is to be noted that PC/ABS $(80 / 20)$ show sea-island morphology. PC/ABS/CNT composite with compatibilizer showed higher electrical conductivities than those without the compatibilizer due to the conductive pathways, which are more easily formed with a decreased domain size, resulting in more evenly dispersed CNTs. $\mathrm{SE}_{\mathrm{T}}$ of the PC/ABS/CNT (3 phr CNT, $2 \mathrm{~mm}$ thick) composite with compatibilizer ranged from -5.4 to $-8.4 \mathrm{~dB}$, and the composite without the compatibilizer ranged from -2.5 to $-4.2 \mathrm{~dB}$ in the frequency range of 0.1 to $1.5 \mathrm{GHz}$ (shown in Fig. 13D).
Further, PC/ABS/CNT composite with the SAN-g-MAH showed higher complex viscosity, especially at lower frequencies than that of the composite without SAN-g$\mathrm{MAH}$, which is possibly caused by the increase in CNT dispersion with compatibilization.

Rai et al. [87] opted for electroless plating of Ni coating on PC/ABS and polyphenylene sulfide (PPS) particles and then used a twin-screw extruder to melt-mix Ni- PC/ABS (45 wt\%) with carbon fibers ( $15 \mathrm{wt} \%)$ and graphite flakes (40 wt\%). Similarly, PPS composites were prepared with Ni-PPS (45 wt\%), carbon fibers (15wt\%) and graphite flakes (40 wt\%). The electrical conductivity of Ni-coated PPS was found to be higher than that of Ni-coated PC/ ABS. The results further confirmed that $\mathrm{Ni}$, carbon fiber and graphite increased $\mathrm{SE}_{\mathrm{T}}$, electrical conductivity, and the composite's mechanical properties. Ni-PPS composites resulted in a higher $\mathrm{SE}_{\mathrm{T}}$ of the order $-67 \mathrm{~dB}$ at $2000 \mathrm{MHz}$ and $-87 \mathrm{~dB}$ at $4000 \mathrm{MHz}$ compared to $\mathrm{Ni}-\mathrm{PC} / \mathrm{ABS}$ composites, which resulted in a $\mathrm{SE}_{\mathrm{T}}$ of the order $-57 \mathrm{~dB}$ at $2000 \mathrm{MHz}$ and $-79 \mathrm{~dB}$ at $4000 \mathrm{MHz}$.

Bose et al. [88] developed polymeric blend-basednanocomposites using PC/SAN containing cobalt nanoparticles dispersed onto reduced graphene oxide (rGO) sheets and CNTs. The nanoparticles were solution mixed with $\mathrm{PC}$ and further diluted with SAN in a melt extruder to yield a blend of PC/SAN (70/30 w/w). PC component was made electrically conducting by selectively localizing the CNTs into it. The blends with both rGO-Co and CNTs as filler show the $\mathrm{SE}_{\mathrm{T}}$ value of $-34 \mathrm{~dB}$ at $18 \mathrm{GHz}$, which is higher than blends with only CNTs or only CNT-Co or only rGO-Co. Moreover, it was observed that the shielding is $63 \%$ via absorption for the blend with both rGO-Co and CNTs. It is to be noted that the concentration of CNT was $3 \mathrm{wt} \%$, Co was found to be $9.6 \mathrm{wt} \%$, and $\mathrm{GO}$ was found to be $2.4 \mathrm{wt} \%$. The mechanism of shielding in both X $(8-12 \mathrm{GHz})$ and $\mathrm{Ku}$-band $(12-18 \mathrm{GHz})$ frequencies were attributed to dielectric losses (space charge polarization, dipolar polarization) and magnetic losses (natural resonance effect, eddy current losses) due to the presence of various fillers.

The effect of lactic acid-grafted multi-walled carbon nanotube (LA-g-CNT) on electrical and EMI shielding

Table $3 \mathrm{SE}_{\mathrm{T}}$ and \% absorption for PC and PC/SAN composites

\begin{tabular}{|c|c|c|}
\hline Sample details & $\mathrm{SE}_{\mathrm{T}}$ at $18 \mathrm{GHz}$ (in $\mathrm{dB}$ ) & $\%$ Absorption at $18 \mathrm{GHz}$ \\
\hline $3 w t \%$ CNT in PC & -23 & - \\
\hline 3 wt $\%$ CNT-grafted $\mathrm{Fe}_{3} \mathrm{O}_{4}$ in PC & -28 & - \\
\hline 3 wt\% CNT in PC/SAN (60/40) & -31 & 38 \\
\hline 3 wt $\%$ CNT and 3 vol\% dopamine anchored $-\mathrm{Fe}_{3} \mathrm{O}_{4}$ in PC/SAN (60/40) & -31 & 65 \\
\hline 3 wt\% CNT-grafted $\mathrm{Fe}_{3} \mathrm{O}_{4}$ in PC/SAN (60/40) & -32.5 & 70 \\
\hline 3 wt\% CNT in PC/SAN (50/50) & $\sim-26$ & 30 \\
\hline 3 wt\% CNT-grafted $\mathrm{Fe}_{3} \mathrm{O}_{4}$ in PC/SAN (50/50) & -30 & 51 \\
\hline
\end{tabular}


(A) (a)

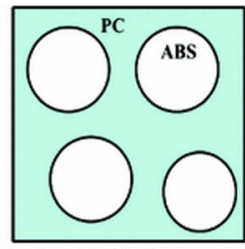

PC/ABS (80/20) blend without compatibilizer

(b)

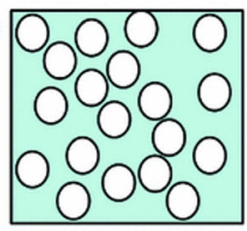

PC/ABS (80/20) blend with compatibilizer

(B)
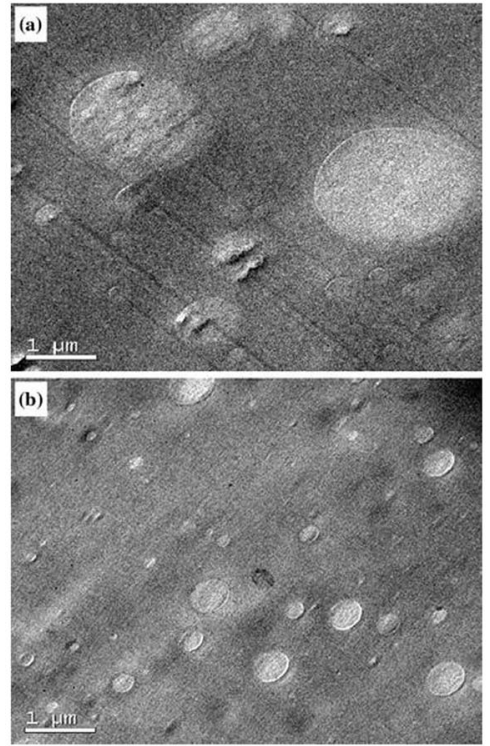

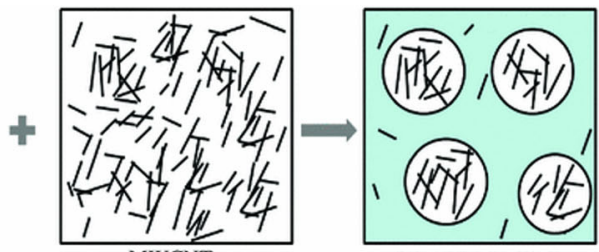

PC/ABS/MWCNT composite without compatibilize

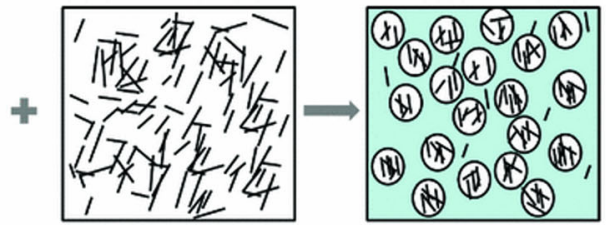

PC/ABS/MWCNT

composite with

compatibilizer

(C)
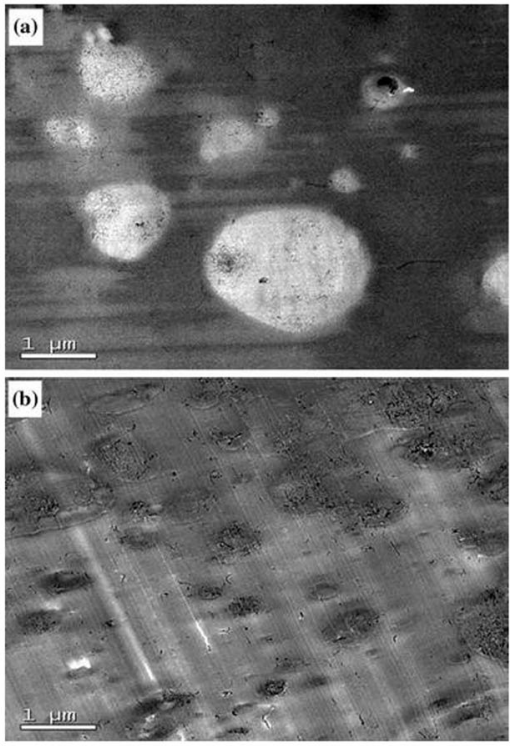

(D)

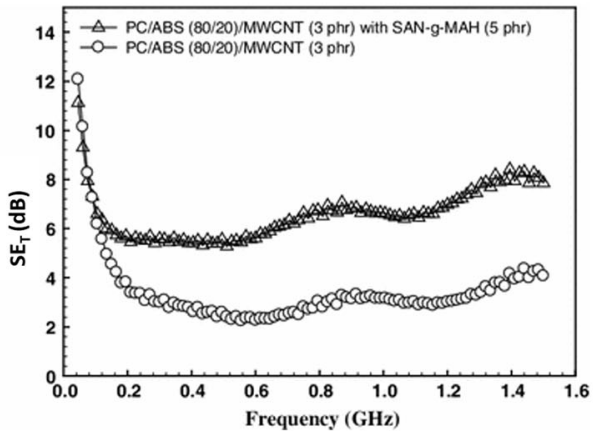

Fig. 13 (A) Schematic of PC/ABS with CNT (here labeled as MWCNT) as filler: (a) without compatibilizer, (b) with compatibilizer; (B) Transmission electron micrographs of (a) PC/ABS (80/20) blend, (b) PC/ABS (80/20) blend with compatibilizer (SAN-g-MAH, 5 phr); (C) Transmission electron micrographs of PC/ABS (80/20)/CNT (3 phr) composites: (a) without compatibilizer, (b) with compatibilizer (SAN-g-MAH, 5 phr); (D) SET of the PC/ABS(80/20)/CNT (3 phr) composites with frequency: without compatibilizer and with compatibilizer (SAN-g-MAH, 5 phr). Reprinted with permission from Kim et al. [86], copyright 2014 Springer 
performance of PC/PLA (70/30) blend was studied by Kim et al. [82]. The aim was to enhance the dispersion of CNTs by their chemical modification. It was expected that LA-g-CNT would act as a compatibilizer between the conductive filler and polymers. PC/PLA/ LA-g-CNT composites were prepared using melt extrusion. It showed higher complex viscosity, electrical conductivity, and electromagnetic interference shielding effectiveness compared to PC/PLA/CNT composite. The increased dispersion of the LA-g-CNT in the PC/ PLA blend is due to the enhancement in CNT-CNT contacts. Since the interfacial tension of the PLA/ CNT composite was lower than that of the PC/CNT composite, CNTs localize in the PLA component. $\mathrm{SE}_{\mathrm{T}}$ of PC/ PLA/LA-g-CNT composite ranged from $3.8 \times 10^{-3}$ to $1.3 \times 10^{1} \mathrm{~dB}$ as the filler concentration varied from 0.1 to $5 \mathrm{phr}$, and it was calculated using eq. 10 (sample thickness of $0.2 \mathrm{~mm}$ ).
Bose et al. [89] designed a co-continuous PC/PVDF $(40 / 60 \mathrm{w} / \mathrm{w})$ blend using melt mixing technique, wherein polyaniline (PANI) modified CNT with $\mathrm{Fe}_{3} \mathrm{O}_{4}$ (3 wt\%) were selectively restricted in PVDF, and the barium titanate (BT) nanoparticles were surface modified to localize in PC via nucleophilic substitution reaction. This approach resulted in an RL value of $-71 \mathrm{~dB}$ at $12.9 \mathrm{GHz}$ frequency. It was observed that in-situ PANI modified CNTs facilitate better charge transport efficiency and absorption-based shielding in the blend compared to the neat CNT-based blend. Further, the synergistic effect of the high relative permittivity (from BT and PANI$\mathrm{CNT}-\mathrm{Fe}_{3} \mathrm{O}_{4}$ ), high relative permeability (PANI-CNT$\mathrm{Fe}_{3} \mathrm{O}_{4}$ ), and high conductivity in the blend system manifested in $90 \%$ of the EM waves being blocked via absorption. $\mathrm{SE}_{\mathrm{T}}$ value of $-37 \mathrm{~dB}$ was achieved for $5 \mathrm{~mm}$ thick sample at $18 \mathrm{GHz}$ frequency which can be attributed to a high total loss tangent $\left(\tan \delta_{\mu}+\tan \delta_{\varepsilon}\right)$. It is to (a)

(A)

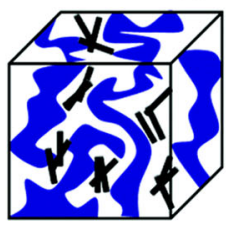

(d)

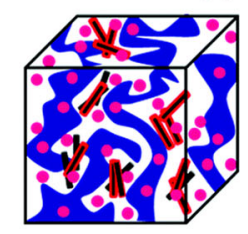

(b)

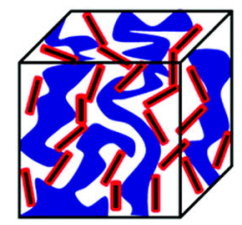

(e)

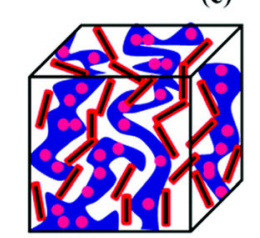

(c)

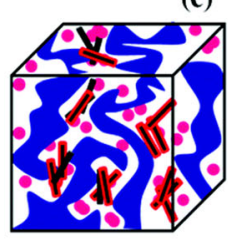

PC

PVDF

MWNT

PDI-MWNT

- $\mathrm{BaTiO}_{3} / \mathrm{NiFe}_{2} \mathrm{O}_{4}$

(B)

\begin{tabular}{|c|c|c|c|c|}
\hline & Sample details & $\begin{array}{l}\mathrm{SE}_{\mathrm{T}}(\mathrm{dB}) @ 18 \mathrm{GHz} \\
\text { for } \quad 5 \quad \mathrm{~mm} \\
\text { thickness }\end{array}$ & $\begin{array}{l}\% \\
\text { Absorption }\end{array}$ & $\sigma_{\mathrm{DC}}(\mathrm{S} / \mathrm{cm})$ \\
\hline a & 3 wt\% MWNT in PVDF & -24.5 & 28.6 & $3.1 \times 10^{-5}$ \\
\hline b & 3 wt\% PDI-MWNT in PVDF & -28.5 & 15.4 & $2 \times 10^{-3}$ \\
\hline c1 & 3 wt\% PDI-MWNT in PVDF + BT in PVDF & -29 & 50.3 & $1.2 \times 10^{-4}$ \\
\hline c2 & 3 wt\% PDI-MWNT in PVDF + NF in PVDF & -29 & 48.3 & $9.8 \times 10^{-5}$ \\
\hline d1 & 3 wt\% PDI-MWNT in PVDF + BT in both phases & -33 & 51.5 & $2 \times 10^{-4}$ \\
\hline d2 2 & 3 wt\% PDI-MWNT in PVDF + NF in both phases & -35.5 & 52.1 & $4 \times 10^{-4}$ \\
\hline e1 & $3 \mathrm{wt} \% \mathrm{PDI}-\mathrm{MWNT}$ in PVDF + BT-NH ${ }_{2}$ in PC & -35 & 62.9 & $8 \times 10^{-4}$ \\
\hline e2 & 3 wt $\%$ PDI-MWNT in PVDF + NF-NH ${ }_{2}$ in PC & -40 & 67.5 & $1.3 \times 10^{-3}$ \\
\hline
\end{tabular}

Fig. 14 (A) Schematic of the various sample configurations obtained by nanoparticle surface treatment and/or interfacial interaction; (B) SET, \% absorption and $\sigma_{D C}$ (obtained from dc plateau of bulk conductivity measurement) of the samples shown in the schematic representation in (A). Adapted with permission from Bose et al. [90], copyright 2015 Royal Society of Chemistry 
be noted that blends with neat CNTs (3wt\%) yielded a $\mathrm{SE}_{\mathrm{T}}$ value of $-22 \mathrm{~dB}$, PANI-CNT (3 $\mathrm{wt} \%$ ) resulted in a $\mathrm{SE}_{\mathrm{T}}$ value of $-26 \mathrm{~dB}$, and PANI-CNT- $-\mathrm{Fe}_{3} \mathrm{O}_{4}$ (3wt\%) yielded a $\mathrm{SE}_{\mathrm{T}}$ value of $-32 \mathrm{~dB}$ for $5 \mathrm{~mm}$ thick sample at $18 \mathrm{GHz}$ frequency.

In another work by Bose et al. [90], they employed a unique strategy to tune the dispersion and arrangement of nanostructured material in the 50/50 (w/w) co-continuous blend of PC and PVDF by surface modification of nanoparticle and/or by facilitating the interfacial interaction. As demonstrated in Fig. 14A, several shield design configurations were attempted using melt mixing followed by a compression molding technique. Figure 14B shows the corresponding table of $\mathrm{SE}_{\mathrm{T}}, \%$ absorption, and $\mathrm{dc}$ conductivity value of each of these configurations. The highest $\mathrm{SE}_{\mathrm{T}}$ of -40 $\mathrm{dB}(\mathrm{RL}=-67 \mathrm{~dB} @ 17 \mathrm{GHz})$ was obtained for a sample with $3 \mathrm{wt} \%$ perylenediimide modified multiwalled carbon nanotubes (PDI-MWNT) in PVDF component along with nickel ferrite (NF) in PC component. Whereas $\mathrm{SE}_{\mathrm{T}}$ of $-35 \mathrm{~dB}$ was obtained for a sample with 3 wt\% PDI-MWNT in PVDF with barium titanate (BT) in the $\mathrm{PC}$ component. It is to be noted that BT shows dielectric properties, and NF shows magnetic behavior, thus contributing to the loss mechanism. Thus, the compartmentalized approach to localize conductive (MWNT) and lossy nanoparticles $(\mathrm{BT} / \mathrm{NF})$ in different components of a co-continuous blend proved to be a superior technique compared to a random mix of nanoparticles.

Further, Bose et al. [91] extended the research work by adding a mutually soluble homopolymer (here PMMA) as a third component to the binary blend of PC/PVDF $(60 / 40)$. This led to an improved stress transfer at the interface, besides retaining the blends' electrical conductivity. Ionic liquid modified-multiwalled carbon nanotube (or IL-MWNT) and $\mathrm{NH}_{2}$ modified-BaFe were used as nanofillers and incorporated in the matrix using a melt mixing approach such that MWNT preferred PVDF component and BaFe preferred PC component. $\mathrm{NH}_{2}$ groups on BaFe and ester group on $\mathrm{PC}$ underwent a nucleophilic substitution reaction to localize $\mathrm{BaFe}$ in the $\mathrm{PC}$ component. $\mathrm{SE}_{\mathrm{T}}$ value of $-37 \mathrm{~dB}$ (2 $\mathrm{wt} \%$ ILMWNT, 5 wt\% BaFe, 10 wt\% PMMA) was obtained for a sample of $5 \mathrm{~mm}$ and at $18 \mathrm{GHz}$ frequency, which was slightly higher than the value of $\mathrm{SE}_{\mathrm{T}}$ without PMMA (shown in Fig. 15B). Shielding via absorption was found to be the dominating mechanism. BaFe was the main cause for absorption-based shielding as it is known to contribute to the losses via magnetic hysteresis, wall displacement, and eddy current loss. The shielding mechanism and total losses are shown in Figs. 15A and D. Figure $15 \mathrm{C}$ shows the digital image depicting the flexibility of the obtained film.

In yet another work by Bose et al. [92], they prepared a PC/SAN (60/40) blend containing CNTs and
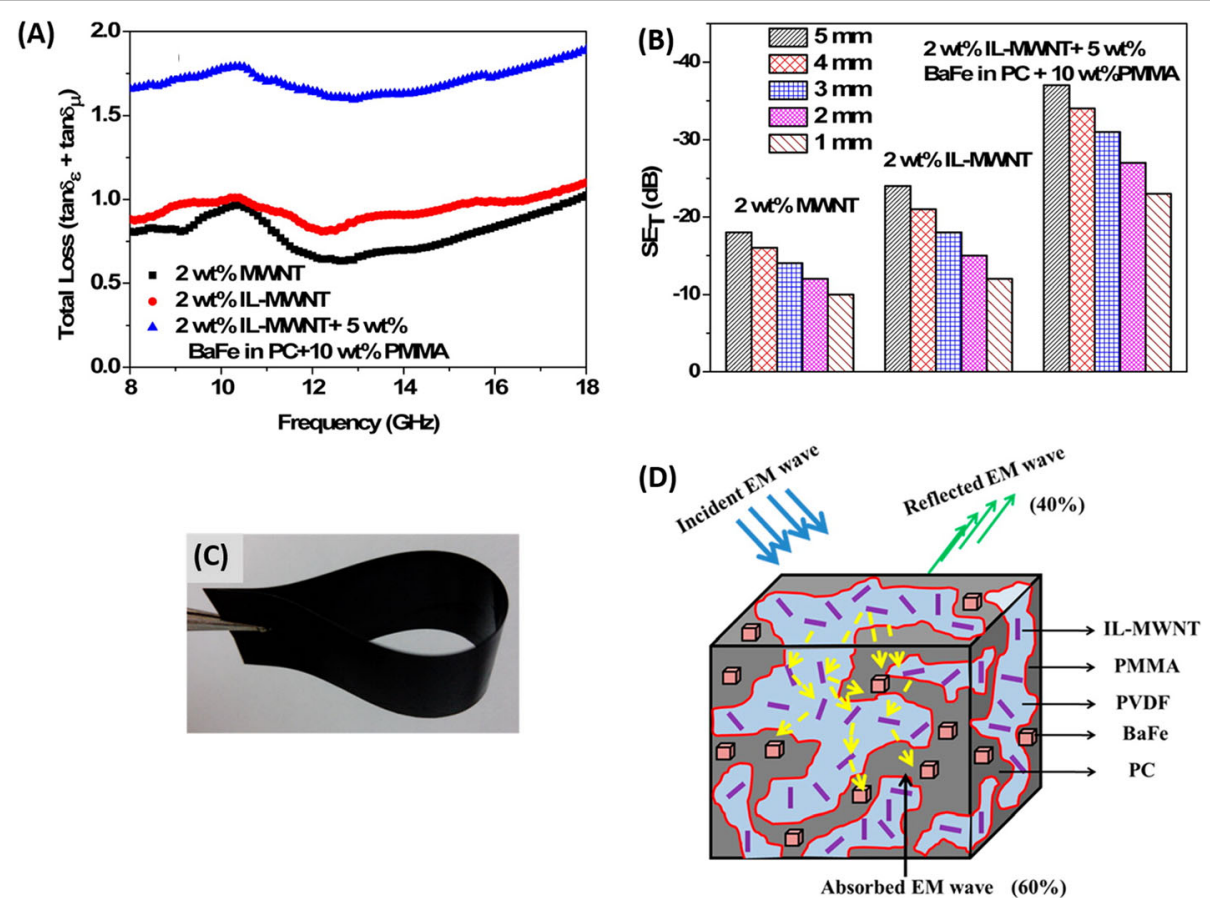

Fig. 15 (A) Total loss tangent for various blends as a function of frequency; (B) SET with respect to thickness; (C) The obtained flexible film; (D) Cartoon representing the mechanism of EM attenuation for blends containing 2 wt\% IL-MWNT in PVDF phase and 5 wt\% BaFe in the PC phase. Reprinted with permission from Bose et al. [91], copyright 2015 American Chemical Society 
ferromagnetic nickel nanoparticles nucleated on partially reduced graphene sheets $(\mathrm{rGO}-\mathrm{Ni})$. The technique involved solution blending to obtain a PC composite masterbatch, followed by melt blending with SAN at $260^{\circ} \mathrm{C}$. It showed a high $\mathrm{SE}_{\mathrm{T}}$ of $-48 \mathrm{~dB}(@ 18 \mathrm{GHz})$ with $3 \mathrm{wt} \%$ $\mathrm{CNT}$ and $10 \mathrm{wt} \% \mathrm{rGO}-\mathrm{Ni}, \sigma_{\mathrm{DC}}$ value being $1.9 \times 10^{-2} \mathrm{~S} /$ $\mathrm{cm}$. The superior EMI shielding properties was attributed to the enhanced losses $\left(\tan \delta_{\varepsilon}+\tan \delta_{\mu}\right)$. This is primarily due to good conductivity, ferromagnetic $\mathrm{Ni}$, and the uneven distribution of nanoparticles in the bi-phasic blend, thus promoting multiple reflections within the nanostructures (shown in Fig. 16B). Further, this sample showed 1.5-fold higher storage modulus as compared to neat blends. $\mathrm{SE}_{\mathrm{T}}$ and electrical conductivity of the various samples are shown in Fig. 16A.

Kim et al. [93] studied the electrical and EMI shielding properties of (70/30) polypropylene/polycarbonate (or $\mathrm{PP} / \mathrm{PC}$ ) composites with nickel-coated carbon fiber (NCCF) as main filler and $\mathrm{TiO}_{2}, \mathrm{CNT}$, graphite as second filler. The pultruded $\mathrm{PP} / \mathrm{NCCF}$ masterbatch was used to prepare the $\mathrm{PP} / \mathrm{PC} / \mathrm{NCCF} /$ second filler composites using screw extrusion and injection molding technique for a comparative study. Polypropylene grafted maleic anhydride (or PP-g-MA) was used as a compatibilizer ( $5 \mathrm{wt} \%$ ) between the PP and PC. PP-g-MA contains a carbonyl group, which can have polar-polar interaction with the carbonyl group in $\mathrm{PC}$, whereas the intermolecular forces dominate its interaction with PP. The average length of the NCCF showed a much higher value in injection molding compared to screw extrusion due to the higher shear force exerted in extrusion. The increase in NCCF content enhanced the electrical conductivity and the $\mathrm{SE}_{\mathrm{T}}$ value for all the composites. $\mathrm{SE}_{\mathrm{T}}$ value (calculated from electrical conductivity using eq. 10) of $-51.6 \mathrm{~dB}$ was obtained for $\mathrm{PP} / \mathrm{PC} / \mathrm{NCCF}(20$ wt\%)/ $\mathrm{TiO}_{2}$ (5 wt\%), which was prepared using an injection molding technique. $\mathrm{TiO}_{2}$ proved to be an effective second filler than CNT or graphite due to its high dielectric constant with dominant dipolar polarization. The authors compared the $\mathrm{SE}_{\mathrm{T}}$ value obtained by injection molding and screw extrusion for $10 \mathrm{wt} \%$ NCCF and $5 \mathrm{wt} \%$ of second filler using the theoretical formula. They

(A)

\begin{tabular}{|c|c|c|c|}
\hline & Sample details & $\begin{array}{lrr}\mathrm{SE}_{\mathrm{T}}(\mathrm{dB}) & 18 \mathrm{GHz} \\
\text { for } \quad 5 & \mathrm{~mm} \\
\text { thickness } & \end{array}$ & $\sigma_{\mathrm{DC}}(\mathrm{S} / \mathrm{cm})$ \\
\hline 1 & PC composites with 3 wt\% CNT & -17.3 & $2.8 \times 10^{-6}$ \\
\hline 2 & PC/SAN with 3 wt $\%$ CNT & -25.1 & $1.8 \times 10^{-3}$ \\
\hline 3 & $\mathrm{PC} / \mathrm{SAN}$ with $3 \mathrm{wt} \% \mathrm{CNT}$ and $10 \mathrm{wt} \% \mathrm{Ni}$ & -32.2 & $3 \times 10^{-3}$ \\
\hline 4 & PC/SAN with 3 wt $\%$ CNT and 5 wt $\%$ rGO & -30.8 & \\
\hline 5 & PC/SAN with 10 wt $\%$ rGO-Ni & -3 & \\
\hline 6 & $\begin{array}{l}\text { PC/SAN blends with } 3 \text { wt\% CNT and } 10 \text { wt\% } \\
\text { rGO-Ni }\end{array}$ & -48 & $1.9 \times 10^{-2}$ \\
\hline
\end{tabular}

(B)

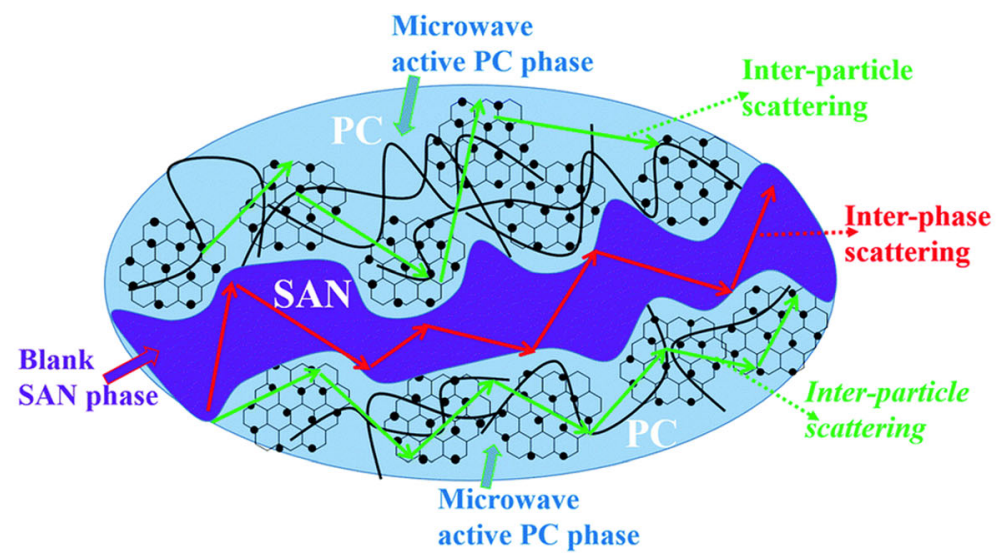

Fig. 16 (A) $\mathrm{SE}_{\mathrm{T}}$ and $\sigma_{\mathrm{DC}}$ (obtained from dc plateau of bulk conductivity measurement) of different samples; (B) Cartoon illustrating the shielding mechanism. Adapted with permission from Bose et al. [92], copyright 2016 Royal Society of Chemistry 
found that $\mathrm{PP} / \mathrm{PC} / \mathrm{NCCF} / \mathrm{TiO}_{2}$ showed the highest shielding of $-28.1 \mathrm{~dB}$, followed by PP/PC/NCCF/CNT ($24 \mathrm{~dB})$ and $\mathrm{PP} / \mathrm{PC} / \mathrm{NCCF} /$ graphite $(-14.4 \mathrm{~dB})$; whereas composites obtained by screw extrusion showed $\mathrm{SE}_{\mathrm{T}}$ value between 0 to $-1 \mathrm{~dB}$.

Sharma et al. [94] reported melt blending $10 \mathrm{wt} \%$ CNTs with PC to obtain PC/CNT masterbatch. It was further diluted by a blend of PC and ethyl methyl acrylate (EMA) $(95 / 5 \mathrm{w} / \mathrm{w})$ in a twin-screw extruder to obtain toughened PC. The loading of CNT ranged from 0.25 to $10 \mathrm{phr}$. The impact strength of a toughened PC was found to be higher than that of a neat PC. Also, the maximum tensile strength and modulus of PC/EMA-CNT showed an increase of $39 \%$ and $60 \%$ with CNT loading of $10 \mathrm{phr}$ compared to the neat PC/EMA blend. The majority of CNTs were localized in the PC component due to effective interaction of CNTs with the carbonate group in PC. The maximum $\mathrm{SE}_{\mathrm{T}}$ value of $\sim-26 \mathrm{~dB}$ was obtained in $\mathrm{X}$ band for a $3 \mathrm{~mm}$ thick sample. This also explains that the losses originate from the 3D conductive network, primarily via absorption mechanism.

In another work by Sharma et al. [95], they studied the effect of incorporating in situ reduced graphene oxide (IrGO) on the electrical and EMI shielding properties of PC/EMA (95/5 w/w) nanocomposites. PC/EMA-IrGO with a loading of 15 phr showed the highest $\mathrm{SE}_{\mathrm{T}}$ value of - $30 \mathrm{~dB}$ in X-band $(8.2-12.4 \mathrm{GHz})$ and surface conductivity of $2.44 \times 10^{-3} \mathrm{~S} / \mathrm{cm}$. The sample was prepared using a melt blending technique, and sample thickness was kept as $3 \mathrm{~mm}$. The mechanical study further illustrates that low filler loading enhances tensile strength and modulus. But higher filler loading ( $>10 \mathrm{phr}$ ) shows the composite's complete failure due to filler agglomeration and poor stress transfer.

Thomas et al. [96] studied the effect of PP-g-MA as a compatibilizer on the state of dispersion of CNT and subsequently the electrical, dielectric, and EMI shielding properties of PC/PP (60/40) blend. A combination of melt mixing and compression molding technique was used to design a $2 \mathrm{~mm}$ thick specimen. The percolation threshold of CNTs in compatibilized PC/PP blend (with $10 \mathrm{wt} \% \mathrm{PP}-$ g-MA) showed a 5-fold decrease and 2.5-fold increase in $\mathrm{SE}_{\mathrm{T}}$ value $(54.78 \mathrm{~dB})$, as compared to immiscible $\mathrm{PC} / \mathrm{PP}$ blends $(22 \mathrm{~dB}) . \mathrm{SE}_{\mathrm{T}}$ measurement was performed in the frequency range of the S-band $(2.6-3.95 \mathrm{GHz})$. The comparison of $\mathrm{SE}_{\mathrm{T}}$ for uncompatibilised vs. compatibilized blends at $3 \mathrm{GHz}$ frequency is shown in Fig. 17C. PP-g-MA (10 wt\%) prevented coalescence and also showed good interfacial adhesion between polymer components by reducing the interfacial tension between PC and PP. The PP portion of the PP-g-MA is miscible with the PP component, and the MA portion reacts with the PC component due to its polar nature. With the addition of CNTs, the domain size of the PP particles further reduced due to the selective localization of CNTs in the PC component mostly. However, some of the CNTs were found in the PP

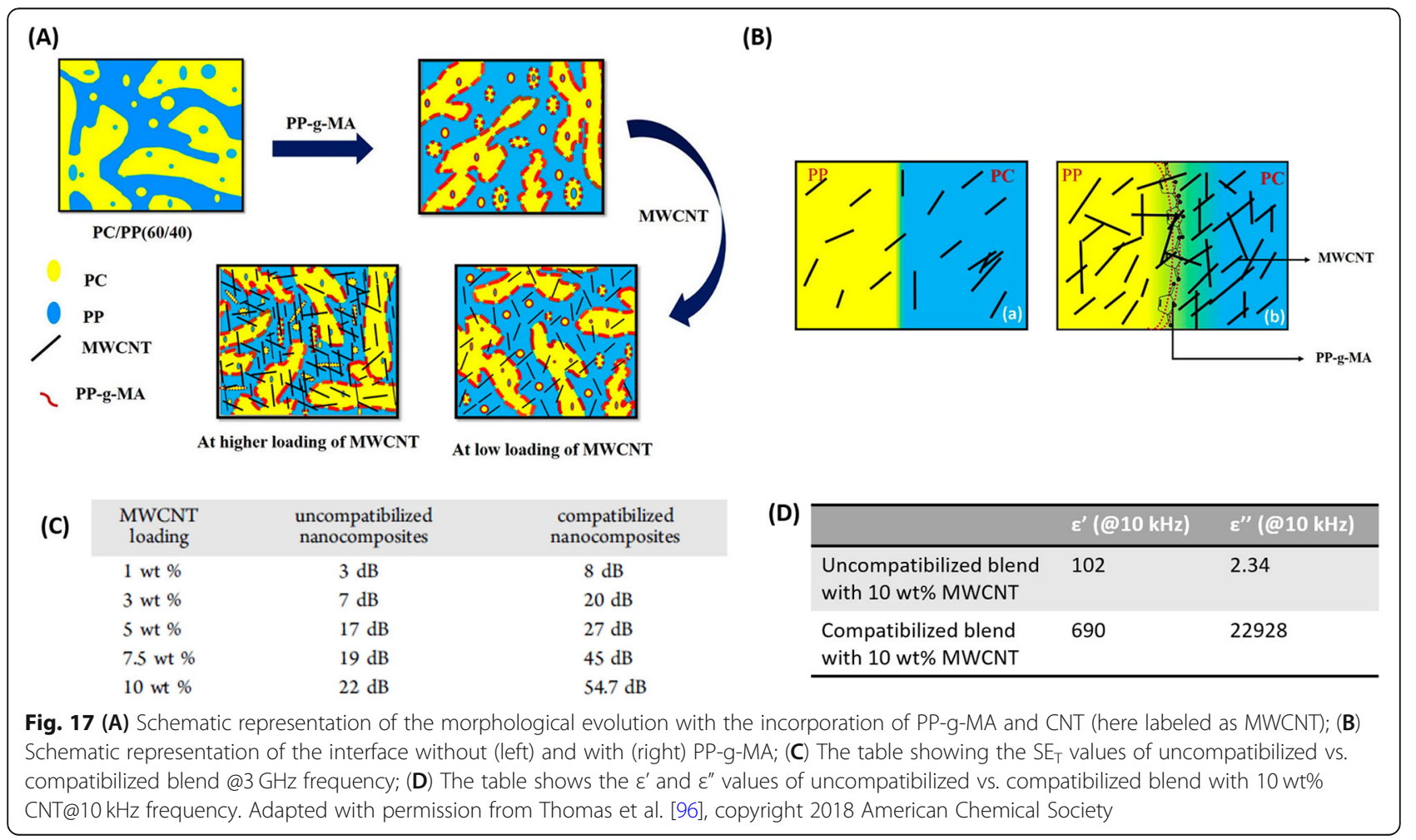


component as well as the interface. The schematic illustrations of the compatibilization of blend and CNT dispersion in the matrix are shown in Fig. 17A and B. The rise in $\mathrm{SE}_{\mathrm{T}}$ is a consequence of the jump in electrical conductivity as well as dielectric properties. As shown in Fig. 17D, the increase in $\varepsilon^{\prime}$ value in the compatibilized blend can be explained through the increased number of nanotube interfaces that contribute to interfacial polarization compared to the agglomerates of CNTs in an uncompatibilized blend. It is to be noted that $\varepsilon$ " also showed a significant jump, as shown in Fig. 17D, suggesting that the 3D conductive network of CNTs dissipates charge in the form of heat and leads to absorption dominated shielding mechanism.

Sharma et al. [97] prepared PC/EMA $(95 / 5 \mathrm{w} / \mathrm{w})$ nanocomposites using graphene: CNT hybrid filler in varying ratios (1:1, $1: 3$ and $3: 1)$ by the melt blending process. In $\mathrm{CNT}$ or graphene as fillers, dc conductivity was found to be $1.56 \times 10^{-3} \mathrm{~S} / \mathrm{cm}$ and $5.7 \times 10^{-3} \mathrm{~S} / \mathrm{cm}$. Hybrid filler showed a synergistic effect with a maximum conductivity of $1.913 \times 10^{-1} \mathrm{~S} / \mathrm{cm}$ with $10 \mathrm{phr}$ filler loading (graphene: $\mathrm{CNT}=1: 3$ ratio). This sample showed the highest $\mathrm{SE}_{\mathrm{T}}$ of approx. $-34 \mathrm{~dB}$ as compared to the sample having identical amounts of CNTs $(\sim-25 \mathrm{~dB})$ or graphene $(\sim-23 \mathrm{~dB})$ in X-band frequency $(8.2-12.4 \mathrm{GHz})$. The authors suggest that the enhancement in $\mathrm{SE}_{\mathrm{T}}$ could be due to forming a bridging and conducting network of CNTs between graphene throughout the electrically insulating PC/EMA matrix. Also, hybrid filler with $10 \mathrm{phr}$ loading (graphene: CNT ratio of 1:3) showed the highest tensile strength and tensile modulus compared to those based on only graphene or only CNT filler.

Kim et al. [98] prepared PC/ABS (70/30)/carbon fiber (CF) using two different methods: the pultrusion process and the screw extrusion process. Samples prepared using the pultrusion process showed higher electrical conductivity of $1.05 \times 10^{1} \mathrm{~S} / \mathrm{cm}$ and $\mathrm{SE}_{\mathrm{T}}$ of $-37.6 \mathrm{~dB}(@ 10 \mathrm{GHz}$, $2 \mathrm{~mm}$ thick) as compared to samples prepared by the screw extrusion process, which showed electrical conductivity of $5.20 \times 10^{-1} \mathrm{~S} / \mathrm{cm}$ and $\mathrm{SE}_{\mathrm{T}}$ of $-6.8 \mathrm{~dB}(@ 10$ $\mathrm{GHz}, 2 \mathrm{~mm}$ thick) for a loading of $20 \mathrm{phr}$. The authors attribute this enhancement to the fiber length in the pultrusion process resulting in a more connected conductive network structure. The average fiber length was $1402 \mu \mathrm{m}$ after the pultrusion process, whereas screw extrusion showed a shorter fiber length of $652 \mu \mathrm{m}$ due to higher shear stress achieved in the screw extrusion process. Another important aspect is that long $\mathrm{CF}$ was used for the pultrusion process compared to chopped $\mathrm{CF}$ used for the screw extrusion process. As control measurement, $\mathrm{SE}_{\mathrm{T}}$ of $\mathrm{PC} / \mathrm{CF}$ composites $(20 \mathrm{phr})$ showed similar behavior as $\mathrm{PC} / \mathrm{ABS} / \mathrm{CF}$ composite, and a value of $-37.1 \mathrm{~dB}$ (@10 GHz, $2 \mathrm{~mm}$ thick) and $-2.8 \mathrm{~dB}$ (@10 GHz, 2 mm thick) was obtained for pultrusion and screw extrusion process respectively. Shielding via absorption is found to be the dominant mechanism. The tensile and flexural strengths of the PC/ABS (70/30)/CF composite prepared by the pultrusion process were slightly higher by 8.2 and $7.0 \%$ than those prepared by the screw extrusion process.

Lim et al. [99] studied the $\mathrm{SE}_{\mathrm{T}}$ of PC/ABS filled with carbon black powder $(\mathrm{CBp})$ or carbon black masterbatch $(\mathrm{CBm})$ at the frequency of 800 and $900 \mathrm{MHz}$. $\mathrm{PC} / \mathrm{ABS} / \mathrm{CB}$ composites were prepared using an injection molding technique with a specimen thickness of $4 \mathrm{~mm}$. CBm is readymixed carbon black plastic. It can be added to compatible plastic and is easy to use as compared to CBp. The higher the amount of carbon black mixing ratio, the higher the dielectric constant and $\mathrm{SE}_{\mathrm{T}}$, and the lower the surface resistivity. The $\mathrm{SE}_{\mathrm{T}}$ of the composite also showed a maximum value of about $-9 \mathrm{~dB}$ at $800 \mathrm{MHz}$ (PC:ABS: $\mathrm{CB}=0.83: 0: 0.17$ ), and about $-5 \mathrm{~dB}$ at $900 \mathrm{MHz}$ (PC:ABS:CB $=0.78: 0.05: 0.17$ ). The study proved that both filler materials could be used to make an EMI shield. However, the $\mathrm{CBm}$ is commercial-grade and easier to use than the powder.

\section{PC-based hybrid multilayer structures}

Miniaturization of electronic devices and the need for lightweight materials pushes the EMI research to focus on thin films and foams. Multilayered thin film structures with tunable properties can be designed by strategically choosing desired fillers in separate layers. On the other hand, foam minimizes reflectivity by introducing low permittivity airy pockets at the expense of thickness. The multilayered structure will be discussed in this subsection, followed by foams in the next subsection.

Huynen et al. [100] stacked the alternating films of dielectric polymer and conducting layers. The conducting layers are comprised of either PC/CNT nanocomposite films or a thin CNT coating deposited on PC $\left(\varepsilon^{\prime}=2.8\right.$ in $\mathrm{GHz}$ range) from a CNT waterborne ink. The idea was to fabricate an effective EM absorber by using low permittivity dielectric material, along with high conductivity interconnected particles with a controlled gradient across the stacked pile. With a systematic increase in conductivity across the stack, the wave progresses deeper into the material (gets absorbed) rather than reflecting at the surface. They observed that CNT ink-based multilayer structure proved to be a more efficient absorber than extruded composite multilayer $(0.25$ to $5 \mathrm{wt} \%$ variation). Both showed a similar absorption index (approx. $80 \%$ with slight variations), but the ink-based multilayered structure showed it at a much lesser thickness $(2.56 \mathrm{~mm})$. The frequency range was kept around 8-70 GHz. The EM characterization study of CNT ink-based multilayer stack with the gradient in conductivity showed $\mathrm{SE}_{\mathrm{T}}$ of $-20 \mathrm{~dB}$ and above, with minima observed 
at specific frequencies for a thickness of $17.97 \mathrm{~mm}$. The mean absorption level was found to be $70 \%$. The simulation study further showed that the multilayer stack with a gradient in conductivity showed a higher power absorption than the stack with no gradient in conductivity.

Kim et al. [101] fabricated FeCoNi-coated glass fabric/ PC composite sheets and studied the EM absorption and EMI shielding properties in near-field and far-field regions. The composite sheets comprise laminated structures with one or two-ply- FeCoNi-coated glass fabrics (MGF), with or without Ni grid in the PC matrix. It is to be noted that the FeCo-based material coating on glass fabric was chosen owing to its soft magnetic properties and conductivity. Additionally, the Ni grid's insertion in a composite sheet can improve the EMI shielding performance due to the high conductivity and can also control the absorption frequency. The thickness of MGF and the total thickness of MGF-filled PC composite sheets were about 2.5 and $500 \mu \mathrm{m}$, respectively. MGFfilled PC composite sheets with or without Ni grid exhibited $\mathrm{SE}_{\mathrm{T}}$ above $-45 \mathrm{~dB}$ in the $\mathrm{X}$-band region. $\mathrm{SE}_{\mathrm{T}}$ above $-70 \mathrm{~dB}$ was obtained for FeCoNi-coated glass fabric with $\mathrm{Ni}$ grid composite sheets in X-band. The $\mathrm{SE}_{\mathrm{T}}$ value of the two-ply-MGF-filled PC composite with the $\mathrm{Ni}$ grid was found to be approx. $-90 \mathrm{~dB}$ at $10 \sim 11 \mathrm{GHz}$, which is comparable with that of the conductive $\mathrm{Cu}$ foil.
Teh et al. [70] prepared an ultra-thin $(0.29 \mathrm{~mm})$ film by sandwiching porous nonwoven carbon fiber/ polypropylene/polyethylene fabric (or CEF-NF) between two films of $\mathrm{PC}$, and the multilayer structure thus obtained was labeled as carbon-fabric/PC sandwiched film (or CF/PC film) as shown in Fig. 18A. It was observed that an optimal temperature, pressure, $\mathrm{CF}$ length, and concentration was required to prepare delamination and crack-free, mechanically robust, and flexible film with superior EMI shielding performance. They found that the CF/PC film with excellent tensile properties and EMI shielding performance can be fabricated using a laminating temperature of $195^{\circ} \mathrm{C}$, laminating pressure of $6 \mathrm{Mpa}, \mathrm{CF}$ length of $6 \mathrm{~mm}$, and a high concentration of uniformly dispersed CFs. The $\mathrm{SE}_{\mathrm{T}}$ for the CF/PC film, with $90 \%$ CF concentration and at an optimized parameter, is observed to be $-38.6 \mathrm{~dB}$ in the frequency range of $30-1500 \mathrm{MHz}$ as shown in $16 \mathrm{~B}$ and $\mathrm{C}$. CF/PC film's comprehensive performance is further expressed by a modified index of SSEt.strength and this value is found to be 138, $320 \mathrm{~dB} \mathrm{Mpa} \mathrm{cm}^{2} \mathrm{~g}^{-1}$, which is comparatively higher than other shielding materials reported in the literature. It is to be noted that CF/PC film composites- $\mathrm{x} \%$ means that $\mathrm{x} \%$ of $\mathrm{CF}$ is present in CEF-NF, rather than $\mathrm{x} \%$ of $\mathrm{CF}$ in $\mathrm{CF} / \mathrm{PC}$ film.

(A)
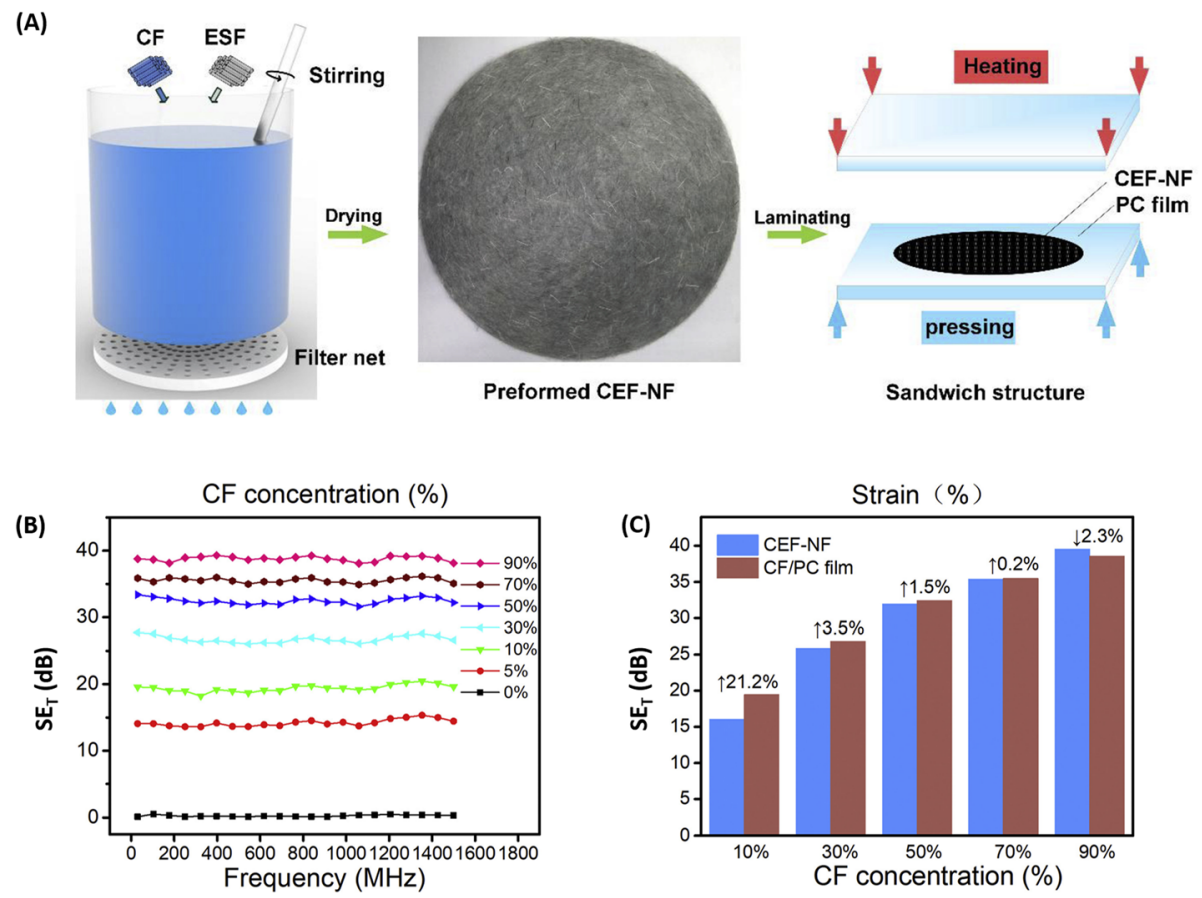

Fig. 18 (A) Schematic of the CF/PC film preparation (ESF refers to polypropylene/polyethylene (PP/PE) core/sheath bi-component fibers); (B) SET values of composites- $x \%$ in the 30-1500 MHz frequency range; (C) SET comparisons between CEF-NF- $x \%$ and composites- $x \%$. Adapted with permission from Teh et al. [70], copyright 2018 Elsevier 
Tang et al. [33] prepared ultra-thin CF/PC/Ni film by sandwiching Ni-plated CEF-NF between two $0.125 \mathrm{~mm}$ thick PC films and subsequently laminating together using a thermal bonding procedure as shown in Fig. 19A. It is to be noted that CEF-NF is a flexible nonwoven fabric comprising of $\mathrm{CFs}$ and polypropylene/polyethylene (PP/PE) core/sheath bicomponent fibers (ESFs). The sandwiched structure with a thickness of $0.31 \mathrm{~mm}$ was tested for EMI shielding performance and mechanical properties. With an increase in Ni plating duration, the electrical conductivity of $\mathrm{CF} / \mathrm{PC} / \mathrm{Ni}$ films improved. $\mathrm{Ni}$ as the metal has higher electrical conductivity than CFs or carbons. $\mathrm{SE}_{\mathrm{T}}$ of $\mathrm{CF} / \mathrm{PC} / \mathrm{Ni}$ films with different $\mathrm{Ni}$ plating times were studied in the frequency range of 30$1500 \mathrm{MHz}$. It was observed that with an increase in $\mathrm{Ni}$ plating time, the $\mathrm{SE}_{\mathrm{T}}$ value increased (Fig. 19C), which can be attributed primarily to the enhanced electrical conductivity and magnetic permeability, resulting in conductance and magnetic losses. CF/PC film without $\mathrm{Ni}$ coating layer showed the $\mathrm{SE}_{\mathrm{T}}$ value of $\sim-25 \mathrm{~dB}$, while $40 \mathrm{~min} \mathrm{Ni}$-plated $\mathrm{CF} / \mathrm{PC} / \mathrm{Ni}$ film with a $\mathrm{Ni}$ thickness of $1.075 \mathrm{~mm}$ showed the $\mathrm{SE}_{\mathrm{T}}$ value of $-72.7 \mathrm{~dB}$, which is $180 \%$ higher than that of a pure CF/PC film.
The SSEt value of $\mathrm{CF} / \mathrm{PC} / \mathrm{Ni}$ film with $40 \mathrm{~min} \mathrm{Ni}$ plating is observed to be $1376.1 \mathrm{dBcm}^{2} \mathrm{~g}^{-1}$. A study of $\mathrm{SE}_{\mathrm{T}}$ with respect to laminating pressure and temperature is shown in Fig. 19B. Pure CEF-NF and PC film have tensile strengths of $15.6 \mathrm{Mpa}$ and $55.1 \mathrm{Mpa}$, respectively, while $\mathrm{CF} / \mathrm{PC} / \mathrm{Ni}$ showed an increase in tensile strength, ranging from $63.8 \mathrm{Mpa}$ to $85 \mathrm{Mpa}$. Interestingly, even after mechanically bending the sandwiched structure 5000 times and heating for $50 \mathrm{~h}$ at $120^{\circ} \mathrm{C}$, the $\mathrm{CF} / \mathrm{PC} / \mathrm{Ni}$ film retains $96.36 \%$ of its EMI shielding performance.

Piraux et al. [63] extended their work by fabricating a multilayered $\mathrm{PC} / \mathrm{Ni}$ nanowire structure with a gradient in the concentration of nickel nanowire by combining electrodeposition and hot press technique. It is observed that the ferromagnetic nature of nickel nanowires enhanced the absorption performances compared to nonmagnetic CNTs having similar conductivity and complex permittivity. The layer-by-layer increase in properties (conductivity or permeability) helps in gradual attenuation. Nickel not only has a strong magnetic susceptibility of 110 but also has good oxidation resistance. $\mathrm{SE}_{\mathrm{A}}$ was found to be higher for the $\mathrm{PC} / \mathrm{Ni}$ gradientmultilayered structure as compared to the $\mathrm{PC} / \mathrm{CNT}$

(A)

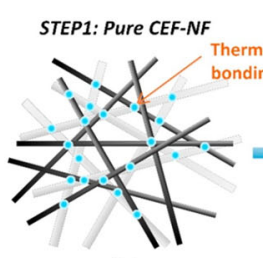

(a)

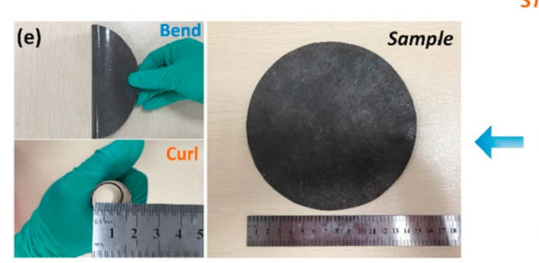

STEP2: Activation and sensitization STEP3: Ni-plated CEF-NF

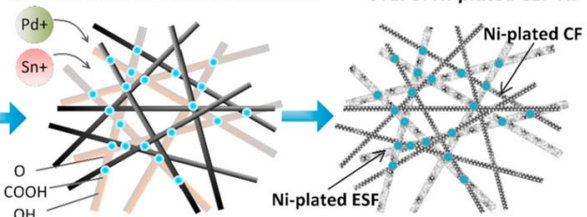

(c)

EP4: Heat pressed with PC films

(d)

CF/PC/Ni film
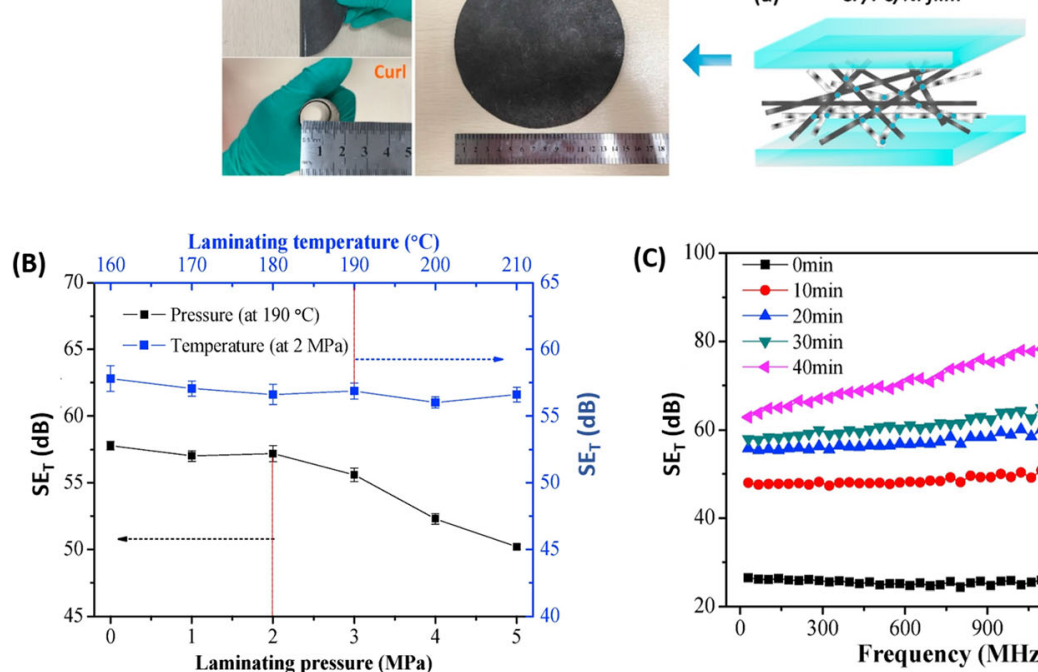

(C)

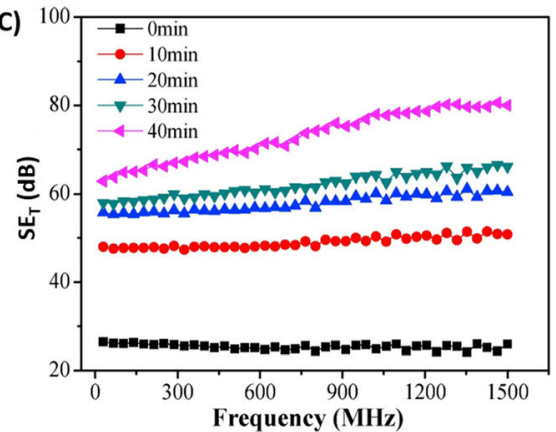

Fig. 19 (A) (a-d) Schematic of the CF/PC/Ni film preparation (e) as-fabricated CF/PC/Ni films subjected to bending and curling; (B) Effect of laminating pressure and temperature on the $\mathrm{SE}_{\mathrm{T}}$ of CF/PC/Ni films; (C) $\mathrm{SE}_{\mathrm{T}}$ of CF/PC/Ni films with different Ni plating times. Adapted with permission from Tang et al. [33], copyright 2018 Elsevier 
gradient-multilayered structure. For a specimen thickness of $600 \mu \mathrm{m}$, the mean $\mathrm{SE}_{\mathrm{A}}$ was found to be $-18 \mathrm{~dB}$ in the frequency range of $8-67 \mathrm{GHz}$. However, the maximum $\mathrm{SE}_{\mathrm{A}}$ was obtained to be $-34.3 \mathrm{~dB}$ at a frequency of $67 \mathrm{GHz}$. The authors also claim that these multilayered structures' flexibility and low thickness make them suitable for sophisticated applications in specific compact devices such as microchips, sensors, and medical probes.

Ozyuzer et al. [102] used the magnetron sputtering technique to deposit ITO/Au/ITO over a PC or soda lime glass substrate. Dielectric/metal/dielectric (D/M/D) multilayer film is one of the effective ways to target enhanced EMI shielding along with optical transparency. Being relatively inert to air/moisture, $\mathrm{Au}$ is preferred over other metals such as $\mathrm{Ag}, \mathrm{Cu}, \mathrm{Al}$, etc. In general, ITO films' electrical conductivity depends on the carrier mobility and the carrier density, which are mainly determined by oxygen vacancies or concentration of substituted $\mathrm{Sn}^{4+}$ on $\mathrm{In}^{3+}$ sites. A maximum $\mathrm{SE}_{\mathrm{T}}$ of $26.8 \mathrm{~dB}$ was obtained for a sample thickness of $141 \mathrm{~nm}$ in the frequency range of $8.2 \mathrm{GHz}$ to $12 \mathrm{GHz}$, which corresponds to $99.8 \%$ power attenuation. The author claims that EMI shielding's primary mechanism reflects the mobile charge carriers (electrons and/or holes). Also, the absorption by the electric and/or magnetic dipole of shielding material played its role.

Shen et al. [103] studied the EMI shielding properties of $\mathrm{PC} / \mathrm{CF}$ laminate, prepared by liquid $\mathrm{PC}$ infiltration through the $\mathrm{CF}$ layer accompanied by thermocompression. PC/CF plates consisted of 8 layers of unidirectional tapes with a thickness of $2 \mathrm{~mm}$. The fraction of $\mathrm{CF}$ in laminate was $60 \mathrm{wt} \%$. It was found that PC/CF composites showed an average value of $-40 \mathrm{~dB}$, which decreased to $-28 \mathrm{~dB}$ after erosion. The measurement was done in the $\mathrm{Ku}$ band $(12-18 \mathrm{GHz})$, and reflection was the dominant shielding mechanism.

\section{PC-based hybrid foams}

Recently, foams have attracted researchers' interest due to their multiple interfaces and air traps, which are expected to enhance the shielding performance while maintaining a low weight. Ozisik et al. [104] prepared PC/GNP-based foam using supercritical carbon dioxide $\left(\mathrm{CO}_{2}\right)$ via a 2-step method. Before foaming, the composite samples were prepared by melt compounding using an internal mixer with a GNP concentration of $0.5 \mathrm{wt} \%$. EMI shielding measurement was performed with a $2 \mathrm{~mm}$ thick foam in the frequency range of $8-12.4 \mathrm{GHz}$. A maximum specific $\mathrm{SE}_{\mathrm{T}}$ of $-78 \mathrm{dBcm}^{3} / \mathrm{g}$ was achieved in foams compared to $-1.1 \mathrm{dBcm}^{3} / \mathrm{g}$ in un-foamed composite, and this was primarily attributed to the reflection mechanism. The authors claim that this specific $\mathrm{SE}_{\mathrm{T}}$ value for a foamed composite is seven times higher than even solid copper. Further, it is suggested that the cellular morphological features of foamed composites, which impact $\mathrm{SE}_{\mathrm{T}}$ and mechanical properties, depend on graphene, the amount of dissolved supercritical $\mathrm{CO}_{2}$, and $\mathrm{CO}_{2}$ saturation/foaming conditions.

$\mathrm{Yu}$ et al. [105] fabricated a lightweight and tough PC/ CNT composite by melt compounding-foaming approach, resulting in a well-dispersed CNT due to strong shear force. It was followed by compression molding for most of the samples (except PC/3 wt\% CNT), and then a well-controlled microcellular structure was constructed using supercritical $\mathrm{CO}_{2}$ foaming. The addition of $1 \mathrm{wt} \%$ CNTs into PC led to a significant decrease in cell size from 11.4 to $1.2 \mu \mathrm{m}$ and nearly three orders of magnitude increase in the cell density (refer to Fig. 20A). A further rise in $\mathrm{CNT}$ content resulted in a slight reduction in cell size with narrower size distribution and a steady cell density increase (refer to Fig. 20A). Thus, a strong dependence of cellular structure was observed with well-dispersed CNTs as it provides adequate interfaces for $\mathrm{CO}_{2}$ accumulation. This further facilitates the heterogeneous nucleation of voids by reducing the critical free energy for nucleation. Interestingly, the foam porosity showed a negligible influence on the electrical conductivity. The percolation threshold of composite foams was similar to that of bulk composites, as shown in Fig. $20 \mathrm{~B}(\mathrm{a})$. It is worthwhile to note that $\mathrm{PC} / \mathrm{CNT}$ composite foam exhibits isotropic conductivity. $\mathrm{PC} / 5$ wt\% CNT showed a specific EMI SE of $\sim-16 \mathrm{~dB} /(\mathrm{g} /$ $\mathrm{cm}^{3}$ ) at $9.5 \mathrm{GHz}$ frequency. The specific SE of composite foams is higher than the bulk composite due to multiple reflections originating from numerous voids, as shown in Fig. 20B(b). In addition, it was found that the presence of the voids or microcellular structure makes the brittle PC/CNT composites tough which was reflected by the improved tensile toughness and notched impact strength of the resulting foam. The highest specific toughness was observed for $\mathrm{PC} / 1 \mathrm{wt} \%$ CNT composite foam with a value of $35.3\left(\mathrm{~kJ} / \mathrm{m}^{2}\right) /\left(\mathrm{g} / \mathrm{cm}^{3}\right)$, which is $435 \%$ higher than that of neat PC and $667 \%$ than its bulk counterpart.

In another work by Ozisik et al. [106], they studied the dielectric and EMI shielding properties of PC/GNP (0.5 wt\%) foam prepared using supercritical $\mathrm{CO}_{2}$ via a one-step process. The foamed sample of the thickness of $5 \mathrm{~mm}$ and an unfoamed sample of the thickness of $3.2 \mathrm{~mm}$ was used. A maximum specific EMI shielding

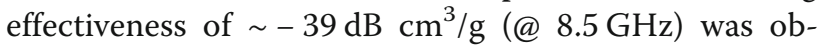
tained for the foamed sample, which is approximately 35 times more than an un-foamed composite $(-1.1 \mathrm{~dB}$ $\mathrm{cm}^{3} / \mathrm{g}$ ). Besides, the relative permittivity increases with the addition of GNPs. Both absorption and reflection play a role in the shielding mechanism; however, the 
(A)

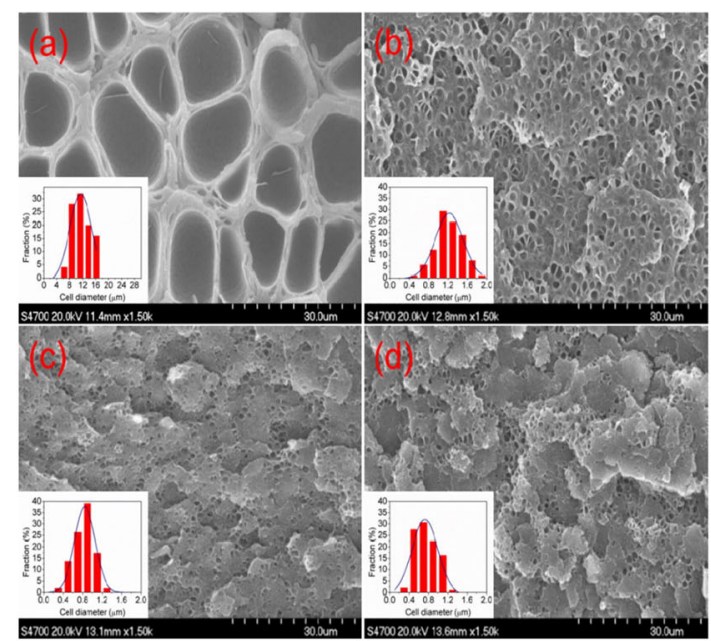

(B)
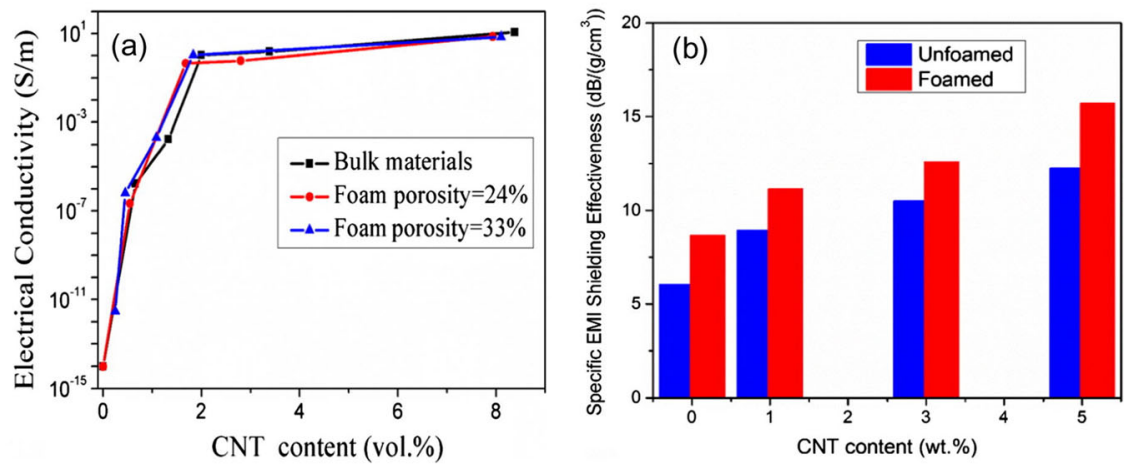

Fig. 20 (A) Scanning electron micrographs of (a) neat PC foam, and PC/CNT composite foams with (b) 1 wt $\%$, (c) 3 wt $\%$ and (d) 5 wt $\%$ of CNTs. The insets are the size distributions of cells in the corresponding foams; (B) Electrical conductivity of PC/CNT composites and their foams with different porosities as a function of CNT content, (b) specific $\mathrm{SE}_{\mathrm{T}}$ of PC/CNT composites and their foams at $9.5 \mathrm{GHz}$. Adapted with permission from Yu et al. [105], copyright 2015 Elsevier

absorption contribution increases with increasing filler concentration.

Detrembleur et al. [107] carried out gradient foaming of $\mathrm{PC} / \mathrm{CNT}$ composite using supercritical $\mathrm{CO}_{2}$ by varying the CNT percentage $(0.5,1,2 \mathrm{wt} \%)$ as shown in Fig. 21. Foaming introduces air pockets in the composite, which favors the wave impedance matching of the expanded material and the ambient atmosphere. At the same time, foaming induces a volume dilution of the CNTs, which results in a reduction of $\mathrm{SE}_{\mathrm{T}}$. An increase in the CNT content improves the $\mathrm{SE}_{\mathrm{T}}$, but it also increases the material's interface reflection. By the partial foaming technique, the author aims to produce a gradient distribution of density. Only the surface material is foamed, while the inner part has been kept unchanged. This results in a comparatively low dielectric constant and the CNT content at the surface, thus reducing the EM wave reflection at the material interface. The solid inner part still holds the ability to dissipates the EM wave. The authors also claim that the addition of CNTs helps in cell nucleation during the foaming process leading to homogeneous and small cells as compared to heterogeneous and big cells formed in neat PC. The gradient sample of PC/CNT (2 wt\%) with a thickness of 2 $\mathrm{mm}$ showed a $\mathrm{SE}_{\mathrm{T}} \sim-14 \mathrm{~dB}$ in the frequency range 15$17 \mathrm{GHz}$, with absorption being the primary shielding mechanism.

\section{Summary of PC-based EMI shielding materials}

Table 4 summarizes the essential fabrication details and the key results of the research articles discussed in this review. The shielding performance depends on nanofiller concentration, specimen thickness, incident angle, polarization type, and frequency [76]. Since there are many variables, a direct comparison of shielding performance in the various publications is difficult. However, this table gives a crude comparison of different PC-based materials and their shielding performance. Figure 22 shows a pie chart representing the percentage of published research papers in various categories since 2010. In the last decade, researchers have extensively explored PC-based composites and PC-based blend 


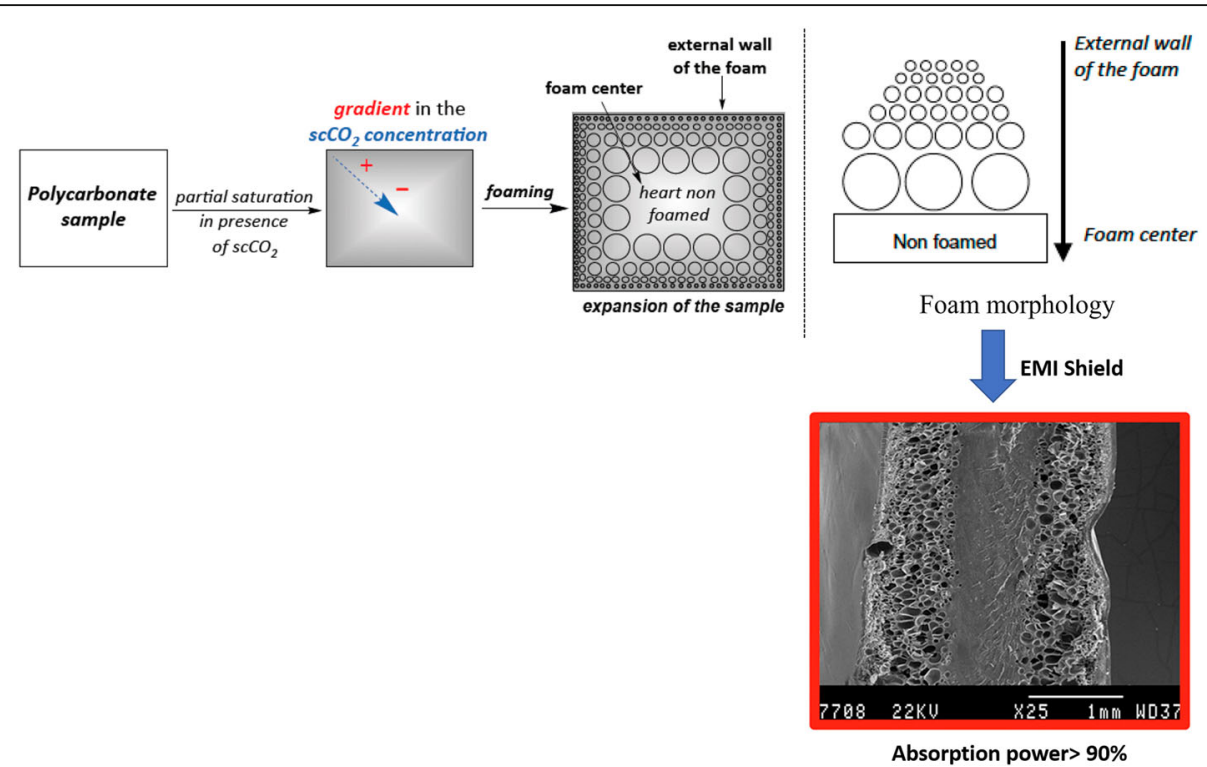

Fig. 21 Schematic of gradient foaming process and scanning electron micrograph of the EMl shield obtained with absorption power $>90 \%$. Adapted with permission from Detrembleur et al. [107], copyright 2015 Elsevier

composites. However, PC-based hybrid multilayer and foam structures are relatively newer, less studied, and holds immense potential to open new avenues for future research

It is important to note that a direct comparison of the shielding performances mentioned in various publications is generally not an accurate way to analyze since these measurements were not done with the same set parameters- i.e. sample thickness, frequency, filler type and polymer grade, method of preparation, and technique of $\mathrm{SE}_{\mathrm{T}} / \mathrm{RL}$ measurement [76]. However, we will try to derive conclusions that hold for PC-based hybrid structures under most processing and measurement conditions.

\section{Conclusions}

Designing an efficient EMI shield requires a suitable combination of permittivity $\left(\varepsilon^{\prime}\right.$ and $\left.\varepsilon^{\prime \prime}\right)$, permeability ( $\mu^{\prime}$ and $\left.\mu^{\prime \prime}\right)$, and conductivity $(\sigma)$ values in the desired frequency range. Parameters such as the intrinsic property of filler/ fillers, dispersion, distribution, agglomerations, and orientation might have a crucial impact on the shielding performance of a polymerbased EMI shield. It is reported that high electrical conductivity, which needs a percolating pathway, need not necessarily lead to higher $\mathrm{SE}_{\mathrm{T}}$ [76]. Furthermore, a material's ability to shield EM waves also depends on various other factors such as the wave incidence angle, type of polarization, frequency, and thickness of the composite [76]. Below are some of the relevant conclusions derived from this review article on PCbased EMI shielding materials.

\section{PC matrix as EMI shielding material}

$\mathrm{PC}$ is transparent to EM radiation with an electrical conductivity of $10^{-12}-10^{-14} \mathrm{~S} / \mathrm{m}$ and a $\mathrm{SE}_{\mathrm{T}}$ value of $0 \mathrm{~dB}$ [35]. It becomes essential to tweak the architectural design with a combination of filler/fillers or layers with different inherent properties or by introducing air pockets to enhance the EMI shielding value. Also, depending upon the nature of filler, the quantity of filler/fillers in the PC matrix and the filler-polymer interaction, the mechanical property either enhances or deteriorates. Since the shield's mechanical property is essential in terms of applicability, there is a need to optimize these parameters to keep the mechanical properties intact yet enhancing the EMI shielding performance.

\section{C-based fillers in PC matrix}

In the last decade, a couple of studies have been done on PC with C-based fillers such as CNTs, CB, GNP, graphene, graphite, rGO and CF. CNTs or long chopped $\mathrm{CF}$ or CF mats have successfully enhanced $\mathrm{SE}_{\mathrm{T}}$ (due to high aspect ratio) and the shield's overall conductivity (generally, this value falls in the semiconducting category). Percolation threshold as low as $0.021 \mathrm{wt} \% \mathrm{CNT}$ is obtained by morphological modification of $\mathrm{PC} / \mathrm{CNT}$ composites by introducing commercial PC beads [73] $\mathrm{CB}$ and GNP show a higher percolation threshold than $\mathrm{CNT}$. The possible interaction is through $\pi-\pi$ between the electron-rich phenyl ring of PC with GNP and CNT. In general, an optimum filler concentration is required to cater to the mechanical and shielding requirements. It is observed that a high amount of CNT not only makes the processing difficult 
Table 4 List of PC-based hybrid structure for EMI shielding applications

\begin{tabular}{|c|c|c|c|c|c|c|c|}
\hline $\begin{array}{l}\text { Sl. } \\
\text { No. }\end{array}$ & Filler & Matrix & Processing & $\begin{array}{l}\mathrm{SE}_{\mathrm{T}} / \mathrm{RLmin} / \\
\text { Specific } \mathrm{SE}_{\mathrm{T}}\end{array}$ & Thickness & Frequency & Reference \\
\hline 1 & CNT (5 wt\%) & PC & $\begin{array}{l}\text { Melt mixing, compression } \\
\text { molding }\end{array}$ & $\mathrm{SE}_{\mathrm{T}} \sim-24 \mathrm{~dB}$ & $1.85 \mathrm{~mm}$ & $\begin{array}{l}8.2-12.4 \\
\mathrm{GHz}\end{array}$ & {$[36]$} \\
\hline 2 & CNT (10 wt\%) & PC & $\begin{array}{l}\text { Melt mixing, injection } \\
\text { molding }\end{array}$ & $\mathrm{SE}_{\mathrm{T}}=-27.2 \mathrm{~dB}$ & & $\begin{array}{l}12.4-18 \\
\mathrm{GHz}\end{array}$ & {$[67]$} \\
\hline 3 & CNT (20 wt\%) & PC & $\begin{array}{l}\text { Layer of } 5 \text { films-solvent } \\
\text { casting }\end{array}$ & $S E_{T}=-43 \mathrm{~dB}$ & $2.15 \mathrm{~mm}$ & $\begin{array}{l}8.2-12.4 \\
\mathrm{GHz}\end{array}$ & {$[72]$} \\
\hline 4 & CNT (10 wt\%) & PC & $\begin{array}{l}\text { Solvent casting, compression } \\
\text { molding (low pressure) }\end{array}$ & $\begin{array}{l}S E_{T}=-35 \mathrm{~dB} \\
(\rho=1.1 \mathrm{~g} / \mathrm{cc})\end{array}$ & $1.97 \mathrm{~mm}$ & $\begin{array}{l}8.2-12.4 \\
\mathrm{GHz}\end{array}$ & {$[72]$} \\
\hline 5 & CNT (10 wt\%) & PC & $\begin{array}{l}\text { Solvent casting, compression } \\
\text { molding (high pressure) }\end{array}$ & $\begin{array}{l}\mathrm{SE}_{\mathrm{T}}=-21 \mathrm{~dB} \\
(\rho=1.17 \mathrm{~g} / \mathrm{cc})\end{array}$ & $1.785 \mathrm{~mm}$ & $\begin{array}{l}8.2-12.4 \\
\mathrm{GHz}\end{array}$ & {$[72]$} \\
\hline 6 & CNT (2 wt\%) & $\begin{array}{l}\text { PC (with } 70 \\
\text { wt\% PC bead) }\end{array}$ & $\begin{array}{l}\text { Solution blending, } \\
\text { compression molding }\end{array}$ & $S E_{T}=-23.1 \mathrm{~dB}$ & $5.6 \mathrm{~mm}$ & $\begin{array}{l}8.2-12.4 \\
\mathrm{GHz}\end{array}$ & [73] \\
\hline 7 & CB (10 wt $\%, 8$ wt $\%)$ & PC & Extrusion, injection molding & $\begin{array}{l}\mathrm{SE}_{\mathrm{T}}=-18.9 \\
\mathrm{~dB}(\text { at } 10 \mathrm{wt} \%),- \\
13.3 \mathrm{~dB}(\text { at } 8 \text { wt } \%)\end{array}$ & $3.2 \mathrm{~mm}$ & $800 \mathrm{MHz}$ & {$[74]$} \\
\hline 8 & CNT (8 wt\%) & PC & Extrusion, injection molding & $\begin{array}{l}S E_{T}=-18.4 \\
d B\end{array}$ & $3.2 \mathrm{~mm}$ & $800 \mathrm{MHz}$ & {$[74]$} \\
\hline 9 & GNP (15 wt\% GNP) & PC & Extrusion, injection molding & $\begin{array}{l}S E_{T}=-6.3 \\
d B\end{array}$ & $3.2 \mathrm{~mm}$ & $800 \mathrm{MHz}$ & {$[74]$} \\
\hline 10 & $\begin{array}{l}\text { CB/CNT ( } 5 \text { wt } \% \text { CB and } 5 \text { wt } \% \\
\text { CNT) }\end{array}$ & PC & Extrusion, injection molding & $\begin{array}{l}S E_{T}=-21.4 \\
d B\end{array}$ & $3.2 \mathrm{~mm}$ & $800 \mathrm{MHz}$ & [74] \\
\hline 11 & $\begin{array}{l}\text { CB/GNP ( } 5 \text { wt } \% \text { CB and } 5 \text { wt } \% \\
\text { GNP) }\end{array}$ & PC & Extrusion, injection molding & $\begin{array}{l}\mathrm{SE}_{\mathrm{T}} \sim-9.2 \\
\mathrm{~dB}\end{array}$ & $3.2 \mathrm{~mm}$ & $800 \mathrm{MHz}$ & [74] \\
\hline 12 & $\begin{array}{l}\text { CNT/GNP ( } 5 \mathrm{wt} \% \text { CNT and } 5 \mathrm{wt} \% \\
\text { GNP) }\end{array}$ & PC & Extrusion, injection molding & $\begin{array}{l}S E_{T} \sim-15.5 \\
d B\end{array}$ & $3.2 \mathrm{~mm}$ & $800 \mathrm{MHz}$ & [74] \\
\hline 13 & GNP/CNT (3:2 by wt) (4 wt\%) & PC & $\begin{array}{l}\text { Melt mixing at high } \mathrm{T} \\
\left(330^{\circ} \mathrm{C}\right) \text {, compression } \\
\text { molding }\end{array}$ & $\begin{array}{l}\mathrm{SE}_{\mathrm{T}}=-21.6 \\
\mathrm{~dB}\end{array}$ & $5.6 \mathrm{~mm}$ & $\begin{array}{l}8.2-12.4 \\
\mathrm{GHz}\end{array}$ & [75] \\
\hline 14 & GNP/CNT (3:2 by wt) ( 4 wt\%) & PC & $\begin{array}{l}\text { Melt mixing at } 280^{\circ} \mathrm{C} \text {, } \\
\text { compression molding }\end{array}$ & $\begin{array}{l}S E_{T}=-8.3 \\
d B\end{array}$ & $5.6 \mathrm{~mm}$ & $\begin{array}{l}8.2-12.4 \\
\mathrm{GHz}\end{array}$ & [75] \\
\hline 15 & CNT (4 wt\%) & PC & & $\begin{array}{l}S E_{T} \sim-14 \\
d B\end{array}$ & & $8.5 \mathrm{GHz}$ & [76] \\
\hline 16 & CB (6wt $\%)$ & PC & & $\begin{array}{l}S E_{T} \sim-13 \\
d B\end{array}$ & & $8.5 \mathrm{GHz}$ & [76] \\
\hline 17 & GNP (12 wt\%) & PC & & $\begin{array}{l}\mathrm{SE}_{\mathrm{T}} \sim-7 \\
\mathrm{~dB}\end{array}$ & & $8.5 \mathrm{GHz}$ & {$[76]$} \\
\hline 18 & CNT (3 wt\%) & PC & $\begin{array}{l}\text { Melt extrusion, compression } \\
\text { molding }\end{array}$ & $\begin{array}{l}\mathrm{SE}_{\mathrm{T}}=-17 \\
\mathrm{~dB} \\
\mathrm{RL}=-32.1 \mathrm{~dB}\end{array}$ & $\begin{array}{l}\mathrm{RL} @ 2 \\
\mathrm{~mm}\end{array}$ & $\begin{array}{l}\mathrm{SE}_{\mathrm{T}} @ 18 \\
\mathrm{GHz} \\
\mathrm{RL} @ 11.2 \\
\mathrm{GHz}\end{array}$ & [77] \\
\hline 19 & $\begin{array}{l}3 \text { wt } \% \text { CNT/10 wt } \% \mathrm{Fe}_{3} \mathrm{O}_{4} \text { (size of } \\
\mathrm{Fe}_{3} \mathrm{O}_{4}=100-150 \mathrm{~nm} \text { ) }\end{array}$ & PC & $\begin{array}{l}\text { Solution followed by melt } \\
\text { extrusion, compression } \\
\text { molding }\end{array}$ & $\begin{array}{l}\mathrm{SE}_{\mathrm{T}} \sim-19.5 \\
\mathrm{~dB} \\
\mathrm{RL}=-21.8 \mathrm{~dB}\end{array}$ & $\begin{array}{l}\mathrm{RL} @ 3 \\
\mathrm{~mm}\end{array}$ & $\begin{array}{l}\mathrm{SE}_{\mathrm{T}} @ 18 \\
\mathrm{GHz} \\
\mathrm{RL} @ 6.1 \\
\mathrm{GHz}\end{array}$ & [77] \\
\hline 20 & $\begin{array}{l}3 \text { wt } \% \text { CNT/10 wt } \% \mathrm{Fe}_{3} \mathrm{O}_{4} @ \mathrm{C} \text { (size } \\
\text { of } \mathrm{Fe}_{3} \mathrm{O}_{4} @ \mathrm{C}=20-80 \text { nm; } 25 \% \text { as C } \\
\text { shell and } 75 \% \text { as } \mathrm{Fe}_{3} \mathrm{O}_{4} \text { ) }\end{array}$ & PC & $\begin{array}{l}\text { Solution followed by melt } \\
\text { extrusion, compression } \\
\text { molding }\end{array}$ & $\begin{array}{l}\mathrm{SE}_{T}=-22.8 \\
\mathrm{~dB} \\
\mathrm{RL}=-41.3 \mathrm{~dB}\end{array}$ & $\begin{array}{l}\mathrm{RL} @ 1 \\
\mathrm{~mm}\end{array}$ & $\begin{array}{l}\mathrm{SE}_{\mathrm{T}} @ 18 \\
\mathrm{GHz} \\
\mathrm{RL} @ 17.7 \\
\mathrm{GHz}\end{array}$ & {$[77]$} \\
\hline 21 & CNT (3 wt\%) & PC & $\begin{array}{l}\text { Melt mixing }\left(250^{\circ} \mathrm{C}\right) \\
\text { compression molding } \\
\left(265^{\circ} \mathrm{C}\right)\end{array}$ & $\begin{array}{l}\mathrm{SE}_{\mathrm{T}}=-14 \mathrm{~dB} \text { (using } \\
\text { scalar network } \\
\text { analyser) }\end{array}$ & $1 \mathrm{~mm}$ & $11 \mathrm{GHz}$ & {$[78]$} \\
\hline 22 & CNT (3 wt\%) & PC & $\begin{array}{l}\text { Solution mixing, } \\
\text { compression molding } \\
\left(265^{\circ} \mathrm{C}\right)\end{array}$ & $\begin{array}{l}\mathrm{SE}_{\mathrm{T}}=-16.4 \mathrm{~dB} \\
\text { (using scalar } \\
\text { network analyser) }\end{array}$ & $1 \mathrm{~mm}$ & $11 \mathrm{GHz}$ & [78] \\
\hline 23 & CNT (2 wt\%) & PC & Melt mixing $\left(250^{\circ} \mathrm{C}\right)$, & $\mathrm{SE}_{\mathrm{T}}=-19.6 \mathrm{~dB}$ & $3.5 \mathrm{~mm}$ & $11 \mathrm{GHz}$ & [78] \\
\hline
\end{tabular}


Table 4 List of PC-based hybrid structure for EMI shielding applications (Continued)

\begin{tabular}{|c|c|c|c|c|c|c|c|}
\hline $\begin{array}{l}\text { Sl. } \\
\text { No. }\end{array}$ & Filler & Matrix & Processing & $\begin{array}{l}\mathrm{SE}_{\mathrm{T}} / \mathrm{RLmin} / \\
\text { Specific } \mathrm{SE}_{\mathrm{T}}\end{array}$ & Thickness & Frequency & Reference \\
\hline & & & $\begin{array}{l}\text { compression molding } \\
\left(265^{\circ} \mathrm{C}\right)\end{array}$ & $\begin{array}{l}\text { (using scalar } \\
\text { network analyser) }\end{array}$ & & & \\
\hline 24 & a-CF (10 phr)/ a-CNT (0.5 phr) & PC & $\begin{array}{l}\text { MiniMAX molder, } \\
\text { compression molding }\end{array}$ & $S E_{T}=-26 \mathrm{~dB}$ & $2 \mathrm{~mm}$ & $10 \mathrm{GHz}$ & [79] \\
\hline 25 & GNP (6 wt\%) & PC & $\begin{array}{l}\text { Solution mixing, hot } \\
\text { compaction }\end{array}$ & $S E_{T \sim}-47 \mathrm{~dB}$ & $2 \mathrm{~mm}$ & $8.2 \mathrm{GHz}$ & {$[35]$} \\
\hline 26 & 3 wt $\%$ CNT & $P C$ & $\begin{array}{l}\text { Melt mixing, compression } \\
\text { molding }\end{array}$ & $S E_{T}=-23 d B$ & $5 \mathrm{~mm}$ & $18 \mathrm{GHz}$ & {$[80]$} \\
\hline 27 & 3 wt $\%$ CNT/ 5 wt $\%$ rGO-Fe $\mathrm{Fe}_{3}$ & PC & $\begin{array}{l}\text { Melt mixing, compression } \\
\text { molding }\end{array}$ & $\mathrm{SE}_{\mathrm{T}}=-28 \mathrm{~dB}$ & $5 \mathrm{~mm}$ & $18 \mathrm{GHz}$ & {$[80]$} \\
\hline 28 & 3 wt $\%$ CNT/ 5 wt $\%$ rGO-Gd ${ }_{2} \mathrm{O}_{3}$ & PC & $\begin{array}{l}\text { Melt mixing, compression } \\
\text { molding }\end{array}$ & $S E_{T}=-33 d B$ & $5 \mathrm{~mm}$ & $18 \mathrm{GHz}$ & {$[80]$} \\
\hline 29 & $\begin{array}{l}4 \mathrm{wt} \% \mathrm{CNT} / 5 \mathrm{wt} \% \mathrm{rGO}-\mathrm{Fe}_{3} \mathrm{O}_{4} \mathrm{Com}- \\
\text { partment approach }\end{array}$ & PC & $\begin{array}{l}\text { Solution approach for } \\
\text { compartment unit, followed } \\
\text { by hot press }\end{array}$ & $S E_{T}=-43.5 \mathrm{~dB}$ & $2 \mathrm{~mm}$ & $\begin{array}{l}8.2-12.4 \\
\mathrm{GHz}\end{array}$ & [81] \\
\hline 30 & $\begin{array}{l}4 \mathrm{wt} \% \mathrm{CNT} / 5 \mathrm{wt} \% \mathrm{rGO}-\mathrm{Fe}_{3} \mathrm{O}_{4} \text { ran- } \\
\text { dom dispersion }\end{array}$ & PC & $\begin{array}{l}\text { Solution approach, followed } \\
\text { by hot press }\end{array}$ & $\mathrm{SE}_{\mathrm{T}}=-35.5 \mathrm{~dB}$ & $2 \mathrm{~mm}$ & $\begin{array}{l}8.2-12.4 \\
\mathrm{GHz}\end{array}$ & [81] \\
\hline 31 & $\begin{array}{l}4 \text { wt } \% \text { CNT compartment } \\
\text { approach }\end{array}$ & $P C$ & $\begin{array}{l}\text { Solution approach for } \\
\text { compartment unit, followed } \\
\text { by hot press }\end{array}$ & $\mathrm{SE}_{\mathrm{T}}=-33.2 \mathrm{~dB}$ & $2 \mathrm{~mm}$ & $\begin{array}{l}8.2-12.4 \\
\mathrm{GHz}\end{array}$ & [81] \\
\hline 32 & 4 wt $\%$ CNT random dispersion & PC & $\begin{array}{l}\text { Solution approach, followed } \\
\text { by hot press }\end{array}$ & $S E_{T}=-31 d B$ & $2 \mathrm{~mm}$ & $\begin{array}{l}8.2-12.4 \\
\mathrm{GHz}\end{array}$ & [81] \\
\hline 33 & $7 \mathrm{wt} \%$ GFs and $3 \mathrm{wt} \% \mathrm{MFs}$ & PC/ABS & Injection molding & $\mathrm{SE}_{\mathrm{T}} \sim-40 \mathrm{~dB}$ & $2 \mathrm{~mm}$ & $1 \mathrm{~Hz}$ & [83] \\
\hline 34 & PPIC (30 wt\%) & $P C$ & Solution blending & $S E_{T}=-52 d B$ & $2 \mathrm{~mm}$ & $8 \mathrm{GHz}$ & {$[84]$} \\
\hline 35 & CNT (5 wt\%) & PC & $\begin{array}{l}\text { Melt mixing, compression } \\
\text { molding }\end{array}$ & $\begin{array}{l}\mathrm{SE}_{T} \sim-40 \mathrm{~dB} \\
\text { (theoretical- from eq. } \\
\text { 11) }\end{array}$ & $4 \mathrm{~mm}$ & $\begin{array}{l}500-3000 \\
\mathrm{MHz}\end{array}$ & [69] \\
\hline 36 & $\mathrm{NH}_{2}$ modified CNT (1 wt\%) & PC/SAN & $\begin{array}{l}\text { Melt blending, compression } \\
\text { molding }\end{array}$ & $S E_{T}=-14 \mathrm{~dB}$ & $\sim 5 \mathrm{~mm}$ & $8-18 \mathrm{GHz}$ & [57] \\
\hline 37 & CNT (3 wt\%) & PC & $\begin{array}{l}\text { Melt mixing, compression } \\
\text { molding }\end{array}$ & $\mathrm{SE}_{\mathrm{T}}=-23 \mathrm{~dB}$ & $\sim 5 \mathrm{~mm}$ & $18 \mathrm{GHz}$ & {$[85]$} \\
\hline 38 & CNT-grafted $\mathrm{Fe}_{3} \mathrm{O}_{4}$ (3 wt\%) & PC & $\begin{array}{l}\text { Melt mixing, compression } \\
\text { molding }\end{array}$ & $\mathrm{SE}_{\mathrm{T}}=-28 \mathrm{~dB}$ & $\sim 5 \mathrm{~mm}$ & $18 \mathrm{GHz}$ & {$[85]$} \\
\hline 39 & CNT (3 wt\%) & PC/SAN (60/40) & $\begin{array}{l}\text { Melt mixing, compression } \\
\text { molding }\end{array}$ & $\mathrm{SE}_{\mathrm{T}}=-31 \mathrm{~dB}$ & $\sim 5 \mathrm{~mm}$ & $18 \mathrm{GHz}$ & {$[85]$} \\
\hline 40 & $\begin{array}{l}\text { CNT ( } 3 \text { wt } \% \text { ) and dopamine } \\
\text { anchored- } \mathrm{Fe}_{3} \mathrm{O}_{4}(3 \text { vol\%) }\end{array}$ & PC/SAN (60/40) & $\begin{array}{l}\text { Solution followed by melt } \\
\text { mixing, compression } \\
\text { molding }\end{array}$ & $\mathrm{SE}_{\mathrm{T}}=-31 \mathrm{~dB}$ & $\sim 5 \mathrm{~mm}$ & $18 \mathrm{GHz}$ & [85] \\
\hline 41 & CNT-grafted $\mathrm{Fe}_{3} \mathrm{O}_{4}(3 \mathrm{wt} \%)$ & PC/SAN (60/40) & $\begin{array}{l}\text { Solution followed by melt } \\
\text { mixing, compression } \\
\text { molding }\end{array}$ & $\mathrm{SE}_{\mathrm{T}}=-32.5 \mathrm{~dB}$ & $\sim 5 \mathrm{~mm}$ & $18 \mathrm{GHz}$ & {$[85]$} \\
\hline 42 & CNT (3 wt\%) & PC/SAN (50/50) & $\begin{array}{l}\text { Melt mixing, compression } \\
\text { molding }\end{array}$ & $\mathrm{SE}_{\mathrm{T}} \sim-26 \mathrm{~dB}$ & $\sim 5 \mathrm{~mm}$ & $18 \mathrm{GHz}$ & [85] \\
\hline 43 & CNT-grafted $\mathrm{Fe}_{3} \mathrm{O}_{4}(3 \mathrm{wt} \%)$ & PC/SAN (50/50) & $\begin{array}{l}\text { Solution followed by melt } \\
\text { mixing, compression } \\
\text { molding }\end{array}$ & $\mathrm{SE}_{\mathrm{T}}=-30 \mathrm{~dB}$ & $\sim 5 \mathrm{~mm}$ & $18 \mathrm{GHz}$ & {$[85]$} \\
\hline 44 & CNT (3 phr CNT) & $\begin{array}{l}\text { PC/ABS/SAN-g- } \\
\text { MAH (5 phr) }\end{array}$ & $\begin{array}{l}\text { Melt mixing, injection } \\
\text { molding }\end{array}$ & $\mathrm{SE}_{\mathrm{T}}=-5.4$ to $-8.4 \mathrm{~dB}$ & $2 \mathrm{~mm}$ & $\begin{array}{l}0.1-1.5 \\
\mathrm{GHz}\end{array}$ & {$[86]$} \\
\hline 45 & $\begin{array}{l}\text { Carbon fibers ( } 15 \mathrm{wt} \%) \text { and } \\
\text { graphite flakes ( } 40 \mathrm{wt} \%)\end{array}$ & $\begin{array}{l}\mathrm{Ni}-\mathrm{PC} / \mathrm{ABS}(45 \\
\text { wt\%) }\end{array}$ & Melt mixing & $\begin{array}{l}\mathrm{SE}_{\mathrm{T}}=-57 \mathrm{~dB}(@ \\
2000 \mathrm{MHz}), \mathrm{SE}_{\mathrm{T}}=- \\
79 \mathrm{~dB}(@ 4000 \mathrm{MHz})\end{array}$ & & $\begin{array}{l}500-4000 \\
\mathrm{MHz}\end{array}$ & {$[87]$} \\
\hline 46 & $\begin{array}{l}\text { CNT ( } 3 \text { wt\%), Co-rGO ( } 9.6 \text { wt\% Co, } \\
2.4 \text { wt } \% \text { GO) }\end{array}$ & PC/SAN & Solution mixing, melt mixing & $S E_{T}=-34 \mathrm{~dB}$ & $\sim 5 \mathrm{~mm}$ & $18 \mathrm{GHz}$ & {$[88]$} \\
\hline 47 & LA-g-CNT (5 phr) & PC/PLA & Melt extrusion & $\mathrm{EMI} \mathrm{SE}=1.3 \times 10^{1} \mathrm{~dB}$ & $0.2 \mathrm{~mm}$ & & [82] \\
\hline
\end{tabular}


Table 4 List of PC-based hybrid structure for EMI shielding applications (Continued)

\begin{tabular}{|c|c|c|c|c|c|c|c|}
\hline $\begin{array}{l}\text { Sl. } \\
\text { No. }\end{array}$ & Filler & Matrix & Processing & $\begin{array}{l}\mathrm{SE}_{\mathrm{T}} / \mathrm{RLmin} / \\
\text { Specific } \mathrm{SE}_{\mathrm{T}}\end{array}$ & Thickness & Frequency & Reference \\
\hline & & & & $\begin{array}{l}\text { (theoretical- from eq. } \\
\text { 10) }\end{array}$ & & & \\
\hline 48 & PANI-CNT- $-\mathrm{Fe}_{3} \mathrm{O}_{4}(3 \mathrm{wt} \%)+\mathrm{BT}$ & $\begin{array}{l}\text { PC/PVDF }(40 / 60 \\
w / w)\end{array}$ & $\begin{array}{l}\text { Melt mixing, compression } \\
\text { molding }\end{array}$ & $\begin{array}{l}\mathrm{SE}_{\mathrm{T}}=-37 \mathrm{~dB} \\
\mathrm{RL}=-71 \mathrm{~dB}\end{array}$ & $5 \mathrm{~mm}$ & $\begin{array}{l}\mathrm{SE}_{\mathrm{T}} @ 18 \\
\mathrm{GHz} \\
\mathrm{RL} @ 12.9 \\
\mathrm{GHz}\end{array}$ & [89] \\
\hline 49 & PANI-CNT- $-\mathrm{Fe}_{3} \mathrm{O}_{4}$ (3 wt\%) & $\begin{array}{l}\text { PC/PVDF }(40 / 60 \\
w / w)\end{array}$ & $\begin{array}{l}\text { Melt mixing, compression } \\
\text { molding }\end{array}$ & $S E_{T}=-32 d B$ & $5 \mathrm{~mm}$ & $18 \mathrm{GHz}$ & [89] \\
\hline 50 & PANI-CNT (3 wt\%) & $\begin{array}{l}\text { PC/PVDF }(40 / 60 \\
w / w)\end{array}$ & $\begin{array}{l}\text { Melt mixing, compression } \\
\text { molding }\end{array}$ & $S E_{T}=-26 d B$ & $5 \mathrm{~mm}$ & $18 \mathrm{GHz}$ & [89] \\
\hline 51 & CNT (3 wt\%) & $\begin{array}{l}\text { PC/PVDF }(40 / 60 \\
w / w)\end{array}$ & $\begin{array}{l}\text { Melt mixing, compression } \\
\text { molding }\end{array}$ & $\mathrm{SE}_{\mathrm{T}}=-22 \mathrm{~dB}$ & $5 \mathrm{~mm}$ & $18 \mathrm{GHz}$ & [89] \\
\hline 52 & $\begin{array}{l}3 \text { wt } \% \text { PDI-MWNT (in PVDF) + NF- } \\
\mathrm{NH}_{2} \text { (in PC) }\end{array}$ & $\begin{array}{l}\text { PC/PVDF }(50 / 50 \\
W / w)\end{array}$ & $\begin{array}{l}\text { Melt mixing, compression } \\
\text { molding }\end{array}$ & $\begin{array}{l}S E_{T}=-40 \mathrm{~dB} \\
\mathrm{RL}=-67 \mathrm{~dB}\end{array}$ & $5 \mathrm{~mm}$ & $\begin{array}{l}\mathrm{SE}_{\mathrm{T}} @ 18 \\
\mathrm{GHz} \\
\mathrm{RL} @ 17 \\
\mathrm{GHz}\end{array}$ & {$[90]$} \\
\hline 53 & $\begin{array}{l}3 \text { wt\% PDI-MWNT (in PVDF) + BT- } \\
\mathrm{NH}_{2} \text { (in PC) }\end{array}$ & $\begin{array}{l}\text { PC/PVDF }(50 / 50 \\
w / w)\end{array}$ & $\begin{array}{l}\text { Melt mixing, compression } \\
\text { molding }\end{array}$ & $\mathrm{SE}_{\mathrm{T}}=-35 \mathrm{~dB}$ & $5 \mathrm{~mm}$ & $18 \mathrm{GHz}$ & {$[90]$} \\
\hline 54 & $2 \mathrm{wt} \% \mathrm{CNT}$ & $\begin{array}{l}\text { PC/PVDF }(40 / 60 \\
W / W)\end{array}$ & $\begin{array}{l}\text { Melt mixing, compression } \\
\text { molding }\end{array}$ & $S E_{T}=-18 d B$ & $5 \mathrm{~mm}$ & $18 \mathrm{GHz}$ & [91] \\
\hline 55 & 2 wt\% IL-MWNT & $\begin{array}{l}\text { PC/PVDF }(40 / 60 \\
W / w)\end{array}$ & $\begin{array}{l}\text { Melt mixing, compression } \\
\text { molding }\end{array}$ & $\mathrm{SE}_{\mathrm{T}}=-24 \mathrm{~dB}$ & $5 \mathrm{~mm}$ & $18 \mathrm{GHz}$ & [91] \\
\hline 56 & 5 wt\% BaFe localized in PC & $\begin{array}{l}\text { PC/PVDF }(40 / 60 \\
W / w)\end{array}$ & $\begin{array}{l}\text { Melt mixing, compression } \\
\text { molding }\end{array}$ & $S E_{T}=-7 \mathrm{~dB}$ & $5 \mathrm{~mm}$ & $18 \mathrm{GHz}$ & [91] \\
\hline 57 & $\begin{array}{l}2 \text { wt } \% \text { IL-MWNT+ } 5 \text { wt\% BaFe (all } \\
\text { in PVDF) }\end{array}$ & $\begin{array}{l}\text { PC/PVDF }(40 / 60 \\
w / w)\end{array}$ & $\begin{array}{l}\text { Melt mixing, compression } \\
\text { molding }\end{array}$ & $S E_{T}=-26 \mathrm{~dB}$ & $5 \mathrm{~mm}$ & $18 \mathrm{GHz}$ & [91] \\
\hline 58 & $\begin{array}{l}2 \text { wt\% IL-MWNT (in PVDF) + } 5 \text { wt } \% \\
\text { BaFe (in PC) }\end{array}$ & $\begin{array}{l}\text { PC/PVDF }(40 / 60 \\
W / w)\end{array}$ & $\begin{array}{l}\text { Melt mixing, compression } \\
\text { molding }\end{array}$ & $S E_{T}=-34 \mathrm{~dB}$ & $5 \mathrm{~mm}$ & $18 \mathrm{GHz}$ & [91] \\
\hline 59 & $\begin{array}{l}2 \text { wt } \% \text { IL-MWNT (in PVDF) }+5 \text { wt } \% \\
\text { BaFe (in PC) }\end{array}$ & $\begin{array}{l}\text { PC/PVDF }(40 / 60 \\
\text { w/w) with } 10 \\
\text { wt\% PMMA }\end{array}$ & $\begin{array}{l}\text { Melt mixing, compression } \\
\text { molding }\end{array}$ & $\mathrm{SE}_{\mathrm{T}}=-37 \mathrm{~dB}$ & $5 \mathrm{~mm}$ & $18 \mathrm{GHz}$ & [91] \\
\hline 60 & 3 wt $\%$ CNT+ 10 wt $\%$ rGO-Ni & $\begin{array}{l}\text { PC/SAN }(60 / 40 \\
W / W)\end{array}$ & $\begin{array}{l}\text { Solution followed by melt } \\
\text { mixing, compression } \\
\text { molding }\end{array}$ & $S E_{T}=-48 d B$ & $5 \mathrm{~mm}$ & $18 \mathrm{GHz}$ & [92] \\
\hline 61 & 3 wt $\%$ CNT+ $10 w t \% ~ N i$ & $\begin{array}{l}\text { PC/SAN }(60 / 40 \\
W / W)\end{array}$ & $\begin{array}{l}\text { Solution followed by melt } \\
\text { mixing, compression } \\
\text { molding }\end{array}$ & $S E_{T}=-32.2 \mathrm{~dB}$ & $5 \mathrm{~mm}$ & $18 \mathrm{GHz}$ & [92] \\
\hline 62 & 3 wt $\%$ CNT+ 5 wt $\%$ rGO & $\begin{array}{l}\text { PC/SAN }(60 / 40 \\
W / W)\end{array}$ & $\begin{array}{l}\text { Solution followed by melt } \\
\text { mixing, compression } \\
\text { molding }\end{array}$ & $S E_{T}=-30.8 \mathrm{~dB}$ & $5 \mathrm{~mm}$ & $18 \mathrm{GHz}$ & [92] \\
\hline 63 & 3 wt $\%$ CNT & $\begin{array}{l}\text { PC/SAN }(60 / 40 \\
W / W)\end{array}$ & $\begin{array}{l}\text { Melt mixing, compression } \\
\text { molding }\end{array}$ & $S E_{T}=-25.1 \mathrm{~dB}$ & $5 \mathrm{~mm}$ & $18 \mathrm{GHz}$ & [92] \\
\hline 64 & $10 \mathrm{wt} \% \mathrm{rGO}-\mathrm{Ni}$ & $\begin{array}{l}\text { PC/SAN }(60 / 40 \\
W / W)\end{array}$ & $\begin{array}{l}\text { Solution followed by melt } \\
\text { mixing, compression } \\
\text { molding }\end{array}$ & $S E_{T}=-3 d B$ & $5 \mathrm{~mm}$ & $18 \mathrm{GHz}$ & [92] \\
\hline 65 & 3 wt $\%$ CNT & PC & $\begin{array}{l}\text { Melt mixing, compression } \\
\text { molding }\end{array}$ & $S E_{T}=-17.3 \mathrm{~dB}$ & $5 \mathrm{~mm}$ & $18 \mathrm{GHz}$ & [92] \\
\hline 66 & NCCF (20 wt $\%) / \mathrm{TiO}_{2}$ (5 wt\%) & $\begin{array}{l}\text { PP/PC (70/30) } \\
\text { with } 5 \text { wt } \% \text { PP- } \\
\text { g-MA }\end{array}$ & $\begin{array}{l}\text { Pultrusion, screw extrusion } \\
\text { and injection molding }\end{array}$ & $\begin{array}{l}\mathrm{SE}_{\mathrm{T}}=-51.6 \mathrm{~dB} \\
\text { (theoretical- from eq. } \\
\text { 10) }\end{array}$ & & Far-field & [93] \\
\hline 67 & $10 \mathrm{phr}$ CNT & $\begin{array}{l}\text { PC/EMA }(95 / 5 \\
W / W)\end{array}$ & Melt blending & $\mathrm{SE}_{\mathrm{T}} \sim-26 \mathrm{~dB}$ & $3 \mathrm{~mm}$ & $\begin{array}{l}8.2-12.4 \\
\mathrm{GHz}\end{array}$ & [94] \\
\hline 68 & 15 phr IrGO & $\begin{array}{l}\text { PC/EMA }(95 / 5 \\
\mathrm{W} / \mathrm{W})\end{array}$ & Melt blending & $\mathrm{SE}_{\mathrm{T}} \sim-30 \mathrm{~dB}$ & $3 \mathrm{~mm}$ & $\begin{array}{l}8.2-12.4 \\
\mathrm{GHz}\end{array}$ & [95] \\
\hline 69 & $10 w t \%$ CNT & PC/PP (60/40 & Melt mixing, compression & $\mathrm{SE}_{\mathrm{T}}=-22 \mathrm{~dB}$ & $2 \mathrm{~mm}$ & $3 \mathrm{GHz}$ & [96] \\
\hline
\end{tabular}


Table 4 List of PC-based hybrid structure for EMI shielding applications (Continued)

\begin{tabular}{|c|c|c|c|c|c|c|c|}
\hline $\begin{array}{l}\text { Sl. } \\
\text { No. }\end{array}$ & Filler & Matrix & Processing & $\begin{array}{l}\mathrm{SE}_{\mathrm{T}} / \mathrm{RLmin} / \\
\text { Specific } \mathrm{SE}_{\mathrm{T}}\end{array}$ & Thickness & Frequency & Reference \\
\hline & & $w / w)$ & molding & & & & \\
\hline 70 & $10 \mathrm{wt} \%$ CNT & $\begin{array}{l}\text { PC/PP }(60 / 40 \\
\text { w/w) with } 10 \\
\text { wt\% PP-g-MA }\end{array}$ & $\begin{array}{l}\text { Melt mixing, compression } \\
\text { molding }\end{array}$ & $S E_{T}=-54.78 \mathrm{~dB}$ & $2 \mathrm{~mm}$ & $3 \mathrm{GHz}$ & {$[96]$} \\
\hline 71 & 10 phr graphene/ CNT hybrid (1:3) & $\begin{array}{l}\text { PC/EMA }(95 / 5 \\
W / W)\end{array}$ & Melt blending & $\mathrm{SE}_{\mathrm{T}} \sim-34 \mathrm{~dB}$ & & $\begin{array}{l}8.2-12.4 \\
\mathrm{GHz}\end{array}$ & [97] \\
\hline 72 & 10 phr graphene & $\begin{array}{l}\text { PC/EMA }(95 / 5 \\
W / W)\end{array}$ & Melt blending & $\mathrm{SE}_{\mathrm{T}} \sim-23 \mathrm{~dB}$ & & $\begin{array}{l}8.2-12.4 \\
\mathrm{GHz}\end{array}$ & [97] \\
\hline 73 & 10 phr CNTs & $\begin{array}{l}\text { PC/EMA }(95 / 5 \\
W / W)\end{array}$ & Melt blending & $\mathrm{SE}_{\mathrm{T}} \sim-25 \mathrm{~dB}$ & & $\begin{array}{l}8.2-12.4 \\
\mathrm{GHz}\end{array}$ & [97] \\
\hline 74 & 20 phr long CF & $\mathrm{PC} / \mathrm{ABS}(70 / 30)$ & Pultrusion, injection molding & $S E_{T}=-37.6 \mathrm{~dB}$ & $2 \mathrm{~mm}$ & $10 \mathrm{GHz}$ & {$[98]$} \\
\hline 75 & 20 phr chopped CF & PC/ABS (70/30) & $\begin{array}{l}\text { Screw extrusion, injection } \\
\text { molding }\end{array}$ & $\mathrm{SE}_{\mathrm{T}}=-6.8 \mathrm{~dB}$ & $2 \mathrm{~mm}$ & $10 \mathrm{GHz}$ & {$[98]$} \\
\hline 76 & 20 phr long CF & PC & Pultrusion, injection molding & $\mathrm{SE}_{T}=-37.1 \mathrm{~dB}$ & $2 \mathrm{~mm}$ & $10 \mathrm{GHz}$ & [98] \\
\hline 77 & 20 phr chopped CF & PC & $\begin{array}{l}\text { Screw extrusion, injection } \\
\text { molding }\end{array}$ & $\mathrm{SE}_{\mathrm{T}}=-2.8 \mathrm{~dB}$ & $2 \mathrm{~mm}$ & $10 \mathrm{GHz}$ & [98] \\
\hline 78 & $\begin{array}{l}\text { CB } \\
(\mathrm{PC}: \mathrm{ABS}: \mathrm{CB}=0.83: 0: 0.17)\end{array}$ & PC & Injection molding & $S E_{T}=-9 d B$ & $4 \mathrm{~mm}$ & $800 \mathrm{MHz}$ & [99] \\
\hline 79 & $\begin{array}{l}C B \\
(P C: A B S: C B=0.78: 0.05: 0.17) .\end{array}$ & PC/ABS & Injection molding & $S E_{T}=-5 d B$ & $4 \mathrm{~mm}$ & $900 \mathrm{MHz}$ & [99] \\
\hline 80 & CNT based- waterborne ink & PC & $\begin{array}{l}\text { Multilayer with conductivity } \\
\text { gradient }\end{array}$ & $\begin{array}{l}\mathrm{SE}_{\mathrm{T}} \sim-20 \mathrm{~dB} \text { and } \\
\text { above }\end{array}$ & $17.97 \mathrm{~mm}$ & $8-70 \mathrm{GHz}$ & {$[100]$} \\
\hline 81 & $\begin{array}{l}2 \text { ply- FeCoNi-coated glass fabrics } \\
\text { (MGF), with or without Ni grid }\end{array}$ & PC & Multilayer & $\mathrm{SE}_{\mathrm{T}} \sim-90 \mathrm{~dB}$ & $\begin{array}{l}\sim 500 \mu \mathrm{m} \\
\text { or more }\end{array}$ & $\begin{array}{l}10 \sim 11 \\
\mathrm{GHz}\end{array}$ & [101] \\
\hline 82 & $90 \%$ CF in CEF-NF & PC layers & Sandwiched film & $\mathrm{SE}_{\mathrm{T}}=-38.6 \mathrm{~dB}$ & $0.29 \mathrm{~mm}$ & $\begin{array}{l}30-1500 \\
\mathrm{MHz}\end{array}$ & {$[70]$} \\
\hline 83 & CF/Ni (Ni thickness of $1.075 \mathrm{~mm}$ ) & PC layers & Sandwiched film & $S \mathrm{E}_{\mathrm{T}}=-72.7 \mathrm{~dB}$ & $0.31 \mathrm{~mm}$ & $\begin{array}{l}30-1500 \\
\mathrm{MHz}\end{array}$ & [33] \\
\hline 84 & Ni nanowire & PC layers & $\begin{array}{l}\text { Multilayer with conductivity } \\
\text { and permeability gradient }\end{array}$ & $\begin{array}{l}\mathrm{SE}_{\mathrm{A}}=-34.3 \mathrm{~dB} \\
\text { Mean } \mathrm{SE}_{\mathrm{A}}=-18 \mathrm{~dB}\end{array}$ & $600 \mu \mathrm{m}$ & $\begin{array}{l}67 \mathrm{GHz} \\
\left(@ \mathrm{SE}_{\mathrm{A}}\right) \\
8-67 \mathrm{GHz} \\
(@ \text { mean } \\
\left.\mathrm{SE}_{\mathrm{A}}\right)\end{array}$ & [63] \\
\hline 85 & ITO/Au/ITO & PC & $\begin{array}{l}\text { Multilayer sputter-deposited } \\
\text { film }\end{array}$ & $\mathrm{SE}_{\mathrm{T}}=-26.8 \mathrm{~dB}$ & $141 \mathrm{~nm}$ & $8.2-12 \mathrm{GHz}$ & {$[102]$} \\
\hline 86 & CF (60 wt $\%)$ & PC & $\begin{array}{l}\text { PC liquid infiltration through } \\
\text { CF- laminate formation by } \\
\text { thermo compression }\end{array}$ & $S E_{T}=-40 \mathrm{~dB}$ & $2 \mathrm{~mm}$ & $12-18 \mathrm{GHz}$ & [103] \\
\hline 87 & GNP (0.5 wt\%) & PC & Foam/ supercritical $\mathrm{CO}_{2}$ & $\begin{array}{l}\text { specific } \mathrm{SE}_{\mathrm{T}}= \\
-78 \mathrm{dBcm}^{3} / \mathrm{g}\end{array}$ & & $8.5 \mathrm{GHz}$ & [104] \\
\hline 88 & CNT (5 wt\%) & PC & Foam/ supercritical $\mathrm{CO}_{2}$ & $\begin{array}{l}\text { specific } S E_{T} \sim \\
-16 \mathrm{dBcm}^{3} / \mathrm{g}\end{array}$ & & $9.5 \mathrm{GHz}$ & [105] \\
\hline 89 & GNP (0.5 wt\%) & PC & Foam/ supercritical $\mathrm{CO}_{2}$ & $\begin{array}{l}\text { specific } \mathrm{SE}_{\mathrm{T}} \sim \\
-39 \mathrm{~dB} \mathrm{~cm}^{3} / \mathrm{g}\end{array}$ & & $8.5 \mathrm{GHz}$ & [106] \\
\hline 90 & CNT (2 wt\%) & PC & Foam/ supercritical $\mathrm{CO}_{2}$ & $\mathrm{SE}_{\mathrm{T}} \sim-14 \mathrm{~dB}$ & & $15-17 \mathrm{GHz}$ & [107] \\
\hline
\end{tabular}




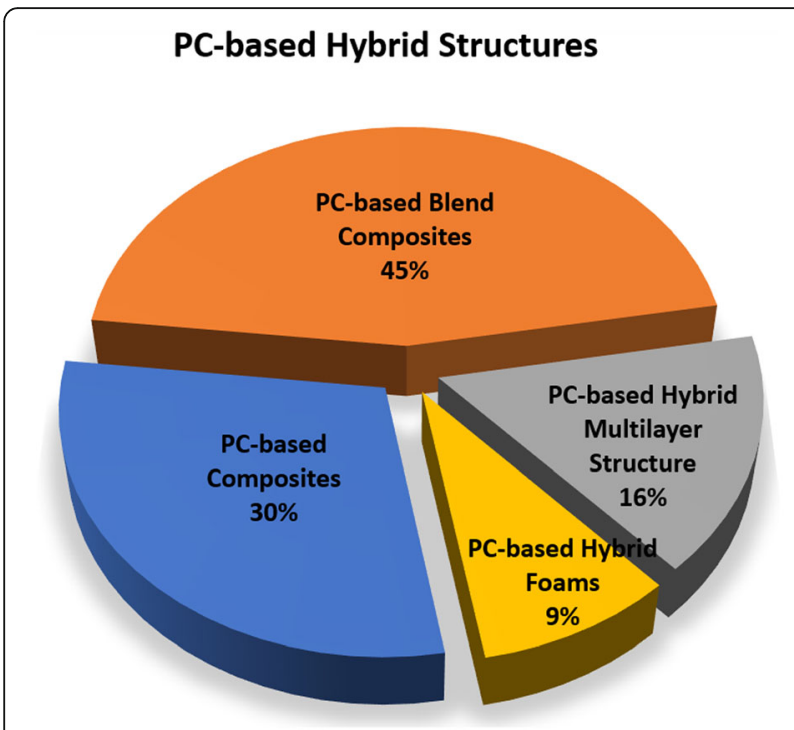

Fig. 22 Percentage of published research papers in different categories of PC-based hybrid structures since 2010

(enhanced viscosity) but also decreases the mechanical aspect of the shield as it undergoes ductile to brittle transition [69, 72].

\section{Absorption or reflection dominant mechanism?}

Depending upon the shield's design, the dominant mechanism of shielding can be either absorption or reflection. It is observed that most of the PC-based composites and PC-based blend composites; published in the last decade were designed with absorption as the dominant mechanism. Also, it is observed that a thicker sample leads to more power dissipation within the composite, resulting in a higher $\mathrm{SE}_{\mathrm{A}}$. However, in the case of PCbased multilayer and foam structures, this trend wasn't observed as some articles reports reflection to be more dominant than absorption. It is worthwhile to note that absorption-based shielding is considered superior to reflection-based shielding. However, it cannot be generalized as it also depends upon the targeted application for the shield.

\section{Effect of processing technique on EMI shielding performance \\ Melt mixing vs. solution mixing}

The melt viscosity and the shear force are the deciding factors for the dispersion of fillers in melt mixing. In contrast, the solution viscosity, sonication time, and power are crucial in the case of solution mixing process. However, in melt mixing, the shear force applied is generally higher than solution mixing, which might cause shortening in the filler length, especially in high aspect ratio fillers such CNTs. This may lead to a decrease in electrical conductivity and $\mathrm{SE}_{\mathrm{T}}$ value [78]. However, it is difficult to conclude if solution mixing is better than melt mixing for EMI shielding enhancement. In this study of PC-based composites, it is noted that changing the processing parameters impacts the shielding performance. For example, the usual melt mixing temperature in PC-based composites is $260-280^{\circ} \mathrm{C}$. It is observed that above the usual processing temperature (here $330{ }^{\circ} \mathrm{C}$ ), the melt viscosity of $\mathrm{PC}$ is low, leading to the homogeneous dispersion of GNPs, enhancing the electrical conductivity and subsequent EMI shielding for PC/GNP composite [75]. Thus, we can infer that temperature and processing parameters significantly impact the dispersion of fillers and subsequently the shielding performance.

\section{Compression molding vs. injection molding}

In the case of CNTs as fillers, it is observed that sample preparation for EMI measurements via compression molding (random distribution) results in an enhanced electrical conductivity and subsequent $\mathrm{SE}_{\mathrm{T}}$ value as compared to the injection molding technique. In injection molding technique, the flow-induced alignment of CNTs was achieved by applying intensive drag/shear force, diminishing the likelihood of CNTs inter-connection, and thus decreasing the electrical conductivity value [36, 69]. It is also reported that annealing the sample after injection molding did not significantly improve the conductivity value of $\mathrm{PC} / \mathrm{CNT}$ composites as CNT mobility during the thermal treatment is not adequate to improve the network structure [69]. Some articles report that the low-pressure compression molding technique results in enhanced shielding than high pressure (due to increased porosity in case of low pressure) [72]. But this happens at the cost of decreased strength. Furthermore, there is also an article that emphasizes that high-pressure compression molding results in enhanced electrical conductivity due to a decrease in the gap between adjacent nanofillers as polymers are more compressible than nanofillers [73]. However, as already mentioned, conductive filler connectivity is essential for conductivity but is not the sole deciding factor for EMI shielding.

Also, researchers have compared screw extrusion with injection molding and pultrusion processes with screw extrusion. Screw extrusion, due to its high shear stress, tends to decrease the aspect ratio compared to the other two processes $[93,98]$.

Having discussed the effect of processing technique on EMI shielding performance of PC-based hybrid structures, we can infer that one method can be better than the other method, only at a specific set of processing conditions and for certain fillers, but generalization would be inappropriate. 


\section{How to design a superior PC-based EMI shield?}

Researchers have been exploring the means to enhance EMI shielding performance while maintaining mechanical stability. Some of these approaches are already discussed in this review article, and it is summarized below.

\section{Modifying the filler/ polymer-filler interaction}

The structure of PC has a carbonate group. Thus, suitable covalent/non-covalent modification of fillers tends to enhance their interaction with the PC matrix. This can further help in controlling the dispersion and distribution of fillers in the PC matrix. It is beneficial in the case of blends where functional groups on fillers may help in confining the filler to a specific component, thus obtaining a compartmentalized model. For exampleamine functional groups on the surface of CNTs undergo interfacial reaction or $\mathrm{H}$-bonding with ester groups in PC, promoting double percolation in the blend and enhancing the EMI shielding properties. Another approach is to synthesize core-shell nanoparticles and, with controlled processing, obtain shielding compartments, enhancing the $\mathrm{SE}_{\mathrm{T}}$ value compared to random incorporation of individual fillers [81]. In general, it is known that in-situ polymerization of host polymer with filler results in homogeneous dispersion [46]. However, in-situ polymerization of $\mathrm{PC}$ might be difficult at the lab scale due to safety concerns (phosgene is toxic). And in the last decade, in-situ polymerization of PC and fillers is hardly focused and remains an intriguing area to explore.

\section{Blending another polymer with PC}

Blending is done primarily for two purposes- 1) To enhance the mechanical properties by introducing another thermoplastic polymer (PET, PBT, ABS, SAN, EMA, PP, etc.) such that a droplet matrix or sea-island morphology is obtained 2) To enhance the $\mathrm{SE}_{\mathrm{T}}$ value by targeting double percolation through a co-continuous structure. The compartmentalized model is well reported, especially for the case of PC/PVDF blend [90]. Several articles also report compatibilization of the blend by introducing the optimum amount of grafted MAHbased compatibilizers that decrease the interfacial tension between the two components of the blend structure. MAH-based compatibilizers work well for PC-based blend structure as MAH contains carbonyl group, making it highly polar and capable of interacting with the polar ester group in PC. This has a significant morphological impact on domain size, filler dispersion, and subsequent $\mathrm{SE}_{\mathrm{T}}$ value. Mechanical property and $\mathrm{SE}_{\mathrm{T}}$ value are reported to improve (or finetune) by the suitable compatibilization of PC-based blends $[86,96]$.

\section{Exploring multilayered hybrid structures and foams}

Multilayered PC-based hybrid systems and foams are comparatively more versatile and less explored research areas. The multilayered hybrid structure is a fascinating field wherein one can obtain a thin film with a combination of layers, each with different inherent properties (conducting or dielectric or magnetic) to enhance $\mathrm{SE}_{\mathrm{T}}$. Here, there is enough flexibility to tune the shield to promote reflection or absorption as per the requirement while minimizing the thickness. For example- with a systematic increase in conductivity across the stack, the wave can progress deeper into the material rather than reflecting at the front surface. This promotes multiple reflections at the material interfaces and has an added advantage over foaming. In contrast, the reflectivity in foams is minimized by introducing low permittivity airy pockets at the expense of thickness. Moreover, interfacial layers can also be incorporated to enhance the mechanical properties of a PC-based shield. In one of the cases [63], it is found that the stack with the gradient in permeability and conductivity together (e.g., conducting ferromagnetic filler such as $\mathrm{Ni}$ ) is more effective in enhancing the absorption performances compared to the stack with a gradient in conductivity (e.g., CNTs) only; however, more experiments are needed before it can be generalized for all such fillers. On the other hand, foams have attracted attention primarily due to their low density and high SSEt. High SSEt in foams are mainly because of multiple interfaces created by airy pockets. It is to be noted that in the last 10 years, $\mathrm{PC}$-based foams have only been prepared using supercritical $\mathrm{CO}_{2}$. The cellular morphological features, which have a crucial role in SSEt enhancement and mechanical properties, can be tuned primarily through the presence/ content of filler, amount of dissolved supercritical $\mathrm{CO}_{2}$, and $\mathrm{CO}_{2}$ saturation/ foaming conditions. The introduction of CNT in PCbased foams decreases the cell size and increases the cell density by providing adequate interfaces for $\mathrm{CO}_{2}$ accumulation and thus promoting nucleation of voids [105, 107]. Also, the SSEt of composite foams is higher than the bulk composite owing to multiple reflections due to numerous voids $[105,106]$. The foams can also be designed with gradient distribution of density and filler by partial foaming the outer layer to enhance absorptionbased shielding [107].

\section{Future prospects}

$\mathrm{PC}$ is a brittle polymer, and often, the incorporation of nanofillers (especially low aspect ratio nanofillers) result in the decline of mechanical properties. The mechanical stability of PC-based shields is of utmost importance for real-life commercial applications. Thus, the first challenging aspect of research is to make PC-based EMI shields with superior mechanical properties. Since PC finds 
application in several areas due to its transparency, it becomes essential to focus more on designing an EMI shield that retains its transparency. It will indeed be an added advantage if future researchers find ways to introduce self-healing property in these EMI shields.

\section{Acknowledgments}

The authors would like to acknowledge the funding as mentioned below.

\section{Authors's contributions}

Kumari Sushmita has collated all the literature and made an overview of the journey of PC-based composites for EMI shielding applications. Suryasarathi Bose and Giridhar Madras have edited the manuscript and provided intellectual inputs. The author(s) read and approved the final manuscript.

\section{Funding}

The authors would like to acknowledge the funding support from DST, India (DST/NM/NS/2018/157).

\section{Availability of data and materials}

Data sharing is not applicable to this article as no datasets were generated or analyzed during the current study.

\section{Declarations}

\section{Competing interests}

The authors declare that they have no known competing financial interests or personal relationships that could have appeared to influence the work reported in this paper.

\section{Author details}

Centre for Nanoscience and Engineering, Indian Institute of Science, Bangalore 560012, India. ${ }^{2}$ Interdisciplinary Centre for Energy Research, Indian Institute of Science, Bangalore 560012, India. ${ }^{3}$ Department of Materials Engineering, Indian Institute of Science, Bangalore 560012, India.

Received: 25 March 2021 Accepted: 9 June 2021

Published online: 31 July 2021

\section{References}

1. D.G. LeGrand, J.T. Bendler, Handbook of Polycarbonate Science and Technology (CRC press, U.S.A, 1999), pp. 1-357.

2. Step Polymerization, Principles of Polymerization (John Wiley \& Sons, Inc, 2004), pp. 39-197

3. C. Kim, D. Paul, Effects of polycarbonate molecular structure on the miscibility with other polymers (American Chemical Society). Macromolecules 25(12), 3097-3105 (1992). https://doi.org/10.1021/ma0003 $8 \mathrm{a} 012$

4. A. Singh, in Encyclopedia of Polymeric Nanomaterials, ed. by S. Kobayashi, K. Müllen. Polycarbonate synthesis (Springer, Berlin Heidelberg, Berlin, Heidelberg, 2014), pp. 1-5

5. D.J. Brunelle, Polycarbonates. In: Encyclopedia of Polymer Science and Technology (2006). https://doi.org/10.1002/0471440264.pst255.pub2

6. D.J. Brunelle, P.M. Smigelski, E.P. Boden, Evolution of Polycarbonate Process Technologies. In: Advances in Polycarbonates, vol. 898. ACS Symposium Series, vol. 898 (American Chemical Society, 2005), pp. 8-21

7. Polycarbonates, Engineering Plastics Handbook (McGraw-Hill Education, U.S.A. 2006), pp. 327-383

8. S. Fukuoka, M. Tojo, H. Hachiya, M. Aminaka, K. Hasegawa, Green and sustainable chemistry in practice: Development and industrialization of a novel process for polycarbonate Production from $\mathrm{CO} 2$ without using phosgene. Polym. J. 39(2), 91-114 (2007). https://doi.org/10.1295/polymj.PJ2 006140

9. Polycarbonates, Thermoplastic Materials: Properties, Manufacturing Methods, and Applications (CRC Press, U.S.A., 2011), pp. 449-472

10. A Complete Guide to Polycarbonate (Omnexus). https://omnexus.specia Ichem.com/selection-quide/polycarbonate-pc-plastic. Accessed 30 Nov 2020

11. T. Schmauder, K.D. Nauenburg, K. Kruse, G. Ickes, Hard coatings by plasma CVD on polycarbonate for automotive and optical applications. Thin Solid Films 502(1), 270-274 (2006). https://doi.org/10.1016/j.tsf.2005.07.296
12. R. Fateh, A.A. Ismail, R. Dillert, D.W. Bahnemann, Highly active crystalline mesoporous TiO2 films coated onto polycarbonate substrates for selfcleaning applications. J. Phys. Chem. C 115(21), 10405-10411 (2011). https:// doi.org/10.1021/jp200892z

13. P. Pedrosa, E. Alves, N.P. Barradas, P. Fiedler, J. Haueisen, F. Vaz, C. Fonseca, TiNx coated polycarbonate for bio-electrode applications. Corros. Sci. 56, 49-57 (2012). https://doi.org/10.1016/j.corsci.2011.11.008

14. S. Kumar, B. Lively, L.L. Sun, B. Li, W.H. Zhong, Highly dispersed and electrically conductive polycarbonate/oxidized carbon nanofiber composites for electrostatic dissipation applications. Carbon 48(13), 3846-3857 (2010). https://doi.org/10.1016/j.carbon.2010.06.050

15. B. Zhou, Y. Li, G. Zheng, K. Dai, C. Liu, Y. Ma, J. Zhang, N. Wang, C. Shen, Z. Guo, Continuously fabricated transparent conductive polycarbonate/carbon nanotube nanocomposite films for switchable thermochromic applications. J. Mater. Chem. C 6(31), 8360-8371 (2018)

16. C.M. Shemelya, A. Rivera, A.T. Perez, C. Rocha, M. Liang, X. Yu, C. Kief, D. Alexander, J. Stegeman, H. Xin, R.B. Wicker, E. MacDonald, D.A. Roberson, Mechanical, electromagnetic, and X-ray shielding characterization of a 3D printable tungsten-polycarbonate polymer matrix composite for spacebased applications. J. Electron. Mater. 44(8), 2598-2607 (2015). https://doi. org/10.1007/s11664-015-3687-7

17. O. Hauenstein, M.M. Rahman, M. Elsayed, R. Krause-Rehberg, S. Agarwal, V. Abetz, A. Greiner, Biobased polycarbonate as a gas separation membrane and "breathing glass" for energy saving applications. Adv. Mater. Technol. 2(5), 1700026 (2017). https://doi.org/10.1002/admt.201700026

18. S. XiaoHui, L. Wei, S. PingHui, S. QingYong, W. QingSong, S. YuSheng, L. Kai, L. WenGuang, Selective laser sintering of aliphatic-polycarbonate/hydroxyapatite composite scaffolds for medical applications. Int. J. Adv. Manuf. Technol. 81(1), 15-25 (2015). https://doi.org/10.1007/s00170-015-7135-x

19. N. Bagotia, V. Choudhary, D.K. Sharma, A review on the mechanical, electrical and EMI shielding properties of carbon nanotubes and graphene reinforced polycarbonate nanocomposites. Polym. Adv. Technol. 29(6), 1547-1567 (2018). https://doi.org/10.1002/pat.4277

20. Polycarbonate Market Analysis By Application. (Grand View Research October 2016) https://www.grandviewresearch.com/industry-analysis/polyca rbonate-market. Accessed 3 May 2021.

21. Polycarbonate Production, Price and Market Demand. (Plastics Insight), https://www.plasticsinsight.com/resin-intelligence/resin-prices/ polycarbonate/. Accessed 3 June 2021

22. S. Kannan, M. Ramamoorthy, Mechanical characterization and experimental modal analysis of 3D printed ABS. PC and PC-ABS materials. Mater. Res. Express 7(1), 015341 (2020). https://doi.org/10.1088/2053-1591/ab6a48

23. M. Schlechter, Plastics in Automobiles: US Materials, Applications, and Markets (Taylor \& Francis, U.S.A., 1994)

24. H. Kim, C.W. Macosko, Processing-property relationships of polycarbonate/ graphene composites. Polymer 50(15), 3797-3809 (2009). https://doi.org/1 0.1016/j.polymer.2009.05.038

25. L. Chen, X.-J. Pang, Z.-L. Yu, Study on polycarbonate/multi-walled carbon nanotubes composite produced by melt processing. Mater. Sci. Eng. A 457(1), 287-291 (2007). https://doi.org/10.1016/j.msea.2007.01.107

26. A. Gupta, I. Fidan, S. Hasanov, A. Nasirov, Processing, mechanical characterization, and micrography of 3D-printed short carbon fiber reinforced polycarbonate polymer matrix composite material. Int. J. Adv. Manuf. Technol. 107(7), 3185-3205 (2020). https://doi.org/10.1007/s00170-02 0-05195-z

27. Y. Ito, M. Yamashita, M. Okamoto, Engineering: Foam processing and cellular structure of polycarbonate-based nanocomposites. Macromol. Mater. Eng. 291(7). 773-783 (2006)

28. A. Wong, S.N. Leung, G.Y.G. Li, C.B. Park, Role of processing temperature in polystyrene and polycarbonate foaming with carbon dioxide. Ind. Eng. Chem. Res. 46(22), 7107-7116 (2007). https://doi.org/10.1021/ie070551z

29. X. Gao, A.I. Isayev, X. Zhang, J. Zhong, Influence of processing parameters during ultrasound assisted extrusion on the properties of polycarbonate/ carbon nanotubes composites. Compos. Sci. Technol. 144, 125-138 (2017). https://doi.org/10.1016/j.compscitech.2017.03.019

30. C.-S. Chen, W.-R. Chen, S.-C. Chen, R.-D. Chien, Optimum injection molding processing condition on EMl shielding effectiveness of stainless steel fiber filled polycarbonate composite. Int. Commun. Heat Mass Transfer 35(6), 744-749 (2008). https://doi.org/10.1016/j.icheatmasstransfer.2008.02.006

31. A.K. Bledzki, H. Kirschling, M. Rohleder, A. Chate, Correlation between injection moulding processing parameters and mechanical properties of 
microcellular polycarbonate. J. Cell. Plast. 48(4), 301-340 (2012). https://doi. org/10.1177/0021955X12441193

32. S. Geetha, K.K. Satheesh Kumar, C.R.K. Rao, M. Vijayan, D.C. Trivedi, EMI shielding: Methods and materials—A review. J. Appl. Polym. Sci. 112(4), 2073-2086 (2009). https://doi.org/10.1002/app.29812

33. D. Xing, L. Lu, K.S. Teh, Z. Wan, Y. Xie, Y. Tang, Highly flexible and ultra-thin Ni-plated carbon-fabric/polycarbonate film for enhanced electromagnetic interference shielding. Carbon 132, 32-41 (2018). https://doi.org/10.1016/j.ca rbon.2018.02.001

34. J. Sun, W. Wang, Q. Yue, Review on microwave-matter interaction fundamentals and efficient microwave-associated heating strategies. Materials 9(4), 231 (2016)

35. P. Nimbalkar, A. Korde, R.K. Goyal, Electromagnetic interference shielding of polycarbonate/GNP nanocomposites in X-band. Mater. Chem. Phys. 206, 251-258 (2018). https://doi.org/10.1016/j.matchemphys.2017.12.027

36. M. Arjmand, M. Mahmoodi, G.A. Gelves, S. Park, U. Sundararaj, Electrical and electromagnetic interference shielding properties of flow-induced oriented carbon nanotubes in polycarbonate. Carbon 49(11), 3430-3440 (2011). https://doi.org/10.1016/j.carbon.2011.04.039

37. Y. Wang, X. Jing, Intrinsically conducting polymers for electromagnetic interference shielding. Polym. Adv. Technol. 16(4), 344-351 (2005). https:// doi.org/10.1002/pat.589

38. K. Lakshmi, H. John, K.T. Mathew, R. Joseph, K.E. George, Microwave absorption, reflection and EMI shielding of PU-PANI composite. Acta Mater. 57(2), 371-375 (2009). https://doi.org/10.1016/j.actamat.2008.09.018

39. M.F. Shakir, I. Abdul Rashid, A. Tariq, Y. Nawab, A. Afzal, M. Nabeel, A. Naseem, U. Hamid, EMI shielding characteristics of electrically conductive polymer blends of PS/PANI in microwave and IR region. J. Electron. Mater. 49(3), 1660-1665 (2020). https://doi.org/10.1007/s11664-019-07631-7

40. Y. Wang, W. Wang, D. Yu, Three-phase heterostructures f-NiFe2O4/PANI/PI EMI shielding fabric with high microwave absorption performance. Appl. Surf. Sci. 425, 518-525 (2017). https://doi.org/10.1016/j.apsusc.2017.07.062

41. Y. Wang, Gu, F.-q.., Ni, L.-j., Liang, K., Marcus, K., Liu, S.-I., Yang, F., Chen, J.j., Feng, Z.-s., Easily fabricated and lightweight PPy/PDA/AgNW composites for excellent electromagnetic interference shielding. Nanoscale 9(46), 1831818325 (2017)

42. S.H. Kim, S.H. Jang, S.W. Byun, J.Y. Lee, J.S. Joo, S.H. Jeong, M.-J. Park, Electrical properties and EMI shielding characteristics of polypyrrole-nylon 6 composite fabrics. J. Appl. Polym. Sci. 87(12), 1969-1974 (2003). https://doi. org/10.1002/app.11566

43. M.S. Kim, H.K. Kim, S.W. Byun, S.H. Jeong, Y.K. Hong, J.S. Joo, K.T. Song, J.K. Kim, C.J. Lee, J.Y. Lee, PET fabric/polypyrrole composite with high electrical conductivity for EMI shielding. Synth. Met. 126(2), 233-239 (2002). https:// doi.org/10.1016/50379-6779(01)00562-8

44. P. Gahlout, V. Choudhary, EMI shielding response of polypyrrole-MWCNT/ polyurethane composites. Synth. Met. 266, 116414 (2020). https://doi.org/1 0.1016/j.synthmet.2020.116414

45. D. Markham, Shielding: Quantifying the shielding requirements for portable electronic design and providing new solutions by using a combination of materials and design. Mater. Des. 21(1), 45-50 (1999). https://doi.org/10.101 6/50261-3069(99)00049-7

46. S. Sankaran, K. Deshmukh, M.B. Ahamed, S.K. Khadheer Pasha, Recent advances in electromagnetic interference shielding properties of metal and carbon filler reinforced flexible polymer composites: A review. Compos. Part A 114, 49-71 (2018). https://doi.org/10.1016/j.compositesa.2018.08.006

47. R. Pandey, S. Tekumalla, M. Gupta, in Materials for Potential EMI Shielding Applications, ed. by K. Joseph, R. Wilson, G. George. Chapter 21 - EMI shielding of metals, alloys, and composites (Elsevier, 2020), pp. 341-355. https://doi.org/10.1016/B978-0-12-817590-3.00021-X

48. D. Jiang, V. Murugadoss, Y. Wang, J. Lin, T. Ding, Z. Wang, Q. Shao, C. Wang, H. Liu, N. Lu, R. Wei, A. Subramania, Z. Guo, Electromagnetic interference shielding polymers and nanocomposites - a review. Polym. Rev. 59(2), 280337 (2019). https://doi.org/10.1080/15583724.2018.1546737

49. K. Sushmita, G. Madras, S. Bose, Polymer nanocomposites containing semiconductors as advanced materials for EMI shielding. ACS Omega 5(10), 4705-4718 (2020). https://doi.org/10.1021/acsomega.9b03641

50. F. Shahzad, M. Alhabeb, C.B. Hatter, B. Anasori, S. Man Hong, C.M. Koo, Y. Gogotsi, Electromagnetic interference shielding with 2D transition metal carbides (MXenes). Science 353(6304), 1137 (2016). https://doi.org/10.1126/science.aag2421

51. Y. Chen, Y. Li, M. Yip, N. Tai, Electromagnetic interference shielding efficiency of polyaniline composites filled with graphene decorated with metallic nanoparticles. Compos. Sci. Technol. 80, 80-86 (2013). https://doi. org/10.1016/j.compscitech.2013.02.024

52. B. Moazzenchi, M. Montazer, Click electroless plating of nickel nanoparticles on polyester fabric: Electrical conductivity, magnetic and EMI shielding properties. Colloids Surf. A Physicochem. Eng. Asp. 571, 110-124 (2019). https://doi.org/10.1016/j.colsurfa.2019.03.065

53. J. Arranz-Andrés, N. Pulido-González, C. Fonseca, E. Pérez, M.L. Cerrada, Lightweight nanocomposites based on poly (vinylidene fluoride) and Al nanoparticles: Structural, thermal and mechanical characterization and EMI shielding capability. Mater. Chem. Phys. 142(2), 469-478 (2013). https://doi. org/10.1016/j.matchemphys.2013.06.038

54. R. Kumaran, M. Alagar, S. Dinesh Kumar, V. Subramanian, K. Dinakaran, Ag induced electromagnetic interference shielding of ag-graphite/PVDF flexible nanocomposites thinfilms. Appl. Phys. Lett. 107(11), 113107 (2015). https:// doi.org/10.1063/1.4931125

55. S.H. Lee, S. Yu, F. Shahzad, J. Hong, S.J. Noh, W.N. Kim, S.M. Hong, C.M. Koo, Low percolation 3D cu and ag shell network composites for EMI shielding and thermal conduction. Compos. Sci. Technol. 182, 107778 (2019). https:// doi.org/10.1016/..compscitech.2019.107778.

56. L.-Q. Zhang, S.-G. Yang, L. Li, B. Yang, H.-D. Huang, D.-X. Yan, G.-J. Zhong, L. $\mathrm{Xu}, \mathrm{Z}$.-M. Li, Ultralight cellulose porous composites with manipulated porous structure and carbon nanotube distribution for promising electromagnetic interference shielding. ACS Appl. Mater. Interfaces 10(46), 40156-40167 (2018). https://doi.org/10.1021/acsami.8b14738

57. S.P. Pawar, K. Pattabhi, S. Bose, Assessing the critical concentration of $\mathrm{NH}_{2}$ terminal groups on the surface of MWNTs towards chain scission of PC in PC/SAN blends: Effect on dispersion, electrical conductivity and EMI shielding. RSC Adv. 4(36), 18842-18852 (2014). https://doi.org/10.1039/C4RA 01610F

58. B. Zhao, C. Zhao, M. Hamidinejad, C. Wang, R. Li, S. Wang, K. Yasamin, C.B. Park, Incorporating a microcellular structure into PVDF/graphenenanoplatelet composites to tune their electrical conductivity and electromagnetic interference shielding properties. J. Mater. Chem. C 6(38), 10292-10300 (2018)

59. A. Kaur, S.K. Dhawan, Tuning of EMI shielding properties of polypyrrole nanoparticles with surfactant concentration. Synth. Met. 162(15), 1471-1477 (2012). https://doi.org/10.1016/j.synthmet.2012.05.012

60. Z. Zeng, Y. Zhang, X.Y.D. Ma, S.I.S. Shahabadi, B. Che, P. Wang, X. Lu, Biomass-based honeycomb-like architectures for preparation of robust carbon foams with high electromagnetic interference shielding performance. Carbon 140, 227-236 (2018). https://doi.org/10.1016/j.carbon.2 018.08 .061

61. J. Li, Y. Ding, N. Yu, Q. Gao, X. Fan, X. Wei, G. Zhang, Z. Ma, X. He, Lightweight and stiff carbon foams derived from rigid thermosetting polyimide foam with superior electromagnetic interference shielding performance. Carbon 158, 4554 (2020). https://doi.org/10.1016/j.carbon.2019.11.075

62. G.G. Bush, Generalization of Snoek's limit for modeling initial permeability of magnetic materials. J. Appl. Phys. 63(8), 3765-3767 (1988)

63. Y. Danlée, C. Bailly, I. Huynen, L. Piraux, Flexible multilayer combining nickel nanowires and polymer films for broadband microwave absorption. IEEE Trans. Electromagn. Compat., 1-8 (2019). https://doi.org/10.1109/TEMC.201 9.2943549

64. Radio spectrum (Wikipedia, 2021). https://en.wikipedia.org/wiki/Radio_ spectrum. Accessed on 3 June 2021

65. N.F. Colaneri, L.W. Schacklette, EMI shielding measurements of conductive polymer blends. IEEE Trans. Instrum. Meas. 41(2), 291-297 (1992). https://doi. org/10.1109/19.137363

66. S.P. Pawar, S. Biswas, Kar, G.P., Bose, S.: High frequency millimetre wave absorbers derived from polymeric nanocomposites. Polymer 84, 398-419 (2016). https://doi.org/10.1016/j.polymer.2016.01.010

67. A.S. Babal, R. Gupta, B.P. Singh, V.N. Singh, S.R. Dhakate, R.B. Mathur, Mechanical and electrical properties of high performance MWCNT/ polycarbonate composites prepared by an industrial viable twin screw extruder with back flow channel. RSC Adv. 4(110), 64649-64658 (2014). https://doi.org/10.1039/C4RA11319E

68. González, M., Mokry, G., de Nicolás, M., Baselga, J., \& Pozuelo, J., Carbon nanotube composites as electromagnetic shielding materials in $\mathrm{GHz}$ range. Carbon Nanotubes-Current Progress of their Polymer Composites (InTech, Croatia, 2016), 11, pp 297-321. https://doi.org/10.5772/62508

69. S.G. Pardo, L. Arboleda, A. Ares, X. García, S. Dopico, M.J. Abad, Toughening strategies of carbon nanotube/polycarbonate composites with 
electromagnetic interference shielding properties. Polym. Compos. 34(11), 1938-1949 (2013). https://doi.org/10.1002/pc.22601

70. W. Tang, L. Lu, D. Xing, H. Fang, Q. Liu, K.S. Teh, A carbon-fabric/polycarbonate sandwiched film with high tensile and EMI shielding comprehensive properties: An experimental study. Compos. Part B 152, 8-16 (2018). https:// doi.org/10.1016/j.compositesb.2018.06.026

71. X. Yan, L. Xiang, Q. He, J. Gu, J. Dang, J. Guo, Z. Guo, Electromagnetic interference shielding polymer nanocomposites. Multifunct. Nanocompos. Energy Environ. Appl., 567-601 (2018). https://doi.org/10.1002/9783527342 501.ch19

72. S. Pande, A. Chaudhary, D. Patel, B.P. Singh, R.B. Mathur, Mechanical and electrical properties of multiwall carbon nanotube/polycarbonate composites for electrostatic discharge and electromagnetic interference shielding applications. RSC Adv. 4(27), 13839-13849 (2014). https://doi.org/1 0.1039/C3RA47387B

73. S. Maiti, S. Suin, N.K. Shrivastava, B.B. Khatua, A strategy to achieve high electromagnetic interference shielding and ultra low percolation in multiwall carbon nanotube-polycarbonate composites through selective localization of carbon nanotubes. RSC Adv. 4(16), 7979-7990 (2014). https:// doi.org/10.1039/C3RA46480F

74. J.A. King, W.A. Pisani, D.R. Klimek-McDonald, W.F. Perger, G.M. Odegard, Shielding effectiveness of carbon-filled polycarbonate composites. J. Appl. Polym. Sci. 132(43) (2015). https://doi.org/10.1002/app.42719

75. S. Maiti, B.B. Khatua, Graphene nanoplate and multiwall carbon nanotubeembedded polycarbonate hybrid composites: High electromagnetic interference shielding with low percolation threshold. Polym. Compos 37(7), 2058-2069 (2016). https://doi.org/10.1002/pc.23384

76. P. Karimi, M. Ostoja-Starzewski, I. Jasiuk, Experimental and computational study of shielding effectiveness of polycarbonate carbon nanocomposites. J. Appl. Phys. 120(14), 145103 (2016). https://doi.org/10.1063/1.4964691

77. S.P. Pawar, M. Gandi, C. Saraf, S. Bose, Polycarbonate composites containing carbon encapsulated "brick-like" Fe3O4 nanoparticles as efficient microwave absorbers with a large bandwidth. ChemistrySelect 1(13), 3829-3838 (2016). https://doi.org/10.1002/slct.201600931

78. S.M. Seyedi Ghezghapan, A. Javadi, Effect of processing methods on electrical percolation and electromagnetic shielding of PC/MWCNTs nanocomposites. Polym. Compos. 38(S1), E269-E276 (2017). https://doi. org/10.1002/pc.24037

79. M.G. Jang, S.C. Ryu, K.J. Juhn, S.K. Kim, W.N. Kim, Effects of carbon fiber modification with multiwall CNT on the electrical conductivity and EMI shielding effectiveness of polycarbonate/carbon fiber/CNT composites. J. Appl. Polym. Sci. 136(14), 47302 (2019). https://doi.org/10.1002/app.47302

80. K. Sushmita, A.V. Menon, S. Sharma, A.C. Abhyankar, G. Madras, S. Bose, Mechanistic insight into the nature of dopants in graphene derivatives influencing electromagnetic interference shielding properties in hybrid polymer nanocomposites. J. Phys. Chem. C 123(4), 2579-2590 (2019). https://doi.org/10.1021/acs.jpcc.8b10999

81. W.-C. Yu, T. Wang, Y.-H. Liu, Z.-G. Wang, L. Xu, J.-H. Tang, K. Dai, H.-J. Duan, J.-Z. Xu, Z.-M. Li, Superior and highly absorbed electromagnetic interference shielding performance achieved by designing the reflection-absorptionintegrated shielding compartment with conductive wall and lossy core. Chem. Eng. J. 393, 124644 (2020). https://doi.org/10.1016/j.cej.2020.124644

82. M.G. Jang, Y.K. Lee, W.N. Kim, Influence of lactic acid-grafted multi-walled carbon nanotube (LA-g-MWCNT) on the electrical and rheological properties of polycarbonate/poly (lactic acid)/ LA-g-MWCNT composites. Macromol. Res. 23(10), 916-923 (2015). https://doi.org/10.1007/s13233-01 5-3129-7

83. S.H. Jeon, H.M. Kim, T.-H. Park, B.-H. Choi, W.C. Choi, Development of polycarbonate/acrylonitrile-butadiene-styrene copolymer based composites with functional fillers for car audio chassis. Mater. Des. 32(3), 1306-1314 (2011). https://doi.org/10.1016/j.matdes.2010.09.027

84. V.L. Reena, J.D. Sudha, R. Ramakrishnan, Development of electromagnetic interference shielding materials from the composite of nanostructured polyaniline-polyhydroxy iron-clay and polycarbonate. J. Appl. Polym. Sci. 128(3), 1756-1763 (2013). https://doi.org/10.1002/app.38320

85. S.P. Pawar, D.A. Marathe, K. Pattabhi, S. Bose, Electromagnetic interference shielding through MWNT grafted Fe3O4 nanoparticles in PC/SAN blends. J. Mater. Chem. A 3(2), 656-669 (2015). https://doi.org/10.1039/C4TA04559A

86. I.-S. Han, Y.K. Lee, H.S. Lee, H.G. Yoon, W.N. Kim, Effects of multi-walled carbon nanotube (MWCNT) dispersion and compatibilizer on the electrical and rheological properties of polycarbonate/poly (acrylonitrile-butadiene-
styrene)/MWCNT composites. J. Mater. Sci. 49(13), 4522-4529 (2014). https:// doi.org/10.1007/s10853-014-8152-0

87. J.N. Sunitha, C.S. Rajesh, S.K. Rai, Electromagnetic interference shielding effectiveness and electrical conductivity of Ni coated Pcabs/Pps composites with reinforcement of carbon fibre. Polym. Polym. Compos. 24(1), 57-64 (2016). https://doi.org/10.1177/096739111602400107

88. S.P. Pawar, S. Bose, Extraordinary synergy in attenuating microwave radiation with cobalt-decorated graphene oxide and carbon nanotubes in polycarbonate/poly (styrene-co-acrylonitrile) blends. ChemNanoMat 1(8), 603-614 (2015). https://doi.org/10.1002/cnma.201500154

89. S. Biswas, G.P. Kar, S. Bose, Attenuating microwave radiation by absorption through controlled nanoparticle localization in PC/PVDF blends. Phys. Chem. Chem. Phys. 17(41), 27698-27712 (2015). https://doi.org/10.1039/C5CP05189D

90. S. Biswas, G.P. Kar, S. Bose, Engineering nanostructured polymer blends with controlled nanoparticle location for excellent microwave absorption: A compartmentalized approach. Nanoscale 7(26), 11334-11351 (2015). https:// doi.org/10.1039/C5NR01785H

91. S. Biswas, G.P. Kar, S. Bose, Tailor-made distribution of nanoparticles in blend structure toward outstanding electromagnetic interference shielding. ACS Appl. Mater. Interfaces 7(45), 25448-25463 (2015). https://doi.org/10.1021/a csami.5b08333

92. S.P. Pawar, M. Gandi, C. Saraf, S. Bose, Exceptional microwave absorption in soft polymeric nanocomposites facilitated by engineered nanostructures. J. Mater. Chem. C 4(22), 4954-4966 (2016). https://doi.org/10.1039/C6TC01062H

93. M.G. Jang, C. Cho, W.N. Kim, Synergistic effects of hybrid conductive fillers on the electrical properties of carbon fiber pultruded polypropylene/ polycarbonate composites prepared by injection molding. J. Compos. Mater. 51(7), 1005-1017 (2016). https://doi.org/10.1177/0021998316658536

94. N. Bagotia, V. Choudhary, D.K. Sharma, Studies on toughened polycarbonate/multiwalled carbon nanotubes nanocomposites. Compos. Part B 124, 101-110 (2017). https://doi.org/10.1016/j.compositesb.2017. 05.037

95. N. Bagotia, V. Choudhary, D.K. Sharma, Superior electrical, mechanical and electromagnetic interference shielding properties of polycarbonate/ethylenemethyl acrylate-in situ reduced graphene oxide nanocomposites. J. Mater. Sci. 53(23), 16047-16061 (2018). https://doi.org/10.1007/s10853-018-2749-7

96. M.A. Poothanari, J. Abraham, N. Kalarikkal, S. Thomas, Excellent electromagnetic interference shielding and high electrical conductivity of Compatibilized polycarbonate/polypropylene carbon nanotube blend nanocomposites. Ind. Eng. Chem. Res. 57(12), 4287-4297 (2018). https://doi. org/10.1021/acs.iecr.7b05406

97. N. Bagotia, V. Choudhary, D.K. Sharma, Synergistic effect of graphene/ multiwalled carbon nanotube hybrid fillers on mechanical, electrical and EMI shielding properties of polycarbonate/ethylene methyl acrylate nanocomposites. Compos. Part B 159, 378-388 (2019). https://doi.org/10.101 6/j.compositesb.2018.10.009

98. S.C. Ryu, J.Y. Kim, C. Cho, W.N. Kim, Improvements of the electrical conductivity and EMI shielding efficiency for the polycarbonate/ABS/carbon Fiber composites prepared by Pultrusion process. Macromol. Res. 28(2), 118-125 (2020). https://doi.org/10.1007/s13233-020-8024-1

99. W. Sriseubsai, A. Tippayakraisorn, J.W. Lim, Robust design of PC/ABS filled with nano carbon black for electromagnetic shielding effectiveness and surface resistivity. Processes 8(5) (2020). https://doi.org/10.3390/pr8050616

100. Y. Danlée, C. Bailly, I. Huynen, Thin and flexible multilayer polymer composite structures for effective control of microwave electromagnetic absorption. Compos. Sci. Technol. 100, 182-188 (2014). https://doi.org/10.1 016/j.compscitech.2014.06.010

101. J. Lee, B.M. Jung, S.B. Lee, S. Lee, K.H. Kim, FeCoNi-coated glass fabric/ polycarbonate composite sheets for electromagnetic absorption and shielding. IEEE Trans. Magn. 53(11), 1-4 (2017). https://doi.org/10.1109/TMA G.2017.2704663

102. N. Erdogan, F. Erden, A.T. Astarlioglu, M. Ozdemir, S. Ozbay, G. Aygun, L. Ozyuzer, ITO/au/ITO multilayer thin films on transparent polycarbonate with enhanced EMI shielding properties. Curr. Appl. Phys. 20(4), 489-497 (2020). https://doi.org/10.1016/j.cap.2020.01.012

103. M. Fang, Y. Ma, N. Zhang, M. Huang, B. Lu, K. Tan, C. Liu, C. Shen, Solid particle erosion resistance and electromagnetic shielding performance of carbon fiber reinforced polycarbonate composites. Mater. Res. Express 7(4), 045305 (2020). https://doi.org/10.1088/2053-1591/ab6fa6

104. G. Gedler, M. Antunes, J.I. Velasco, R. Ozisik, Electromagnetic shielding effectiveness of polycarbonate/graphene nanocomposite foams processed 
in 2-steps with supercritical carbon dioxide. Mater. Lett. 160, 41-44 (2015). https://doi.org/10.1016/..matlet.2015.07.070

105. X. Zhi, H.-B. Zhang, Y.-F. Liao, Q.-H. Hu, C.-X. Gui, Z.-Z. Yu, Electrically conductive polycarbonate/carbon nanotube composites toughened with micron-scale voids. Carbon 82, 195-204 (2015). https://doi.org/10.1016/j.ca rbon.2014.10.062

106. G. Gedler, M. Antunes, J.I. Velasco, R. Ozisik, Enhanced electromagnetic interference shielding effectiveness of polycarbonate/graphene nanocomposites foamed via 1-step supercritical carbon dioxide process Mater. Des. 90, 906-914 (2016). https://doi.org/10.1016/j.matdes.2015.11.021

107. L. Monnereau, L. Urbanczyk, J.-M. Thomassin, T. Pardoen, C. Bailly, I. Huynen, C. Jérôme, C. Detrembleur, Gradient foaming of polycarbonate/carbon nanotube based nanocomposites with supercritical carbon dioxide and their EMI shielding performances. Polymer 59, 117-123 (2015). https://doi. org/10.1016/j.polymer.2014.11.063

\section{Publisher's Note}

Springer Nature remains neutral with regard to jurisdictional claims in published maps and institutional affiliations.

\section{Submit your manuscript to a SpringerOpen ${ }^{\circ}$ journal and benefit from:}

- Convenient online submission

- Rigorous peer review

- Open access: articles freely available online

High visibility within the field

- Retaining the copyright to your article

Submit your next manuscript at $\boldsymbol{\nabla}$ springeropen.com 